LBL- -33488

DE93 010453

\title{
Healing of Lithographically Introduced Flaws in Glass and Glass Containing Ceramics
}

\author{
Harold Dale Ackler \\ (M.S. Thesis) \\ Center for Advanced Materials \\ Materials Sciences Division \\ Lawrence Berkeley L,aboratory \\ University of California \\ Berkeley, CA 94720
}

December 1992

This work was supported by the Director, Office of Energy Research, Office of Basic Energy Sciences, Materials Sciences Division, of the U.S. Department of Energy under Contract No. DE-AC03-76SF00098. 


\title{
Healing of Lithographically Introduced Flaws in Glass and Glass Containing Ceramics
}

\author{
Copyright $\subset 1992$
}

by

Harold Dale Ackler

The U.S. Department of Energy has the right to use this document for any purpose whatsoever including the right to reproduce all or any part thereof 


\section{Table of Contents}

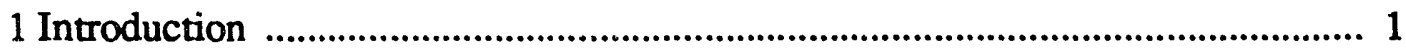

1.1 Background ................................................................................................ 1

1.2 Motivation ............................................................................................... 2

1.3 Systems Studied and Objectives .................................................................... 3

2 Theoretical Background ................................................................................. 5

2.1 Initial Stage Crack Healing .......................................................................... 5

2.1.1 Crack healing in crystalline systems ................................................ 5

2.1.2 Crack healing in pure glass ............................................................. 8

2.1.3 Crack healing in glass-containing ceramics ...................................... 8

2.1.4 Crack healing via thin intergranular films ......................................... 10

2.1.5 Complicating factors in real systems ................................................ 12

2.2 Channel Evolution ....................................................................................... 15

2.2.1 Thermodynamic channel instability ................................................ 15

2.2.2 Kinetics of channel breakup ........................................................ 17

2.2.3 Role of pre-existent perturbations .................................................... 21

3 Experimental Procedures .................................................................................... 25

3.1 Corning 7056 Glass and Soda-Lime Glass ................................................... 26

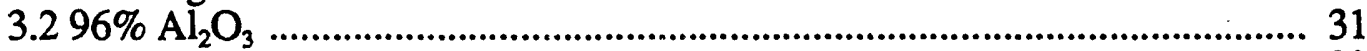

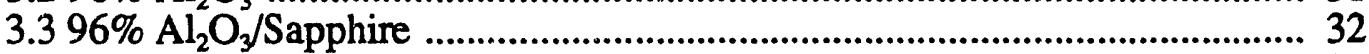

$3.4 \mathrm{SiO}_{2} / \mathrm{Sapphire}$............................................................................................. 35

4 Results and Discussion .................................................................................. 38

4.1 Corning 7056 Glass ............................................................................ 38

4.1.1 Corning 7056, Crack Healing …………........................................... 39

4.1.2 Corning 7056, Channel Evolution .................................................... 41

4.2 Soda-Lime Glass ................................................................................... 45

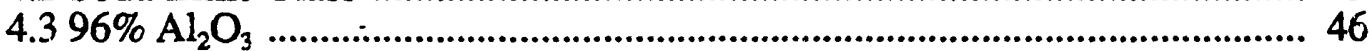

4.3.1 $96 \% \mathrm{Al}_{2} \mathrm{O}_{3}, 1150^{\circ} \mathrm{C}$ Anneals ......................................................... 46

4.3.2 96\% $\mathrm{Al}_{2} \mathrm{O}_{3}$, Glass Film Thickness and Viscosity ............................. 47

$4.496 \% \mathrm{Al}_{2} \mathrm{O}_{3} / \mathrm{Sapphire}$................................................................................. 51

$4.4 .196 \% \mathrm{Al}_{2} \mathrm{O}_{3} /$ Sapphire, $1300^{\circ} \mathrm{C}$ Anneal ................................................ 51

4.4.296\% $\mathrm{Al}_{2} \mathrm{O}_{3} /$ Sapphire, $1250^{\circ} \mathrm{C}$ Anneal .......................................... 51

4.4.3 96\% $\mathrm{Al}_{2} \mathrm{O}_{3} /$ Sapphire, Glass Chemistry and Crystallization ................ 52

$4.5 \mathrm{SiO}_{2} /$ Sapphire .......................................................................................... 54

4.5.1 $\mathrm{SiO}_{2} /$ Sapphire, Behavior During Annealing ....................................... 54

4.5.2 $\mathrm{SiO}_{2}$ /Sapphire, Interfacial Crystals ................................................ 56

4.5.3 $\mathrm{SiO}_{2}$ /Sapphire, Approximate Glass Flow Rate …………………….... 59

5 Summary and Conclusions ................................................................................. 61

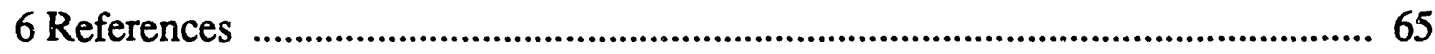

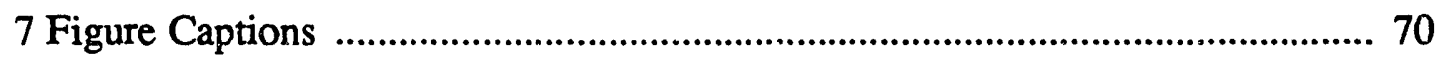

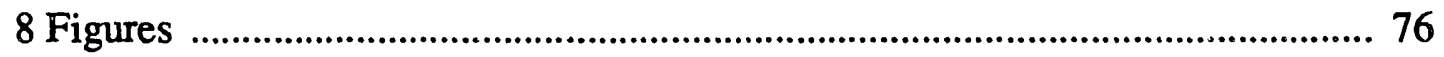




\section{Acknowledgements}

I would like to thank my advisor, Professor Andreas M. Glaeser, for the opportunity to participate in ceramics research both as an undergraduate and graduate student. Without these opportunities and his support, this work would not have been possible. I also want to acknowledge the financial support of this work by the U.S. Department of Energy under Contract Number DE-AC03-76SF00098.

There were many people who provided assistance, in varying forms, during this work. I want to express my thanks to Lawrence Berkeley Laboratory staff scientists Dr. Rowland Cannon, Dr. Brian Dalgleish, and Dr. Antoni Tomsia. Their technical assistance, insight, and advice, whether in the lab or the pub, were very helpful and very much appreciated. The friendly folks in the Department front office and the support shops also deserve my thanks for fixing what wasn't working. I am also grateful to Dr. William McLean of the Materials Technology Group at Lawrence Livermore National Laboratory for the use of certain instruments.

The other students in the Ceramics Research Labs, both graduate and undergraduate, with whom I wallowed in the trenches of academic endeavor, deserve very sperial thanks. These characters, Rich Hashimoto, Kenmore Johnson, Mark "Markatelli" Locatelli, A-bel Nickles, J. Danforth Powers, Mark "Prankster" Shalz, and Jämës Stölkën, made the retention of one's sanity possible, even when it seemed hopeless. Their assistance and friendship are very much appreciated. I can only hope to find another group of coworkers that make such good friends.

Finally, had it not been for my family, I would not have gotten this far. I am eternally grateful to my mother, Shirley, and my father and stepmother, Dale und Wendy, for their support, be it money, cookies, or a reassuring hug. My sister Ellen was also there to pick up my spirits when things occasionally got tough. My grandparents and uncles also deserve thanks for their help. My buddy Bill cannot be forgotten for administering his effective periodic "De-Nerding" treatments. 


\title{
Healing of Lithographically Introduced Flaws in Glass and Glass Containing Ceramics \\ by
}

\author{
Harold D. Ackler
}

\begin{abstract}
The morphological evolution of cylindrical pores or "channels" and crack-like cavities in glass and glass-containing ceramics at elevated temperatures was studied. The systems studied were: Coming 7056 alkali borosilicate glass, soda-lime glass (microscope slides), a commercially available $96 \% \mathrm{Al}_{2} \mathrm{O}_{3}$ with $\approx 5-10 \%$ intergranular glass, $96 \% \mathrm{Al}_{2} \mathrm{O}_{3}$ bonded to sapphire, and a model sapphire/glass/sapphire system fabricated by diffusion bonding etched and unetched pieces of sapphire onto which 30-50 nm of $\mathrm{SiO}_{2}$ had been sputter deposited. These systems span a broad range of glass contents, and permit observation of healing behavior with varying glass content. The results were compared with analytical models and results of similar studies in completely crystalline systems.
\end{abstract}




\section{Introduction}

\subsection{Background}

The past century has seen numerous analytic treatments and experimental investigations of the morphological evolution of bodies of matter or voids therein bounded by cylindrical surfaces [1-14]. More recently, similar efforts have been directed toward the morphological evolution of features with plate-like geometry such as cracks [15-40] or thin, flat inclusions inside a material [41-43]. The interest in such phenomena has been multifacetted. The earlier studies of the stability of fluid jets or cylindrical voids in a fluid were primarily related to observations on the spheroidization or breakup of jets or streams of fluids like water or of long, thin voids in very viscous materials. The more recent interest regards the observed behavior of cracks, cylinder-like voids, thin-plate shaped inclusions, and cylinder or rod-shaped particles and inclusions during heat treatments for more practical purposes [4-21,23-43]. Mass transport at elevated temperatures driven by the reduction of surface energy results in not only a change in the geometry of the feature but may also reduce its volume if it is a void. Many studies [15-21,23,26-33,36,39,40] have shown that cracked ceramics can recover strength partially or even fully depending on the system and heat treatment. Other studies $[5,6,10,12,24,27,33,34,37,38]$ have explored the similarity of cylinder or channel breakup and crack healing with various stages of sintering. The driving forces, mechanisms of mass transport, and geometries are the same in these situations. The geometry of crack healing resembles that of initial stage sintering when the neck between two particles is still very small. The geometry of channel breakup resembles that of intermediate stage sintering when continuous channels are found between particles. Channel breakup is also useful in that it is 
observed as the final stage of crack healing, after the edge of a crack has receded and pinched off a tubular bulge along the crack edge leaving a channel. Thus, studying the evolution of cylindrical voids or cracks may be used to study the phenomena occurring during sintering.

If the geometry of the cylinders and cracks can be strictly contrciled, the extraction of thermodynamic and kinetic parameters is greatly improved, as shown by Rödel [15] and Rödel and Glaeser [34,37,38]. When the initial geometry of a crack or channel is precisely controlled, any morphological changes during heat treatment can be easily quantified. This also provides a means of determining the surface curvatures which act as the driving forces for mass transport. In addition, detailed analysis of the evolution of flaw geometries, especially with respect to the scale of the most significant mass redistribution, may reveal which of competing transport mechanisms is dominant [44]. Hence, with detailed knowledge of the surface geometry (driving force) and its rate of evolution (velocity), reasonably accurate atomic diffusivities can be calculated, primarily for the dominant mechanism. Obviously, the effects of impurities or dopants on mass transport will be easily determined by comparison with behavior in undoped materials. This may show how particular dopants affect particular transport mechanisms.

\subsection{Motivation}

The majority of the studies on the evolution of cracks or cylindrical voids in materials have been performed with crystalline materials [5-21,23-35,37-40]. In modelling the evciution of cracks or cylindrical voids surface energy isotropy is generally assumed $[1-5,8,10-14]$. This assumption greatly simplifies the mathematical treatment of the problem, however it does so at the expense of some 
accuracy and true physical understanding since the surface energy of crystalline materials is anisotropic. For amorphous materials, however, this assumption is accurate as these materials are completely isotropic above the molecular scale. With this in mind, it seemed an appropriate means for comparing aspects of these models with experimental behavior would be the study of cracks and cylindrical pores in an amorphous material such as glass. Such a study would also provide a basis for assessing the effects of intergranular glassy phases on defect evolution in glass bonded ceramics.

\subsection{Systems Studied and Objectives}

This work studies the morphological evolution during heat treatment of cylindrical pores, hereafter referred to as "channels", and crack-like cavities, hereafter referred to as "cracks", in glass and glass-containing ceramic systems. A means of sample preparation using photolithographic techniques, ion beam etching, and diffusion bonding developed by Rödel and Glaeser [34] was used to produce internal channels and cracks of precisely controlled geometry. The systems chosen were Corning 7056 alkali borosilicate glass, a soda-lime glass, Coors $96 \% \mathrm{Al}_{2} \mathrm{O}_{3}$ electronic substrate material, Coors $96 \% \mathrm{Al}_{2} \mathrm{O}_{3}$ bonded to sapphire, and a thin sputter deposited layer (about $30-50 \mathrm{~nm}$ ) of $\mathrm{SiO}_{2}$ between two pieces of sapphire. These systems allow study of materials with an extremely broad range of glass contents. The 7056 and soda-lime glasses define the $100 \%$ glass limit. The "96\%" $\mathrm{Al}_{2} \mathrm{O}_{3}$ has a glass content in the 5-10 vol\% range. Typical aluminas have a grain size of 20-30 $\mathrm{mm}$, and thus the $50 \mathrm{~nm}$ glass layer in the present $\mathrm{SiO}_{2} /$ sapphire system simulates a polycrystalline material with $\approx 0.4 \%$ glass. The crack healing behavior exhibited by these systems are compared to one another and to that observed in 
crystalline systems $[15,45]$. 


\section{Theoretical Background}

Though the underlying physical processes of crack healing and channel or rod spheroidization are the same, the development of mathematical models for these processes are somewhat different and far more developed for the latter. As channel spheroidization can be considered as the later stages of crack healing, they will be discussed separately with crack healing treated first.

\subsection{Initial Stage Crack Healing}

\subsubsection{Crack healing in crystalline systems}

Studies in crystalline materials, summarized in a review paper by Gupta [33], discuss the capillarity driven healing of cracks. The initial stages involve either regression and bulging of the crack tip or pinching across the crack faces [33]. When the crack tip regresses, it results in the formation of cylindrical bulges parallel to the crack edge which may pinch off leaving tubular voids. When it pinches, the opposite faces of the crack come into contact in the interior of the crack. The portions of the crack that remain will continue to evolve in the same ways.

The mass redistribution at a crack tip is very similar to interparticle neck formation during initial stage sintering. When surface or volume diffusion are the dominant mechanisms of mass transport, calculations have shown that "undercutting" results at the neck joining particles [46], see Figure 1. This undercutting is produced by the distance dependence of these mass transport mechanisms which are capable of producing rapid mass transport over short distances, surface diffusion typically being dominant for very short distances [44]. The very small radius at $A$ in Figure 1 results in a very large curvature at the neck, 
hence a large local driving force, $\nabla \mu$, to reduce the curvature. This is accomplished most expeditiously by short range diffusion to fill in the neck by removing material from the region just outside the neck, resulting in undercutting. This same phenomena is responsible for the formation of tubular bulges at crack tips during the initial stage of crack healing.

As noted earlier, the anisotropy in surface energy in crystalline materials can complicate matters. Since the product of surface energy and curvature provides the driving force for mass transport, the morphological evolution of cracks will most certainly be influenced to some degree by the anisotropy in surface energy. Anisotropy in surface energy may be manifestci by morphological changes that do not reduce the surface area. These changes typically result in the formation of facets on curved or even flat surfaces. Another possible result is the rotation of an entire flat surface. The motivation for such phenomena was described by Herring [47]. The conclusions of these arguments indicate that when the surface energy $\gamma$ of a material is dependent on the surface orientation $\mathbf{n}(\theta)$, where $\theta$ is the angle between the surface normal $\mathbf{n}$ and some reference axis, then the surface may experience a torque tending to rotate its orientation to one of lower surface energy. In other words, a surface of energy $\gamma(\theta)$ will behave like a membrane with strain (or stretch) energy $\gamma$ with a torque $\partial \gamma / \partial \theta$ per unit area superimposed. If the surface orientation happens to be at a sharp minimum in $\gamma(\theta)$, or a cusp, then this orientation will be stable with respect to any applied torque trying to rotate its orientation, provided the torque is smaller than that represented by $\partial \gamma \partial \theta$ in the cusp. As stated above, the result of these phenomena may be observed by the facetting of a curved surface or flat surface of an orientation noncoincident with a 
low energy one, or the rotation of an entire flat surface to a lower eriergy orientation. These actions may actually increase the total surface area yet still decrease the total energy. With respect to curved surfaces, the chemical potential of material at the surface, discussed earlier, is modified by anisotropy in surface energy to give [48]

$$
\mu=\mu_{0}+\Omega\left[K_{1}\left\{\gamma+\frac{d^{2} \gamma}{d \theta_{1}^{2}}\right\}+K_{2}\left\{\gamma+\frac{d^{2} \gamma}{d \theta_{2}^{2}}\right\}\right]
$$

where now $K_{\mathrm{i}}$ and $\theta_{\mathrm{i}}$ are the curvature and angle from the surface normal in principle direction " $\mathrm{i}$ ", respectively. Hence, it is obvious that anisotropy of surface energy can influence the morphological evolution of flaws in ways different from those expected to result by mere reduction of surface area.

Studies of the morphological evolution of lithographically introduced cracks in sapphire with crack planes oriented parallel to a number of low index crystal planes show striking differences in healing behavior due to differences in crystallographic orientation $[7,15,34,37,38,45,49]$. These studies used lithographic techniques to introduce internal cracks of precise geometry and orientation in sapphire. The planes studied were the basal, prismatic, and pyramidal planes. Crack edges were oriented at a variety of angles to crystallographic directions in plane. The results clearly showed that healing behavior was different not only between different planes, but could also differ between edges of cracks with different orientation with respect to the crystal. Significant facetting was often seen to be the manner in which healing took place, particularly in the prismatic and pyramidal planes. These experiments are convincing evidence of the importance of surface energy anisotropy in determining the morphological 
evolution of internal flaws.

In the present experiments, driving forces and mass transport are expected to be produced solely by the glass phase. Hence, healing should proceed as in an isotropic material, even when the glass content is low.

\subsubsection{Crack healing in pure glass}

Jagota and Dawson [50] performed numerical calculations of the sintering of two spheres with viscous fiow as the transport mechanism. In contrast to the behavior in systems controlled by diffusional transport, they calculate that no undercutting will occur, see Figure 2. Hence, again making the analogy between this stage of sintering and crack healing, it is not expectrd that a tubular bulge will develop at the crack tip when transport is by viscous flow, as in glass. Instead, the crack ip should just recede while the crack cross section approaches a circle. Inis behavior is actually what is observed, as will be discussed later. It should be noted that over very short distances, some transport may occur by surface diffusion in glass [51], however transport by this mechanism has not yet been verified.

\subsubsection{Crack healing in glass-containing ceramics}

In the $96 \% \mathrm{Al}_{2} \mathrm{O}_{3}$ and $96 \% \mathrm{Al}_{2} \mathrm{O}_{3}$ /sapphire systems, crack healing will take place by intergranular glass flowing between grains. The viscosity of the glassy phase and the thickness of the film between grains are expected to control this process. However, in the present study observation of crack healing in samples of etched $96 \% \mathrm{Al}_{2} \mathrm{O}_{3}$ bonded to unetched $96 \% \mathrm{Al}_{2} \mathrm{O}_{3}$ requires the ability to break the sample along the bond interface to expose cracks after annealing. As glass is 
expected to redistribute at the interface during annealing, thereby improving the bond, it was not certain whether the sample would easily fracture along the interface to allow post anneal inspection. Bonding a piece of sapphire (transparent) to etched $\mathrm{Al}_{2} \mathrm{O}_{3}$ was pursued as an alternative method to observe crack healing in this material. However, this arrangement creates a discontinuity in the sample chemistry. Possible effects of this will be discussed later.

The microstructures of samples in these systems, namely polycrystalline with an intergranular glassy phase, will result in healing behavior that can not be described by the theories for pure glass or crystalline materials. The crystalline network will prevent significant distortion of the crack faces, with crack healing accomplished almost exclusively by the flow of the intergranular glass at the temperatures used in this work. The expected behavior is best described by the theories used for pore filling during liquid phase sintering [52]. In such systems, pores are bounded by many grains, typically with a film of glass between grains and on their faces bounding the pores. Negative curvature at the pore surface induces the flow of glass toward the pore center through capillary forces. These phenomena are expected to lead to the flow of glass into flat cracks, starting from the crack edges where curvature is largest in magnitude. These capillary forces may also lead to minor rearrangements of grains bounding the cracks, partially moving some of them into the crack volume. Once glass is present in the cracks, material dissolved from grains may diffuse through the glass into the cracks where it may precipitate on grain faces bounding the crack. This is especially a possible evolution path in the $\mathrm{Al}_{2} \mathrm{O}_{3}$ /sapphire system wherein the sapphire surface acts like that of an enormous grain, "coarsening" at the expense of the grains in the $\mathrm{Al}_{2} \mathrm{O}_{3}$ 
material. It should be emphasized, however, that the stages of crack filling of present interest in these materials are those up to the point at which the crack has been at least partially filled with glass. Subsequent processes are not considered.

\subsubsection{Crack healing via thin intergranular films}

The sapphire/SiO $/$ /sapphire system provides a means of studying crack healing by transport in a very thin "intergranular" glass film. This also provides a method to study redistribution of intergranular glassy phases during sintering with very low glass contents. As the film thickness is only $30-50 \mathrm{~nm}$, it is expected that transport by viscous flow will be very slow, even when the glass viscosity is low. Figure 3 shows a plot of the temperature dependence of the viscosity of $\mathrm{SiO}_{2}$.

Figure 4 shows a schematic cross section of the sapphire/SiO $/$ sapphire system. The driving force for $\mathrm{SiO}_{2}$ flow is caused by the curvature at the corners of cracks creating a pressure difference between the region at the corner, $\mathbf{P}_{1}$, and the region in the interface, $P_{2}$, see Figure 4. The following calculation is intended to provide an overly optimistic upper bound for the flow of $\mathrm{SiO}_{2}$ from the interface into the cracks for an idea of the time scale of healing and is based on a few assumptions. First, flow will be approximated by that between two large parallel plates. Second, the pressure differences, or pressure gradient, at the corner of cracks will be approximated by that surrounding a hollow cylinder in an elastic material. $\mathrm{SiO}_{2}$ will be viscoelastic at the temperatures involved in these experiments, but assuming elastic behavior will provide the largest pressure gradient.

The volume flow rate $Q$ between two large parallel plates, shown schematically in Figure 5, is given by [53] 


$$
Q=\int_{-\frac{h}{2}}^{\frac{\hbar}{2}} u(y) b d y=\frac{b h^{3}}{12 v}\left[-\frac{d}{d x}(p+\rho g z)\right]=-\frac{b h^{3}}{12 v} \frac{d p}{d x}
$$

where $v$ is the visccsity and the other parameters are defined in the figure. The gradient in pressure, $d p / d x$, is approximated from that around a cylindrical hole in an elastic material. For cylindrical symmetry, the compatibility equation [54] reduces to

$$
\left(\frac{d^{2}}{d r^{2}}+\frac{1}{r} \frac{d}{d r}\right)\left(\frac{d^{2} \phi}{d r^{2}}+\frac{1}{r} \frac{d \phi}{d r}\right)=\frac{d^{4} \phi}{d r^{4}}+\frac{2 d^{3} \phi}{r} \frac{1}{d r^{3}}-\frac{d^{2} \phi}{r^{2}} \frac{1}{d r^{2}}+\frac{d \phi}{r^{2}} \frac{}{d r}=0
$$

where $\varphi$ is the stress function (or potential), dependent only on $r$. This ordinary differential equation gives $\phi(r)=A \log r+B r^{2} \log r+C r^{2}+D$, where $A, B, C$, and $D$ are determined by the boundary conditions. This gives the stress components

$$
\begin{aligned}
& \sigma_{r}=\frac{1}{r} \frac{d \phi}{d r}=\frac{A}{r^{2}}+B(1+2 \log r)+2 C \\
& \sigma_{\theta}=\frac{d^{2} \phi}{d r^{2}}=-\frac{A}{r^{2}}+B(3+2 \log r)+2 C \\
& \sigma_{r \theta}=0
\end{aligned}
$$

For a hollow cylinder in a cylindrical body with no external pressure, this reduces to

$$
\begin{aligned}
& \sigma_{r}=\frac{a^{2} p_{i}}{b^{2}-a^{2}}\left(1-\frac{b^{2}}{r^{2}}\right) \\
& \sigma_{\theta}=\frac{a^{2} p_{i}}{b^{2}-a^{2}}\left(1+\frac{b^{2}}{r^{2}}\right)
\end{aligned}
$$

where $a$ is the internal radius, $b$ is the external radius, and $p_{\mathrm{i}}$ is the internal pressure. When $b \Rightarrow \infty$, this gives 


$$
\begin{aligned}
& \sigma_{r} \cong \frac{-a^{2} p_{i}}{r^{2}} \\
& \sigma_{\theta} \cong \frac{a^{2} p_{i}}{r^{2}}
\end{aligned}
$$

Approximating the inside comer of a crack to be similar to part of a cylinder in its stress conditions and assuming the $\mathrm{SiO}_{2}$ to be elastic (yielding largest $\nabla p$ ), $p_{\mathrm{i}}$ will be determined by equating $\sigma_{\theta}=K \gamma$ at $r=a$, where $a$ is now the radius of the corner and $K$ is the curvature, $1 / r$. Using this value of $p_{\mathrm{i}}, \sigma_{\mathrm{r}}(r)$ is obtained. Since $\rho(r)=\sigma(r)$ (hydrostatic stress), $\nabla p$ can be calculated to be $\frac{2 a^{2} p_{i}}{r^{3}}$. Substituting $R=r / a$, this becomes $\frac{2 p_{i}}{a R}=\nabla p$. So, for a region of the film $2 a$ from the corner, $\nabla p=\frac{p_{i}}{a}$ and we get $Q=-b h^{3} p_{i}$. This is a large value for $Q$ and represents its upper bound. This calculation is crude, but gives an upper bound for the volume flow rate to fill cracks.

\subsubsection{Complicating factors in real systems}

The soda-lime glass used in this work may exhibit different behavior due to its chemistry. The microscope slides of this glass, like many common use soda-lime glasses, contain substances called fining agents intended to enhance bubble growth in the melt and expedite bubble rising. These agents, composed of $\mathrm{S}-\mathrm{O}$, As-O, and $\mathrm{Na}-\mathrm{O}$ compounds, act by producing gases which are exsolved from the glass into any voids. It was suspected that the gas pressures produced by fining agents might affect the morphological evolution of internal cracks and channels. If the pressures are great enough, internal voids may grow rather than shrink. The temperature dependence of the viscosity of the soda-lime glass is very 
similar to that of the 7056 glass with softening points of about $710^{\circ}$ and $715^{\circ} \mathrm{C}$, respectively. Hence, any differences in tehavior between these glasses are expected to be due to differences in chemistry.

Investigations of glass bonded aluminas, such as the material used here, have shown that the intergranular glass may crystallize in certain conditions [55a,b,c]. Powell-5ogan and Heuer [55a,b,c] used transmission electron microscopy to study the crystallization of the glassy intergrariular phase in several commercially available high aluminas after annealing for times froin $30 \mathrm{~min}$ to $168 \mathrm{~h}$ at temperatures between $800^{\circ} \mathrm{C}$ and $1500^{\circ} \mathrm{C}$. The alumina used in the present study corresponds to their material " $F$ ".

Up to eight crystalline phases nucleated and grew in the amorphous material, depending on glass composition and annealing conditions. The temperature range over which crystallization occurred and its extent of development was particularly dependent on the $\mathrm{MgO}$ to $\mathrm{CaO}$ ratio in the glass. For materials with $\mathrm{MgO}: \mathrm{CaO}>$ 2, denoted "high-MgO" [55b], crystallization occurred extensively between $1050^{\circ} \mathrm{C}$ and $1150^{\circ} \mathrm{C}$, very little at $1200^{\circ} \mathrm{C}$, and not at all at $1300^{\circ} \mathrm{C}$. For materials with $1<\mathrm{MgO}: \mathrm{CaO}<2$, or "intermediate" materials, crystallization occurred from $1050^{\circ} \mathrm{C}$ to $1300^{\circ} \mathrm{C}$. It was also observed that as the $\mathrm{MgO}: \mathrm{CaO}$ ratio decreased, the amount of crystallization increased.

The present material is a "high-MgO" material with $\mathrm{MgO}: \mathrm{CaO}$ about 2.5. Hence, if the sample is heated above $1200^{\circ} \mathrm{C}$, no crystallization should occur and the intergranular phase is expected to remain viscous, free to flow into the introduced cracks. However, the circurastances created by bonding a piece of pure sapphire to this material produce a chemical discontinuity, placing the 
system initially out of equilibrium, which may initiate other processes. Therefore, it is possible that an interaction between the intergranular glass in the $96 \% \mathrm{Al}_{2} \mathrm{O}_{3}$ and the sapphire substrate may alter the glass chemistry. The commercial alumina is densified at temperatures and times that will allow the $\mathrm{Al}_{2} \mathrm{O}_{3}$ particles to incorporate components of the glass, possibly approaching their solubility limits in $\mathrm{Al}_{2} \mathrm{O}_{3}$. The glass should also contain a concentration of dissolved $\mathrm{Al}_{2} \mathrm{O}_{3}$, close to the equilibrium concentration in the temperature range $1500^{\circ}-1600^{\circ} \mathrm{C}$, at which it was initially processed. However, this is not necessarily the equilibrium concentration of $\mathrm{Al}_{2} \mathrm{O}_{3}$ at the current anneal temperatures. The glass may contain excess $\mathrm{Al}_{2} \mathrm{O}_{3}$, which might be removed from the glass by precipitation or epitaxial growth of $\mathrm{Al}_{2} \mathrm{O}_{3}$ or by inco.poration into a multicomponent crystalline oxide, effectively crystallizing some of the intergranualr glass. Obviously, crystallizing some of the integranular glass will greatly impede the flow of the remaining viscous material.

As seen in Figure 3, the viscosity of $\mathrm{SiO}_{2}$ is quite large at $1200^{\circ}-1300^{\circ} \mathrm{C}$. To lower the $\mathrm{SiO}_{2}$ viscosity, higher temperatures are required which may introduce further complications. Crystallization of silica can occur when held at elevated temperatures, typically above $1300^{\circ} \mathrm{C}$. The rate at which this may occur is dependent on impurities and the surrounding atmosphere [56]. Another potential problem is the formation of aluminosilicates, primarily mullite, $\mathrm{Al}_{6} \mathrm{Si}_{2} \mathrm{O}_{13}$. The $\mathrm{Al}_{2} \mathrm{O}_{3} / \mathrm{SiO}_{2} / \mathrm{Al}_{2} \mathrm{O}_{3}$ sandwich geometry involves a discontinuity in chemistry which will drive interdiffusion. At temperatures above $1300^{\circ} \mathrm{C}$ the formation of mullite from $\mathrm{Al}_{2} \mathrm{O}_{3} / \mathrm{SiO}_{2}$ mixtures has been observed [57,58]. Hence, raising the temperature enough to lower the viscosity of the thin $\mathrm{SiO}_{2}$ film may result in its 
crystallization or reaction with the sapphire substrates to form an aluminosilicate.

\subsection{Channel Evolution}

\subsubsection{Thermodynamic channel instability}

The treatments of the instability of fluid jets and jets of air in liquids by Lord Rayleigh [1-3] provide a basis for the study of breakup of channels in a material. As comparison of the mathematical predictions with experimental data are the purpose of this work, the derivations will be briefly repeated. For a cylinder with its axis parallel to the $\mathbf{z}$ axis in cylindrical coordinates, the radius is described as [1]

$$
r(z)=a+\alpha \cos (k z)
$$

where $\alpha(t) \ll 1, k=\frac{(2 \pi)}{\lambda}$, and $\lambda$ is the wavelength of the perturbation. This allows the calculation of the surface area per unit length, $s$, and the volume per unit length $S$

$$
\begin{gathered}
S=2 \pi a+\left(\frac{1}{2}\right) \pi a k^{2} \alpha^{2} \\
S=\pi a^{2}+\left(\frac{1}{2}\right) \pi \alpha^{2}
\end{gathered}
$$

If $s_{0}$ is the surface area per unit length for the undisturbed cylinder, then the change in $s$ with a growing perturbation is

$$
s-s_{0}=\frac{\left(\pi \alpha^{2}\right)}{(2 a)}\left(k^{2} a^{2}-1\right)
$$


which implies

$$
\begin{array}{ll}
s-s_{0}<0 & \text { if }(k a)^{2}<1 \\
s-s_{0}>0 & (k a)^{2}>1
\end{array}
$$

As the energy associated with the interface is $\gamma s$ where $\gamma$ is the surface energy of the material, it is seen that small perturbations with $k a<1$, or $\lambda>2 \pi a$, will reduce the surface area, lowering the energy associated with the interface. Such perturbations are expected to grow. Conversely, if $\lambda<2 \pi a$ the surface area is increased as is the energy associated with it, and the perturbation is expected to decay. This establishes the minimum, or critical, stable wavelength for an infinitesimal perturbation, $\lambda_{\text {cris }}=2 \pi a$.

Obviously, the fluids discussed in the above derivations of minimum stable perturbation wavelengths on infinite cylinders are isotropic in surface energy. As mentioned earlier in the discussion of crack healing, anisotropy in surface energy will almost certainly produce different behavior than is observed in isotropic materials. The effect of surface energy anisotropy on the minimum stable perturbation wavelength on an infinite cylinder was modelled by Cahn for a hypothetical material with the simplest possible anisotropy in $\gamma[59]$. In this model, a single crystal rod was hypothesized to be transversely isotropic, but $\gamma$ was dependent on the angle " $\Psi$ " between the surface and the rod axis, set to be the $\mathbf{z}$ axis in cylindrical coordinates. Following a derivation similar to that of Rayleigh, Cahn showed that the rod would be unstable with respect to infinitesimal sinusoidal perturbations of wavelength $\lambda$ when

$$
\lambda>2 \pi a\left[1+\left(\frac{\partial^{2} \gamma}{\partial \psi^{2}}\right) \gamma\right]^{1 / 2}
$$


where $a$ is the unperturbed rod radius. Clearly, when $\gamma$ is isotropic the Rayleigh value $2 \pi a$ is obtained. However, the term $\partial^{2} \gamma / \partial \psi^{2}$ is seen to either increase or decrease the critical wavelength depending on its sign. Consequently, the minimum stable wavelength may differ greatly from the Rayleigh result if anisotropy is significant.

\subsubsection{Kinetics of channel breakup}

The wavelength which actually grows to appreciable amplitude will exceed the critical wavelenjh, but will depend on the mechanism of mass transport. Rayleigh [1] determined the wavelength of maximum instability (the wavelength of the fastest growing perturbation) und $i$ a variety of conditions. For a fluid of low viscosity, the initial growth rate of a perturbation has a maximum value when $\lambda_{\max }=4.508(2 a)$. A similar calculation [2] for a cylinder of a highly viscous fluid predicts that $\lambda_{\max }$ will be much larger (i.e. approaching $\infty$ ) than the cylinder circumference, $2 \pi a$. For a cylindrical gas-filled void in a low viscosity fluid, $\lambda_{\max }=6.48(2 a)$. Growth rates, normalized with respect to cylinder radius, of perturbations vs. $\mathrm{x}(\mathrm{x}=k a)$ on jets and cylindrical voids for the low viscosity fluid and on jets for the high viscosity fluid are plotted in Figure 6. A kinetic analysis of the instability of a cylindrical void in a highly viscous fluid was not performed until recently [8]. The growth behavior parallels that predicted by Rayleigh for jets of highly viscous fluid. No wavelength of maximum instability is found. The

growth rate increases monotonically as $\frac{\lambda}{a}$ approaches infinity. This is different from the kinetic maxima for a low viscosity fluid mentioned previously. 
The models suggest that channels in a highly viscous material like glass should prefer to develop perturbations of very long wavelength with no particular finite value being kinetically preferred. Shieh and Evans predict a normalized perturbation growth rate [8]

$$
\frac{\dot{\alpha}}{\alpha}=\frac{\gamma}{v 2(k a)^{2}}\left(1-(k a)^{2}\right)\left\{\frac{1}{1-\left[\frac{K_{0}(k a)}{K_{1}(k a)}\right]^{2}+\frac{1}{(k a)^{2}}}\right\} \frac{1}{a}
$$

where $\alpha$ is the perturbation amplitude, $v$ is the viscosity and $K_{0}(k a), K_{1}(k a)$ are modified Bessel functions of the second kind of order zero and one, respectively. A plot of the expression $\frac{\dot{\alpha}}{\alpha}\left(\frac{v}{\gamma}\right)$ vs. ka, Figure 7, indicates a linear decrease in growth rate as $k a$ increases in the range $k a=0.2$ to 1 . For $k a<0.2$ the curve levels off to approach a value of 0.5 at $\mathrm{ka}=0(\lambda=\infty)$. This shows that for $k a<0.2$, corresponding to $\lambda>30 a$, the growth rate changes very slowly as $\lambda$ increases. Thus, there is a broad spectrum of perturbation wavelengths with approximately the same normalized growth rate.

Hence, it seems likely that end effects (for a finite cylinder) and processing flaws or preexisting imperfections on the cylinder, which result in finite amplitude perturbations, may grow and dominate the development of "natural" infinitesimal perturbations resulting in a number of wavelengths growing simultaneously. It is also expected that the magnitude of a perturbation will affect relative growth rates. Intuitively, one would expect that larger amplitudes would produce larger growth rates due to the increased gradients in curvature (driving force). Unfortunately, the differential equations that must be solved to give a relation of growth rate vs. perturbation amplitude are unbearably cumbersome [60]. These topics will be discussed more later. 
The driving force for mass transport required for perturbation growth is caused by the local variation in chemical potential along the length of the cylinder. For an isotropic material, Herring [47] derived an expression for the excess chemical potential of a crrved surface at a point $P$ over that of a flat surface, which was modified oy Mullins [61] to give

$$
\mu(P)=\Omega\left[\left(\gamma+\frac{d^{2} \gamma}{d \theta_{1}^{2}}\right) K_{1}+\left(\gamma+\frac{d^{2} \gamma}{d \theta_{2}^{2}}\right) K_{2}\right]
$$

where $\Omega$ is the atomic volume, $\theta_{\mathrm{i}}$ is the angle between the surface normal and that of a $\mathrm{fl}^{-} \mathrm{t}$ surface in the direction $i$ with directions 1 and 2 orthogonal, and $K_{\mathrm{i}}$ is the principal curvature in the direction $i$. Here, the surface energy $\gamma$ is a function of surface orientation, $\gamma=\gamma\left(\theta_{1}, \theta_{2}\right)$ and all quantities are evaluated at $P$. For an isotropic material, $\gamma$ is constant and (5) reduces to the Gibbs-Thomson equation

$$
\mu=\Omega \gamma K
$$

where $K$ is the mean curvature, $K_{1}+K_{2}$. The gradient in $\mu$ is the driving force for mass transport and, with $a$ defined in (1) and small slopes assumed,

$$
\begin{gathered}
K=\frac{1}{r}+\left(\frac{d^{2} r}{d z^{2}}\right)^{-1} \\
K=\frac{1}{a+\alpha \cos (k z)}-\frac{1}{\alpha k^{2} \cos (k z)}
\end{gathered}
$$

Hence 


$$
\begin{gathered}
\nabla \mu=\frac{d \mu}{d z}=\frac{d}{d z}(\Omega \gamma K) \\
=\Omega y\left[\frac{-K \alpha \sin (k z)}{(a+\alpha \cos (k z))}+\frac{\alpha K^{3} \sin (k z)}{\left(\alpha K^{2} \cos (k z)\right)^{2}}\right] \\
\nabla \mu(z)=\Omega \gamma K \alpha \sin (k z)\left[\frac{K^{2}}{\left(\alpha K^{2} \cos (k z)\right)^{2}}-\frac{1}{(a+\alpha \cos (k z))^{2}}\right]
\end{gathered}
$$

Following this, Nichols and Mullins [5] derived the wavelengths of maximum instability to be $\lambda_{\max }=8.89 a\left(\approx 2^{1 / 2} 2 \pi a\right)$ for surface diffusion and $\lambda_{\max }=12.96 a$ for volume diffusion. Recall that the previous result for the highly viscous material differs in not exhibiting a wavelength of maximum instability. Consequently, there is a substantial difference between the behavior expected for noncrystalline (viscous) and crystalline systems.

As mentioned above, anisotropy in surface energy is expected to alter the minimum stable perturbation wavelength calculated by Rayleigh. It should follow that the wavelength of maximum instability will be different from that for isotropic materials as well. Following the work of Cahn [59] and Nichols and Mullins [5], Stölken and Glaeser [62] examined the dependence of perturbation growth rate on wavelength in a single crystal rod, again with transverse isotropy in $\gamma$ and anisotropy with the angle between the surface and rod axis. Their results for transport by surface diffusion indicate that, as in the case of an isotropic material, the wavelength of maximum instability $\lambda_{\max }$, is just $2^{1 / 2}$ times the minimum stable wavelength, $\lambda_{\text {crit }}$

$$
\lambda_{\max }=2^{\frac{1}{2}} 2 \pi R_{0}\left[1+\left(\frac{\partial^{2} \gamma}{\partial \psi^{2}}\right) \gamma\right]=2^{\frac{1}{2}} \lambda_{c r i s}
$$


Again, anisotropy in surface energy is seen to have the potential to control the spacings of pores left by the breakup of a channel. Hence, we see rather different behavior not only between isotropic materials with different transport mechanisms, but additionally when the surface energy is anisotropic.

\subsubsection{Role of pre-existent perturbations}

The above analyses for the breakup of channels (or rods) are carried out under the assumptions that the channels are infinite in extent and perfectly smooth with the exception of the imposed infinitesimal sinusoidal perturbation. These models do not consider the coincident evolution of perturbations with different wavelengths. Having noted significant scatter in reported wavelengths and pore (or particle) spacings during the spheroidization of channels (or rods), Hackney, et al [63] undertook a theoretical investigation of the behavior of channels or rods with numerous infinitesimal sinusoidal perturbations with different wavelengths. The material they considered was assumed to be isotropic, crystalline, and with transport governed by surface diffusion. They also noted that a "cylindrical" surface with a radius dependent on axial position, $r(z)$, that was composed of a sum of harmonic functions, like a Fourier series, could represent a surface with isolated perturbations or a "noisy" distribution of perturbations. This model was found to show that a number of wavelengths could be observed to grow simultaneously. Additional results from this study, which incorporated nonlinear interactions between different wavelengths, were that the stability of a wave was dependent on its own magnitude and also on that of another wave with a different wavelength with which it might interact. The former conclusion is similar to one derived by other researchers [12], but the latter has significant implications. Even 
if a peraubation with the kinetically favored wavelength, $\lambda_{\max }$, is present, other wavelengths preseint as components of an initially noisy surface or of isolated imperfections may destabilize it or eliminate its preferential development. Thus, the wavelengths or pore spacings observed may not be those expected to be favored. This may very well be an explanation for the scatter in experimental data. The investigation of the behavior of cylindrical surfaces with multiharmonic perturbations was carried out for infinitely long bodies. However, any real channel or rod is clearly finite. As a consequence, this surface will terminate with end caps which create a drastic change in radius with position. To investigate the potential role of end effects in the morphological evolution of these channels analytically, it was postulated that the surface of the channels including the end cap could te expressec' as a sum of trigonometric functions, like sines and/or cosines, as in a Fourier series described above.. This is basically assuming that the cylinder profile is constructed from the sum of many perturbations of differing wavelengths and amplitudes. The relative contribution, or magnitude, of each perturbation is determined by its coefficient in the sum. Those perturbations with larger coefficients mignt be more likely to grow faster than the others, thus dominating the measured data. The difficulty in expressing the actual cylinder geometry at the end led io an alternate treatment (still needing refinement) of the chann'il curvature as a funtion 0 ? arc length along the surface starting at the very end of the channel [64]. The problem was set up as follows:

The curvature, $K(\mathrm{~s})$, was assumed to have the form

$$
K(s)=e^{-b s}\{\operatorname{csin}(k s)+d \cos (k s)\}+f
$$


where $s=\operatorname{arclength}, k$ is the wavenumber, and $b, c, d$, and $f$ are dependent on $k$ and a parameter $\beta$, defined by the arc length from the end of the cylinder to the first neck equalling $\beta a$. The curvature was required to meet several boundary conditions, drawn from observations of channels. These are:

1) at $s=0$ (the end of cylinder at axis), $K(s=0)$ is assumed spherical over some region near the axis with the same radius as the cylinder, $K(\mathrm{~s}=0)=-\frac{2}{a}$

2) at $\mathrm{s}=0,\left.\frac{\partial \mathrm{K}(s)}{\mathrm{\partial}}\right|_{s=0}=0$

3) at $s=\beta a, K(\beta a)=K_{\text {neck }}$

4) at $s=\beta a,\left.\frac{\partial K(s)}{\partial t}\right|_{s=\beta a}=0$

5) at $s=\infty$ (far from end), $\left.K(s)\right|_{s=\infty}=-\frac{1}{a}$

Trial values were assumed for $\beta$ and $K_{\text {neck }}$ and $b, c, d$, and $f$ were calculated to form a trial solution, $K(\mathrm{~s})$. Values for $\beta$ started at $\pi$, corresponding to the minimum wavelength which can grow, and ranged up to about 30 or 40 . Values for $K_{\text {neck }}$ were usually chosen to be less than $1 \%$ greater than $K_{\infty}=-1 / a$. Finally, the Fourier transform of $K(\mathrm{~s})$ was calculated to determine the intensities of all values of $k$ (Note:b,c,d,f are also dependent on $k$ ). A value of $k$ with a maximum in intensity, if any, was sought to calculate a wavelength for comparison with measured node spacing data. Figure 8 shows schematic plots of $\mathrm{r}(\mathrm{z})$ and $k(\mathrm{~s})$ for such solutions.

It was found that the Fourier transforms of trial solutions $K(s)$ were somewhat sharply peaked at $k$ values smaller than the value of $k$ used in $K(\mathrm{~s})$. The 
value at which the peak occurred was found to vary inversely with the value of $\beta$ and proportionally to the difference $K_{\text {meck }}-K_{\infty}$. As $\beta$ increases, it effectively makes the "wavelength" associated with end bulge longer, so one expects the preferred $k$ to decrease. The variation with the neck curvature shows that the $k$ value of the maximum moves closer to that value used in $K(\mathrm{~s})$, indicating it is making a greater contribution to the profile. For the values of $\beta$ and $K_{\text {neck }}$ described above, the values of $k$ at which the maximum in the Fourier transform of $K(\mathrm{~s})$ occurred were in the range $0.1 / a$ to $0.3 / a$, corresponding to wavelengths in the range $20 a$ to $50 a$. 


\section{Experimental Procedures}

The general procedures of the sample preparation and experiments performed will be presented first, with the details of the different systems following. A technique using photolithography, ion beam etching, and diffusion bonding was used to produce internal flaws in the three systems described earlier [34]. This technique involved spinning photoresist ${ }^{1}$ onto a polished substrate at $5000 \mathrm{rpm}$ to produce a resist thickness of $\cong 2.5 \mu \mathrm{m}$. The resist is then soft baked at $90^{\circ} \mathrm{C}$ for $20 \mathrm{~min}$. The resist was subsequently exposed to ultra violet light through a mask containing precisely defined geometric features in a mask projection aligner ${ }^{2}$. The resist was developed to remove the exposed resist material, rinsed, then dried with a gas jet, and hard baked at $120^{\circ} \mathrm{C}$ for $20 \mathrm{~min}$. The substrate was now coated with a hard baked photoresist except for areas defined by the mask. The substrate was next ion beam etched in an ionmill ${ }^{3}$ under conditions set by the sample material requirements. Following etching, the substrate was thoroughly cleaned in solutions of $\mathrm{NH}_{4} \mathrm{OH}: \mathrm{H}_{2} \mathrm{O}_{2}: \mathrm{H}_{2} \mathrm{O}(1: 1: 5)$, denoted as $\mathrm{SCl}$, and $\mathrm{HCl}: \mathrm{H}_{2} \mathrm{O}_{2}: \mathrm{H}_{2} \mathrm{O}$ (1:1:6), denoted SC2, to remove organic and metallic contaminants, respectively. The surface was profiled with a contact profilometer ${ }^{4}$ to characterize the etch depth. 5

Diffusion bonding was done by placing a polished substrate on an etched one in a graphite die and hot pressing. Conditions were determined by the diffusion bonding characteristics of the materials being studied. The as bonded samples were photographed

\footnotetext{
${ }^{1}$ Shipley 1400-31, Shipley Co., Inc., Santa Clara, CA

${ }^{2}$ Canon Projection Mask Aligner, Canon, Santa Clara, CA

${ }^{3}$ Veeco Microetch System, Veeco Instruments Inc., Plainview, NY

${ }^{4}$ Alphastep 200, Tencor Instruments, Mountain View, CA

${ }^{5}$ This work was done in the Microfabrication Laboratory in the Department of Electrical Engineering and Computer Science at the University of Califomia at Berkeley
} 
on an optical microscope, then run through a series of anneals with intermittent inspections and photographing to monitor the evolution of the internal flaws. The details of each system will be discussed below. Results are discussed in a later section.

\subsection{Corning 7056 Glass and Soda-Lime Glass}

Eight pieces of 7056 glass were cut to $1 " \times 1 " x \equiv 0.7 \mathrm{~mm}$ and polished for etching and bonding. The composition of this glass is listed in Table 1. Four pieces were etched. A mask hereafter referred to as "Mask \# 1"1, see Figure 9, was used to develop features. Each piece had four masks exposed in each $0.5^{\prime \prime} \times 0.5^{\prime \prime}$ corner for a total of sixteen masks per substrate. All four pieces were placed in the ionmill. The samples were etched in four runs. After each run, one substrate was removed, giving four different etch depths. As a maximum etch depth of about $1.2 \mu \mathrm{m}$ was desired, etching conditions expected to etch $0.3 \mu \mathrm{m} /$ run were used. Using past etching conditions and resulting etch depths, an approximate relationship between beam current density "J", depth "d", and time " $\mathrm{t}$ " was calculated to be $d=0.032\left(\frac{\mu \mathrm{cm}^{2}}{\min \mathrm{mA}}\right) \mathrm{Jt}$. The ionmill conditions were a beam voltage of $1 \mathrm{kV}$ and current density of 0.5 $\mathrm{mA} / \mathrm{cm}^{2}$ which required about $20 \mathrm{~min}$ for the desired depth of $0.3 \mu \mathrm{m}$. Since a uniform etching rate over a 3" diameter region is claimed, uniform etch depths within each sample were expected. However, when two samples had been removed, the last two were centered and the final one was centered during its solo run. By moving the current detector through the ion beam the current density was found to vary from 0.2 $0.5 \mathrm{~mA} / \mathrm{cm}^{2}$ from the outer edge to the center. Hence, etch depths were determined by profiling the masks on the outer comers of each piece and one mask near the

\footnotetext{
${ }^{1}$ Designed by Jürgen Rödel and W. Craig Carter.
} 
interior. This pattern allows the determination of etch depths across the entire sample by linearly extrapolating from measured masks to unmeasured masks. The measured etch depths for these samples are summarized in Table 2A.

Unetched pieces were bonded to the etched pieces by hot pressing for $1 \mathrm{~h}$ at $520^{\circ} \mathrm{C}$ with $17 \mathrm{MPa}$ pressure in vacuum of $\leq 5 \times 10^{-5}$ torr. The samples were then cut into four pieces, each with four masks. Since all masks on the 1 " samples were not the same depth, the four masks on the cut samples were of different depths as well. As some mask regions debonded during cutting, there were not enough useful masks to have all etch depths represented. The temperatures $610^{\circ}$ and $650^{\circ} \mathrm{C}$ were chosen for annealing as they are in a range wherein features will undergo detectable morphological evolution in times from about a day to a few hours. Selected features in the as hot pressed masks on all samples were photographed. Selection was based on the absence of bond defects and particulate contamination. Some samples were annealed at $610^{\circ} \mathrm{C}$ and some at $650^{\circ} \mathrm{C}$. The heat treatment histories of theses samples are tabulated in Table 2B. Anneal times were set in an attempt to allow several stages of evolution to be observed, i.e. to avoid complete evolution during a single anneal. Samples were always cooled at $<5^{\circ} \mathrm{C} / \mathrm{min}$. After each anneal, samples were inspected on an optical microscope. If morphological changes were pronounced, the samples were photographed and annealed again. If no changes were apparent, the sample was annt;aled again without photographing. Hence, with each anneal in the sample heat tre?.tment histories the comment "Inspected" or "Photographed" will indicate whether a sample was annealed again without photographing or photographed before the next anneal, respectively. Measurements of node and pore spacings for channel breakup and crack edge regression were determined from photographs. 
From 1" $\times 3 "$ soda-lime glass microscope slides, two $1 "$ square pieces were cut. Mask 1 was exposed on one piece, just as for the 7056 glass. The sample was processed exactly as the 7056 glass sample. It was annealed for about $15 \mathrm{~min}$ at $650^{\circ} \mathrm{C}$ and photographed. 
Table 1.

Material Compositions

Corning 7056 Glass

Composition

Component

wt.\%

$\mathrm{SiO}_{2} \quad 68$

$\mathrm{B}_{2} \mathrm{O}_{3} \quad 18$

$\mathrm{K}_{2} \mathrm{O} \quad 9$

$\mathrm{Al}_{2} \mathrm{O}_{3} \quad 3$

$\mathrm{Li}_{2} \mathrm{O} \quad 1$

$\mathrm{Na}_{2} \mathrm{O} \quad 1$

Coors $96 \% \mathrm{Al}_{2} \mathrm{O}_{3}$ Composition

\begin{tabular}{ccc} 
Component & & wt.\% \\
\cline { 1 - 2 } $\mathrm{Al}_{2} \mathrm{O}_{3}$ & & 96.4 \\
$\mathrm{SiO}_{2}$ & 2.5 \\
$\mathrm{MgO}$ & 0.65 \\
$\mathrm{CaO}$ & 0.23 \\
$\mathrm{FeO}$ & 0.1 \\
$\mathrm{Na}_{2} \mathrm{O}$ & 0.06
\end{tabular}


Table 2A.

7056 Etch Depths

\begin{tabular}{|c|c|c|}
\hline $650^{\circ}$ samples & Masks & Depth $(\mu \mathrm{m})$ \\
\hline \multirow[t]{3}{*}{ sample \#2 } & $\mathrm{L}$ & 0.5 \\
\hline & $\mathbf{N}$ & 0.58 \\
\hline & $\mathbf{O}$ & 0.63 \\
\hline \multirow[t]{2}{*}{ sample \#4 } & A & 1.05 \\
\hline & B & 1.1 \\
\hline \multirow[t]{2}{*}{$610^{\circ}$ Samples } & all masks & 0.5 \\
\hline & $7056 \mathrm{~A}$ & $\begin{array}{l}\text { Table } 2 \mathrm{~B} \text {. } \\
\text { nealing/Photographing } \\
\text { Histories }\end{array}$ \\
\hline \multirow[b]{2}{*}{$\begin{array}{l}\text { Treatment (total) } \\
650^{\circ} \text { Samples } \\
\text { as bonded } \\
1 \mathrm{hr}, 650^{\circ} \text { (1) } \\
2 \mathrm{hr}, 650^{\circ} \text { (3) } \\
1 \mathrm{hr}, 650^{\circ} \text { (4) } \\
2 \mathrm{hr}, 650^{\circ}(6) \\
2 \mathrm{hr}, 650^{\circ}(8) \\
5 \mathrm{hr}, 650^{\circ} \text { (13) }\end{array}$} & & Photographed/Inspected \\
\hline & & $\begin{array}{l}\text { Photographed } \\
\text { Inspected } \\
\text { Photographed } \\
\text { Photographed } \\
\text { Photographed } \\
\text { Inspected } \\
\text { Photographed }\end{array}$ \\
\hline $\begin{array}{l}610^{\circ} \text { Samples } \\
\text { as bonded } \\
10 \mathrm{hr}, 610^{\circ}(10) \\
10 \mathrm{hr}, 610^{\circ}(20) \\
10 \mathrm{hr}, 610^{\circ}(30) \\
5 \mathrm{hr}, 610^{\circ}(35) \\
10 \mathrm{hr}, 610^{\circ}(45)\end{array}$ & & $\begin{array}{l}\text { Photographed } \\
\text { Inspected } \\
\text { Inspected } \\
\text { Photographed } \\
\text { Inspected } \\
\text { Photographed }\end{array}$ \\
\hline
\end{tabular}




\section{$3.296 \% \mathrm{Al}_{2} \mathrm{O}_{3}$}

Several 1" $\times 1$ " pieces of $96 \% \mathrm{Al}_{2} \mathrm{O}_{3}$ were cut and polished on an automatic polishing machine ${ }^{1}$ with $1 \mu \mathrm{m}$ diamond compound. Sixteen copies of Mask 1 were exposed and etched onto one of the pieces, as for the $1 " \times 1$ " glass samples. The features were etched under conditions of $1 \mathrm{kV}$ and $0.6 \mathrm{~mA} / \mathrm{cm}^{2}$ for $30 \mathrm{~min}$. The resulting etch depth was about $0.3 \mu \mathrm{m}$. This piece and an unetched piece were cleaned in $\mathrm{SC} 1$ and $\mathrm{SC} 2$ and baked in air at about $600^{\circ} \mathrm{C}$ for $1 \mathrm{~h}$. The pieces were bonded in a hot press by ramping at $5^{\circ} \mathrm{C} / \mathrm{min}$ to $750^{\circ} \mathrm{C}$, held $20 \mathrm{~min}$ to improve vacuum, ramped at $15^{\circ} \mathrm{C} / \mathrm{min}$ to $1000^{\circ} \mathrm{C}$ and held for $15 \mathrm{~min}$, ramped at $10^{\circ} \mathrm{C} / \mathrm{min}$ to $750^{\circ} \mathrm{C}$ and held $2 \mathrm{~h}$, then ramped at $10^{\circ} \mathrm{C} / \mathrm{min}$ to room temperature. The applied pressure was $17 \mathrm{MPa}$ throughout the run and vacuum was $<5 \times 10^{-5}$ torr. This schedule was used to attain temperatures high enough for bonding but held only for a short time at $1000^{\circ} \mathrm{C}$ to avoid creep by deformation of the intergranular glass. The sample was cut into four $0.5^{\prime \prime} \times 0.5^{\prime \prime}$ pieces. To inspect the as-bonded interface, one of the four pieces was glued between two steel rods and fractured open at the interface by applying a quick three-point bending load to the rod/sample/rod "beam". One piece was annealed $1 \mathrm{~h}$ and another $3.5 \mathrm{~h}$ at $1150^{\circ} \mathrm{C}$ in flowing gettered argon. The annealed samples were difficult to break open. The edges required pre-notching of the interface on a diamond saw before they would break. All samples were inspected on a scanning electron microscope. The composition of this $\mathrm{Al}_{2} \mathrm{O}_{3}$ is listed in Table 1.

To determine the grain size of this material, which could be used to calculate an average intergranular film thickness, a piece of the $96 \% \mathrm{Al}_{2} \mathrm{O}_{3}$ was annealed in air for $10 \mathrm{~h}$ at $1200^{\circ} \mathrm{C}$ to cause glass to partially fill in some of the voids in the surface. The

\footnotetext{
${ }^{1}$ Multipol, Malvem Instruments, Malvern, Worcestershire, United Kingdom
} 
sample was then etched in an ion mill under the same conditions for etching masks above. The surface was photographed on an SEM. The grain size was calculated using ASTM Standard E112 [65].

\section{$3.396 \% \mathrm{Al}_{2} \mathrm{O}_{3} /$ Sapphire}

Two pieces of basal sapphire of known edge orientation (see Figure 35F) were cut, one $7.5 \mathrm{~mm} \times 17 \mathrm{~mm} \times 0.38 \mathrm{~mm}$ and the other $7.5 \mathrm{~mm} \times 8.5 \mathrm{~mm} \times 0.38 \mathrm{~mm}$, to match the sizes of two pieces of $96 \% \mathrm{Al}_{2} \mathrm{O}_{3}$. The $\mathrm{Al}_{2} \mathrm{O}_{3}$ was polished to $1 \mu \mathrm{m}$ on an automatic polishing machine. A mask, hereafter referred to as "Mask JDP7"1, see Figure 10, was etched into the $\mathrm{Al}_{2} \mathrm{O}_{3}$, two in the larger piece and one in the smaller. The ion beam conditions were $1 \mathrm{kV}$ and a current density of $1.3 \mathrm{~mA} / \mathrm{cm}^{2}$ and etching was done for about $12 \mathrm{~min}$. The resulting etch depth was about $0.35 \mu \mathrm{m}$. The $\mathrm{Al}_{2} \mathrm{O}_{3}$ and sapphire pieces were cleaned in SC1 and SC2 and baked in air for $1 \mathrm{~h}$ at $600^{\circ} \mathrm{C}$. The pieces were then bonded in a hot press, in a vacuum in the $10^{-5}$ torr range. Bonding at $1000^{\circ} \mathrm{C}$, used for the $96 \% \mathrm{Al}_{2} \mathrm{O}_{3}$ sample, was not found to produce sufficient bonding of the $96 \% \mathrm{Al}_{2} \mathrm{O}_{3}$ /sapphire samples. Hence, the samples were bonded by ramping at $7.5^{\circ} \mathrm{C} / \mathrm{min}$ to $1200^{\circ} \mathrm{C}$, held for $15 \mathrm{~min}$ with no load, ramped down at $7.5^{\circ} \mathrm{C} / \mathrm{min}$ to $1100^{\circ} \mathrm{C}$, held for $90 \mathrm{~min}$ with a pressure of about $2.8 \mathrm{MPa}$, and ramped to room temperature at $7.5^{\circ} \mathrm{C} / \mathrm{min}$. This resulted in a partial bond. A second bonding run of $4 \mathrm{~h}$ at $1100^{\circ} \mathrm{C}$ and about $3.4 \mathrm{MPa}$ (ramping at $+/-7.5^{\circ} \mathrm{C} / \mathrm{min}$ ) resulted in a good bond over the majority of the sample interfaces. Selected features were photographed on both as-bonded samples and they were subjected to different annealing schedules. All anneals were done in flowing gettered argon. Annealing conditions are tabulated in Table 3. A temperature of $1300^{\circ} \mathrm{C}$ was chosen first as it

\footnotetext{
${ }^{1}$ Designed by James D. Powers.
} 
was above the temperature range wherein crystallization of the intergranular glass may occur. Due to the rapid crack filling at this temperature, $1250^{\circ} \mathrm{C}$ was selected for further studies as it was at the upper end of the glass crystallization range. 
Treatment (total)

large sample

as bonded

$1 \mathrm{~h}, 1300^{\circ} \mathrm{C}(1 / 1300)$

small sample

as bonded

$1 \mathrm{~h}, 1200^{\circ} \mathrm{C}(1 / 1200)$

$1 \mathrm{~h}, 1200^{\circ} \mathrm{C}(2 / 1200)$

$2 \mathrm{~h}, 1200^{\circ} \mathrm{C}(4 / 1200)$

$6 \mathrm{~h}, 1200^{\circ} \mathrm{C}(10 / 1200)$

$10 \mathrm{~h}, 1200^{\circ} \mathrm{C}(20 / 1200)$

$13 \mathrm{~h}, 1200^{\circ} \mathrm{C}(33 / 1200)$

$5 \mathrm{~h}, 1250^{\circ} \mathrm{C}(5 / 1250)(33 / 1200)$

$10 \mathrm{~h}, 1250^{\circ} \mathrm{C}$

$(15 / 1250)(33 / 1200)$

$20 \mathrm{~h}, 1250^{\circ} \mathrm{C}$

$(35 / 1250)(33 / 1200)$

$25 \mathrm{~h}, 1250^{\circ} \mathrm{C}$

$(60 / 1250)(33 / 1200)$

$1 \mathrm{~h}, 1300^{\circ} \mathrm{C}$

$(1 / 1300)(60.1250)(33 / 1200)$
Table 3.

$96 \% \mathrm{Al}_{2} \mathrm{O}_{3} /$ Sapphire

Annealing/Photographing

Histories

etch depth is $0.35 \mu \mathrm{m}$

Photographed/Inspected

Photographed

Photographed

Photographed

Photographed (bond improved)

Inspected

Inspected

Inspected

Photographed

Inspected

Inspected

Inspected

Inspected

Photographed

Photographed 


\section{$3.4 \mathrm{SiO}_{2} /$ Sapphire}

Two pieces of basal sapphire of known edge orientation were cut to about $15 \mathrm{~mm} \times 17 \mathrm{~mm} \times 0.38 \mathrm{~mm}$. Mask JDP7 was etched into one piece four times, with two of the masks in an orientation orthogonal to the other two. The etching conditions were $1 \mathrm{kV}, 1.7 \mathrm{~mA} / \mathrm{cm}^{2}$ for 12 min resulting in a depth of $0.25 \mu \mathrm{m}$. The etched and unetched pieces were cleaned in $\mathrm{SC} 1$ and $\mathrm{SC}$, dried with a gas jet, then placed in a sputter deposition system ${ }^{1}$ on a microscope slide for coating with $\mathrm{SiO}_{2}$. The deposition conditions were a sputtering power setting of 300 watts with a $20 \%$ $\mathrm{O}_{2}, 80 \% \mathrm{Ar}$ gas mixture flowing at $100 \mathrm{cfm}$. These conditions have been determined to give a deposition rate of about $6 \mathrm{~nm} / \mathrm{min}$ [66]. As a coating thickness of $10-15 \mathrm{~nm}$ was desired, the deposition time was $1.5 \mathrm{~min}$. Such a thin coating is difficult to characterize. The shadowed region on the microscope slide was profiled on the contact profilometer, which indicated a thickness of about $25 \mathrm{~nm}$, however the accuracy of this small value is uncertain on this instrument and it has not been verified by another technique. As it is within an acceptable range, it is satisfactory. The pieces were then bonded with $\mathrm{SiO}_{2}$ sides together with essentially no misorientation between the sapphire crystals, using bonding conditions described elsewhere [67]. The first bonding run was at $1100^{\circ} \mathrm{C}$ for $2 \mathrm{~h}$ with about $4 \mathrm{MPa}$, ramping at $+/-$ $7.5^{\circ} \mathrm{C} / \mathrm{min}$. Bonding was incomplete, so a second bonding run using the same conditions but with a $4 \mathrm{~h}$ duration was performed. This resulted in bonding over almost the entire interface. Selected mask features were photographed in the as-bonded sample, and it was given multiple anneals. All anneals were done in flowing gettered argon. For annealing, samples were heated at $10^{\circ} \mathrm{C} / \mathrm{min}$ to $1100^{\circ} \mathrm{C}$,

\footnotetext{
${ }^{1}$ Randex Sputtering System, Randex Corp. location?
} 
then ramped at $30^{\circ} \mathrm{C} / \mathrm{min}$ to anneal temperatures at or below $1400^{\circ} \mathrm{C}$, held for the prescribed time, and ramped down using the same rates as during heating. For the anneals at $1620^{\circ} \mathrm{C}$, the temperature was raised to $1400^{\circ}$ as before, then ramped at $50^{\circ} \mathrm{C} / \mathrm{min}$ to $1620^{\circ} \mathrm{C}$ and held for the prescribed time, ramped at $100^{\circ} \mathrm{C} / \mathrm{min}$ down to $1100^{\circ} \mathrm{C}$ and $10^{\circ} \mathrm{C} / \mathrm{min}$ from there to room temperature. The heat treatment and micrograpl; history are tabulated in Table 4. The technique of "Becke lines" was used to determine the relative index of refraction between the interfacial film and cry stals that nucleated and grew in it [71]. 


\section{Table 4. \\ $\mathrm{SiO}_{2} /$ Sapphire \\ Annealing/Photographing \\ History \\ etch depth is $0.25 \mu \mathrm{m}$}

$\begin{array}{ll}\text { rreatment (total) } & \text { Photographed/Inspected } \\ \text { as bonded }(0) & \text { Photographed } \\ 0.5 \mathrm{~h}, 1250^{\circ} \mathrm{C}(0 / 1250) & \text { Inspected } \\ 1 \mathrm{~h}, 1250^{\circ} \mathrm{C}(1.5 / 1250) & \text { Photographed defects } \\ 1 \mathrm{~h}, 1250^{\circ} \mathrm{C}(2.5 / 1250) & \text { Inspected } \\ 1 \mathrm{~h}, 1250^{\circ} \mathrm{C}(3.5 / 1250) & \text { Inspected } \\ 3 \mathrm{~h}, 1250^{\circ} \mathrm{C}(6.5 / 1250) & \text { Photographed } \\ 1 \mathrm{~h}, 1300^{\circ} \mathrm{C} & \text { Inspected } \\ (1 / 1300)(6.5 / 1250) & \text { Inspected } \\ 3 \mathrm{~h}, 1300^{\circ} \mathrm{C} & \\ (4 / 1300)(6.5 / 1250) & \\ 6 \mathrm{~h}, 1300^{\circ} \mathrm{C} & \\ (10 / 1300)(6.5 / 1250) & \text { Photographed } \\ 10 \mathrm{~h}, 1300^{\circ} \mathrm{C} & \\ (20 / 1300)(6.5 / 1250) & \\ 3 \mathrm{~h}, 1400^{\circ} \mathrm{C} & \text { Inspected } \\ (3 / 1400)(20 / 1300)(6.5 / 1250) & \\ 10 \mathrm{~h}, 1400^{\circ} \mathrm{C} & \text { Photographed } \\ (13 / 1400)(20 / 1300)(6.5 / 1250) & \\ 10 \mathrm{~h}, 1400^{\circ} \mathrm{C} & \text { Photographed } \\ (23 / 1400)(20 / 1300)(6.5 / 1250) & \\ 20 \mathrm{~h}, 1400^{\circ} \mathrm{C} & \text { Photographed and Becke lines } \\ (43 / 1400)(20 / 1300)(6.5 / 1250) & \\ 0.25 \mathrm{~h}, 1620^{\circ} \mathrm{C} & \text { Inspected } \\ (.25 / 1620)(43 / 1400)(20 / 1300) & \\ (6.5 / 1250) & \\ 0.5 \mathrm{~h}, 1620^{\circ} \mathrm{C} & \text { Photographed } \\ (.75 / 1620)(43 / 1400)(20 / 1300) & \\ (6.5 / 1250) & \end{array}$




\section{Results and Discussion}

\subsection{Corning 7056 Glass}

From the dimensions of the channels in the as bonded samples, the radii of cylinders with equivalent cross sectional areas, denoted r, were calculated for each channel. These data, along with the measured initial crack dimensions, are tabulated in Table 5.

Table 5.

\section{Initial Crack and Channel}

Dimensions

\begin{tabular}{llll} 
& \multicolumn{3}{c}{$\mathrm{r}_{\mathrm{eq}}(\mu \mathrm{m})$} \\
Channel no. & mask 2L & mask 2N & mask X \\
1 & damaged & 0.96 & 0.89 \\
2 & $"$ & 1.1 & 1.06 \\
3 & $"$ & 1.22 & 1.13 \\
4 & 1.21 & 1.3 & 1.21 \\
5 & 1.26 & 1.35 & 1.26 \\
6 & 1.33 & 1.43 & 1.33
\end{tabular}

Mean Crack Dimensions: $212 \mu \mathrm{m} \times 105 \mu \mathrm{m}$ 


\subsubsection{Corning 7056, Crack Healing}

As mentioned earlier, it was not expected that bulges would develop at the edges of cracks as they healed due to the nature of mass transport by viscous flow. This was indeed what was observed. The crack edges merely receded while the crack developed an elliptical cross section with an aspect ratio that decreased with increasing anneal time and temperature. Figure 11 shows a cross section of a crack after $13 \mathrm{~h}$ at $650^{\circ} \mathrm{C}$. This cross section was initially $105 \mu \mathrm{m} \times 0.5 \mu \mathrm{m}$. It is now an ellipse with minor and major axes of $4.49 \mu \mathrm{m}$ and $26.22 \mu \mathrm{m}$, respectively. Figures 12-13 show top views of cracks as they develop through the annealing.

There were some observations, similar to what has been observed in sapphire $[15,45]$, that were not expected in the evolution of cracks in glass. Cracks from mask $2 \mathrm{~N}, 650^{\circ} \mathrm{C}$, and mask $\mathrm{X}, 610^{\circ} \mathrm{C}$, exhibit channels left at comers as adjacent edges receded, see Figures 12 and 14. Cracks from mask 2L, $650^{\circ} \mathrm{C}$, do not appear to have remnant channels at corners, Figure 13. Instead, the corners merely appear to have lagged slightly behind the receding edges.

Differences in crack depth are probably not responsible for the difference in this aspect of healing behavior as $2 \mathrm{~L}\left(650^{\circ} \mathrm{C}\right)$ and $\mathrm{X}\left(610^{\circ} \mathrm{C}\right)$ are both etched about $0.5 \mu \mathrm{m}$ deep, while $2 \mathrm{~N}\left(650^{\circ} \mathrm{C}\right)$ is $0.58 \mu \mathrm{m}$ deep. However, $2 \mathrm{~L}$ and $2 \mathrm{~N}$ were in the same sample about half an inch apart. Mask $2 \mathrm{~L}$ was always near the top of the crucible and $2 \mathrm{~N}$ near the bottom during anneals. As the furnace in which these anneals were performed was not equipped with controlled ramping, repeatable ramping up and down was achieved by simply turning the furnace on at full power with the anneal temperature as the setpoint and turning it off at the end of the anneal with the same mass in the furnace in all runs. Turning the furnace on and 
off in this manner produced very rapid heating and cooling rates. Such rapid rates can cause warping in glass. To avoid this, the crucible was placed in a hole in a refractory brick to provide insulation which slowed heating and cooling sufficiently to prevent significant warping. This may have resulted in significantly faster heating near the top of the crucible. This would allow the portion of the sample near the top to reach the final temperature well before that near the bottom. If the lag in temperature near the bottom were enough, it may not even spend the majority of a few hour anneal at the prescribed temperature. Note, however, that for a given amount of crack edge recession, the length of corner channels in $2 \mathrm{~N}\left(650^{\circ} \mathrm{C}\right)$ is less than that in the $610^{\circ}$ sample. Also note that the cracks in $2 \mathrm{~L}$ shrunk much faster than those in $2 \mathrm{~N}$ which indicates a lower viscosity, hence higher temperature. Now it is apparent that the temperatures in the three groups of cracks are in the order $T_{2 L}>T_{2 N}>T_{X}$. Similarly, the lengths of corner channels, 1 , are in the order $\mathrm{l}_{2 \mathrm{~L}}<\mathrm{l}_{2 \mathrm{~N}}<\mathrm{l}_{\mathrm{X}}$, consistent with the order of the viscosities of the material in which the cracks exist. It is therefore surmised that the extent to which channels are left at corners by receding crack edges is dependent on viscosity which is varied between groups of cracks by variations in local sample temperature. The corner channels are filled faster when the viscosity is lower. From Figure 15 it is seen that the viscosity of this glass varies by about one order of magnitude between $600^{\circ} \mathrm{C}$ and $650^{\circ} \mathrm{C}$. Consequently, small deviations in temperature can significantly affect mass flow rates. The behavior of channels at different temperatures, discussed below, also serves to demonstrate this. 


\subsubsection{Corning 7056, Channel Evolution}

During annealing, the channels of smaller radius developed perturbations faster than those of larger radius and broke up into spheres faster, as one would expect. Table 6 shows the mean node spacings (or wavelengths) to radius ratios for channels of constant length (about $3200 \mu \mathrm{m}$ ) and various radii after different anneals and the cumulative spacing/radius mean for each anneal. Inspection of the data for each channel shows that the means for larger channels (\#5-6) decrease from values of about 50-65 for shorter anneals to 25-43 after longer anneals. The midsized channels (\#3-4) start with values from 26-54 after the first anneals and show values of 35-50 after longer anneals. The spread in values does not change much, however the mean ratios for some channels increase, some decrease, and some barely change at all. For the small channels (\#1-2) mean values start in a range 18-32, and grow to 64-115 after longer annealing. These data are plotted in Figures 16-19. 
Table 6.

Node spacings/radius

3200 $\mu \mathrm{m}$ Channels

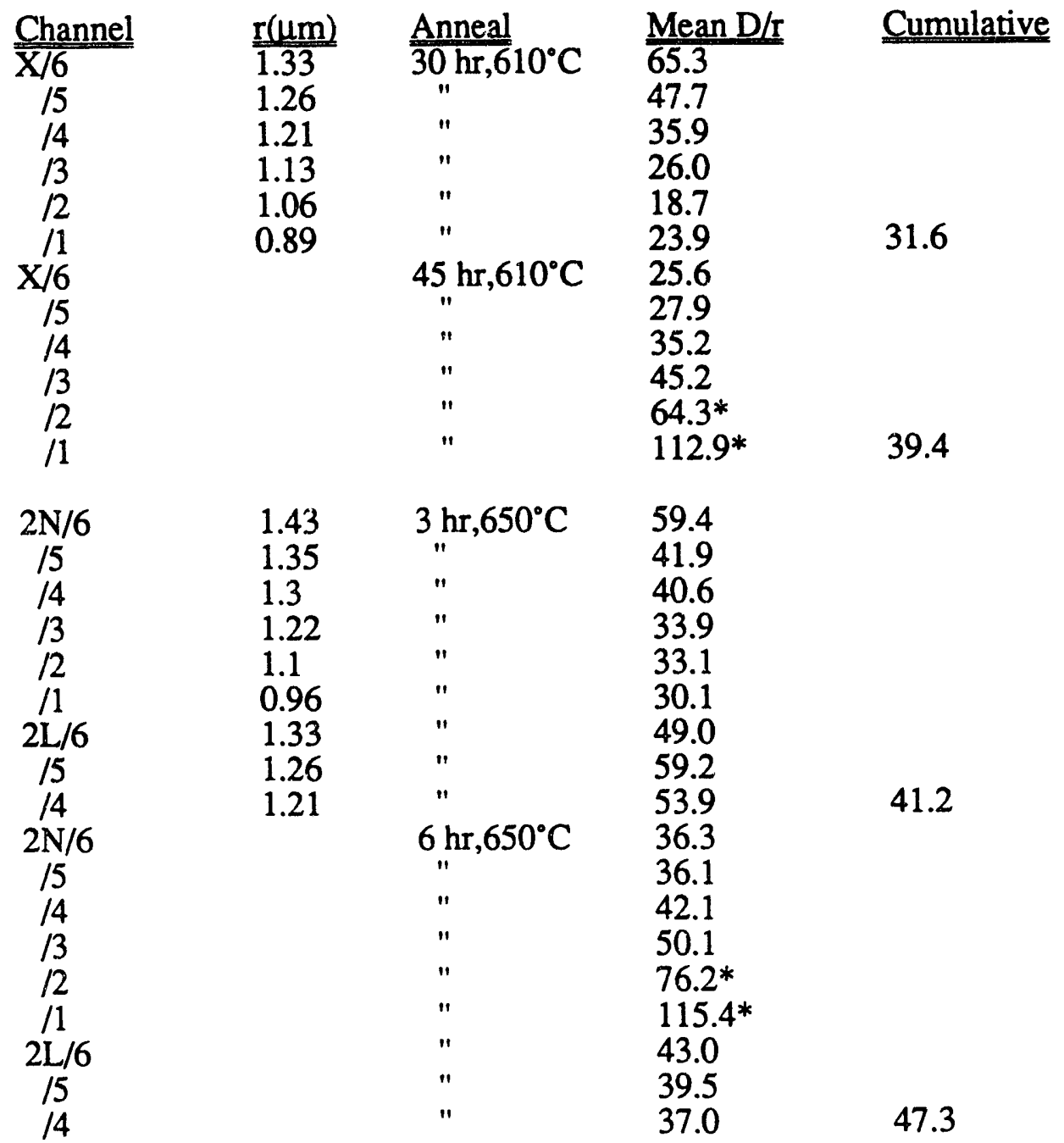

*Many large spacings which are actually pore-pore or pore-node distances for small channels that broke up into pores 
The very large values for the small channels after longer anneals arise because the small channels had substantially broken up into spheres after these longer anneals. These pores were frequently rather far apart. Therefore, these pore-pore or pore-node spacings serve to push the mean up when the channel is reduced to a few pores in some regions. Figures 20C,21C,D, and 22C,D show segments of these small channels that have spheroidized. Note that some regions of channels display a perturbation of a given wavelength growing on top of a perturbation of much greater wavelength. As the longer wavelength perturbation has an advantage in growth rate, one expects to find a few large, widely spaced pores when a channel has broken up rather than numerous small pores at spacings comparable to the smaller perturbation wavelength.

The mean values of the midsized channels are in the middle of the range of numbers seen for most channels after the shorter anneals and are in the same range after longer annealing. The larger channels, however, have mean spacing/r values toward the upper end of the typical range early on, but always evolve toward numbers in the middle of the observed values. These values are very close to those of the midsized channels and some of the early values observed in small channels.

As mentioned earlier, the initial growth rate of an infinitesimal perturbation on an infinite cylinder due to viscous flow increased monotonically with wavelength above the critical value, $2 \pi a$. This indicates that any perturbation with a wavelength greater than this will continue to grow at a rate that increases almost linearly as $1 / \lambda$ decreases until $\lambda \cong 30 a$, at which point the growth rate changes little with increasing $\lambda$, see Figure 7 . Therefore, it is possible to observe a 
number of wavelengths growing simultaneously as predicted by others [63]. Again, it is also expected that the magnitude of a perturbation will affect relative growth rates, with larger amplitude perturbations exhibiting larger growth rates.

One expects that any perturbation (or defect) initially present on the channel will probably continue to grow. Figures $20 \mathrm{~A}, 21 \mathrm{~A}$, and $22 \mathrm{~A}$ show defects present on channels before annealing began and it is clear they have grown much faster than perturbations elsewhere on the channel that are too small to see initially. In Figure 20A, near the middle of the channels, channels 3 and 4 ( 1 is smallest, 6 largest) show defects that have substantially reduced their radii locally. These defects lead to the early pinching of these channels. After these points have pinched, these portions of the channels behave like any other end. Near the right end of these channels, a scratch running across all channels is not even clearly visible in the as-bonded sample, Figure $20 \mathrm{~A}$. It is easily seen that this scratch has caused the growth of bulges in the channels as annealing proceeded, see Figures 20B and 20C. However, the presence of these defects does not seem to have induced extensive growth of perturbations at any appreciable distance from them. If one inspects the ends of the channels, particularly in Figures $21 \mathrm{C}$ and $22 \mathrm{C}$, it is particularly interesting to note that the end has bulged a little and a sinusoidal oscillation in channel radius has developed, propagating well into the channel. These perturbations can be seen to be growing at distances of order $100 a$ from the end, while the wavelength varies little over this region. This observation seems to indicate that end effects do play a significant role in the morphological evolution of channels in glass, as discussed in Section 2.2.3. 
As noted, the mean values of node spacing to radius ratios typically are in the range-20-60, excluding the large values for spheroidized channel segments. From Figures 16-19, particularly 16G, 17G, 18J, and 19J showing data for all channels in an anneal, it is clearly evident that the most frequent values of node spacing/radius occur between 20-50. Comparing these values with the range of values, 20-50, calculated for the maximum in the Fourier transform of $K(\mathrm{~s})$, see Section 2.2.3, it seems likely that end effects are very active in the morphological evolution of channels due to viscous flow. Preexisting defects clearly contribute to perturbation growth and breakup, but given that perturbations with wavelengths in the range "prescribed" by end effects are also in the range of maximum growth rate, it is possible that end effects are primarily responsible for observed behavior.

\subsection{Soda-Lime Glass}

From the soda-lime glass sample, Figures 23 show cracks and varying aspect ratio channels as-bonded and after $15 \mathrm{~min}$ at $650^{\circ} \mathrm{C}$. The cracks have bloated into pillows and the channels have obviously increased in volume. The etch depth of this sample was $0.5 \mu \mathrm{m}$. The initial volume of the fifth smallest narrow channel, marked "A" in the figure, is $84 \mu \mathrm{m}^{3}$. The final volume of this spheroidized channel is about $900 \mu^{3}$. The volume has increased by an order of magnitude. Using an estimate of the surface tension of this glass at 300 dyne $/ \mathrm{cm}$ and the sphere radius of $6 \mu \mathrm{m}$, the pressure difference across the pore surface is calculated to be about $10^{6} \mathrm{dyne} / \mathrm{cm}^{2}$ or $1 \mathrm{~atm}$. It is concluded that the pressures produced in voids by fining agents is large enough to control their morphological evolution. 


\section{$4.396 \% \mathrm{Al}_{2} \mathrm{O}_{3}$}

\subsection{1 $96 \% \mathrm{Al}_{2} \mathrm{O}_{3}, 1150^{\circ} \mathrm{C}$ Anneals}

From the fractured interface of the as-bonded sample, it appears that there was bonding over most of the surface. Figures 24 show a crack and short channels in the exposed surface of the etched piece. Abundant native porosity is also visible. The features have not changed noticeably irom their as-etched shapes. The smooth surface between features shows that the interface fractured cleanly. As it fractured rather easily, the bond was probably weak, being provided by the intergranular glass between the two surfaces.

After $1 \mathrm{~h}$ at $1150^{\circ} \mathrm{C}$, changes in the feature shape are apparent. Figures 25 show a crack and short channels from a fractured interface. Bulges of material, probably glass, have protruded from the edges of the crack into the crack. The edge in the upper right corner has moved in several microns. Similar protrusions are visible on channel edges. The ends of channels are sometimes very distorted by redistributed glass. The narrowest of the six channels has been reduced to shorter segments by glass filling in portions of it. The rough surface between features, including pulled out grains, indicate bonding was much better after the anneal. This was expected due to the increased difficulty of breaking the sample open.

After $3.5 \mathrm{~h}$ at $1150^{\circ} \mathrm{C}$, the cracks have not changed much more than after the $1 \mathrm{~h}$ anneal. The channels have evolved only slightly more. Figures 26 show a crack and short channels after this last anneal. Figures 27 show higher magnification micrographs of the ends of some channels, where glass redistribution is most apparent. Figure 27A corresponds to channel "A" and 
similarly for B and C. These micrographs show how the interfacial flaws are being filled by the growth of an interfacial film of glass into the flaws. The surface between features, rougher than that in the sample annealed $1 \mathrm{~h}$, attests to the still improved bonding. Bonding had improved enough that only a small portion of the interface fractured, yet with great difficulty. Much of the exposed interface was damaged by pulled out grains, so few features were available for observation. It should be noted that the temperature at which these samples were annealed, $1150^{\circ} \mathrm{C}$, is the upper limit of the range wherein crystallization of the intergranular glass was observed in this material [55]. Therefore, healing by flow of intergranular glass might proceed only as long as the glass has not crystallized. If the glass does not crystallize extensively or is very slow to do so, healing may proceed to completion. As it is not believed possible to break open samples after further annealing, given the difficulty after $3.5 \mathrm{~h}$, it is consequently not believed possible to further observe healing using this method. The $96 \% \mathrm{Al}_{2} \mathrm{O}_{3} /$ sapphire provides an alternate means to accomplish this.

\subsection{2 $96 \% \mathrm{Al}_{2} \mathrm{O}_{3}$, Glass Film Thickness and Viscosity}

Figure 28 shows the etched surface of a piece of this $96 \% \mathrm{Al}_{2} \mathrm{O}_{3}$. Using ASTM Standard E112 with circular intercepts, the grain size was calculated to be approximately $3.5 \mu \mathrm{m}$. Knowing the grain size, an approximate intergranular film thickness can be calculated. As the grains in this material are not generally symmetric or homogeneous in shape, they will be assumed to be dodecahedra with an inscribed spherical diameter equal to the average grain size. The surface area and volume of such polyhedra are tabulated in standard references [68]. For an inscribed diameter, $d$, of $3.5 \mu \mathrm{m}$, the surface area $T$ of an "average" grain is 
$T=16.66\left(\frac{d}{2}\right)^{2}=51 \mu m^{2}$. Its volume $V$ is given by $V=5.55\left(\frac{d}{2}\right)^{3}=29.7 \mu m^{3 .}$ The volume of the intergranular phase, $V_{g}$, assuming the film thickness $t$ is very small, is approximately $V_{g} \cong t T$. The total volume of the material is $V_{c o t}=V+V_{g}$. As the glass constitutes about $4 \%$ of the volume, $V_{g} V_{e x}=0.04$. Substituting and solving for $t$ gives $t=\frac{0.04 V_{\text {tot }}}{0.06 T}=0.02 \mu \mathrm{m}$. The total distance between grain faces is $2 t$, giving an intergranular film thickness of about $0.04 \mu \mathrm{m}$. There are, however, regions of thicker glass along grain junctions.

The composition of the intergranular glass in the as-processed material, determined by energy dispersive spectroscopy [55a], is listed in Table 7. Viscosity data for a glass of this composition was not available, however that for glasses with very similar compositions was. The compositions and viscosities for two commercial glasses ${ }^{1}$ are listed in Table 8. As seen in the tables, the glass in the $96 \% \mathrm{Al}_{2} \mathrm{O}_{3}$ differs from these commercial glasses in that it contains about twice as much $\mathrm{MgO}$, half as much $\mathrm{CaO}$, less $\mathrm{BaO}$ and no $\mathrm{Na}_{2} \mathrm{O}$ or $\mathrm{B}_{2} \mathrm{O}_{3}$. However, $\mathrm{MgO}, \mathrm{CaO}$, and $\mathrm{BaO}$ lower the viscosity of silicate glasses similarly so these differences are not expected to alter the viscosity of the intergranular glass much from these commercial glasses. The lowering of the viscosity by these oxides may be countered somewhat by $\mathrm{B}_{2} \mathrm{O}_{3}$ or $\mathrm{Al}_{2} \mathrm{O}_{3}$ [69]. In conclusion, the viscosity of the intergranular glass in this $96 \% \mathrm{Al}_{2} \mathrm{O}_{3}$ will be very close to that of these commercial glasses. Hence, annealing at $1150^{\circ} \mathrm{C}$ will result in a viscosity close to the working point of the glass, defined as $10^{4}$ poise.

\footnotetext{
${ }^{1}$ Corning Glass Works, Corning, New York
} 
Table 7.

Composition of Intergranular Glass in $96 \% \mathrm{Al}_{2} \mathrm{O}_{3}$

(From Powell-Dogan and Heuer, (55a))

Component

weight \%

$\mathrm{SiO}_{2}$

67

$\mathrm{Al}_{2} \mathrm{O}_{3}$

15

$\mathrm{MgO}$

13

$\mathrm{CaO}$

5

$\mathrm{BaO}$

1 
Table 8.

Compositions and Viscosity

Data for Commercial Glasses

(From CRC Handbook of tables for

Applied Engineering Science, 2nd Ed. (68))

\begin{tabular}{|c|c|c|c|c|c|c|}
\hline Coming Glass Code & Component & Weight $\%$ & $\begin{array}{l}\text { Strain } \\
\text { Point,"C }\end{array}$ & $\begin{array}{l}\text { Anneal } \\
\text { Point, }{ }^{\circ} \mathrm{C}\end{array}$ & $\begin{array}{l}\text { Softering } \\
\text { Point, }{ }^{\circ} \mathrm{C}\end{array}$ & $\begin{array}{l}\text { Working } \\
\text { Point,"C }\end{array}$ \\
\hline \multirow[t]{6}{*}{1720} & $\mathrm{SiO}_{2}$ & 62 & 670 & 715 & 915 & 1190 \\
\hline & $\mathrm{Al}_{2} \mathrm{O}_{3}$ & 17 & & & & \\
\hline & $\mathrm{MgO}$ & 7 & & & & \\
\hline & $\mathrm{CaO}$ & 8 & & & & \\
\hline & $\mathrm{B}_{2} \mathrm{O}_{3}$ & 5 & & & & \\
\hline & $\mathrm{Na}_{2} \mathrm{O}$ & 1 & & & & \\
\hline \multirow[t]{6}{*}{1723} & $\mathrm{SiO}_{2}$ & 57 & 670 & 710 & 910 & 1175 \\
\hline & $\mathrm{Al}_{2} \mathrm{O}_{3}$ & 15 & & & & \\
\hline & $\mathrm{MgO}$ & 7 & & & & \\
\hline & $\mathrm{CaO}$ & 10 & & & & \\
\hline & $\mathrm{BaO}$ & 6 & & & & \\
\hline & $\mathrm{B}_{2} \mathrm{O}_{3}$ & 5 & & & & \\
\hline
\end{tabular}




\section{$4.496 \% \mathrm{Al}_{2} \mathrm{O}_{3} /$ Sapphire}

\subsection{1 $96 \% \mathrm{Al}_{2} \mathrm{O}_{3} /$ Sapphire, $1300^{\circ} \mathrm{C}$ Anneal}

The $96 \% \mathrm{Al}_{2} \mathrm{O}_{3} /$ sapphire sample annealed at $1300^{\circ} \mathrm{C}$ for $1 \mathrm{~h}$ shows dramatic healing, see Figure 29. Not only have poorly bonded regions been joined, but most features have been reduced to pores of sizes comparable to the native porosity in the $\mathrm{Al}_{2} \mathrm{O}_{3}$. This residual porosity is, however, more closely spaced. It appears the intergranular glass has flowed into the cracks, producing enough crack filling to consider most of them completely healed. Figure 29 shows rectangular and circular cracks, respectively, before and after the anneal. Many of the pores remaining after the anneal correspond to pores visible before annealing, but it is clear that there is no correspondence between the residual porosity and the crystallography of the sapphire substrate. As crack edge orientation also seems to have no effect on resultant morphology, it is concluded thar the sapphire crystallography has no effect on the healing behavior observed in these conditions and that it is purely by viscous flow through the polycrystalline material. The evolution of channels in this system merely entailed glass flowing between grains to fill them. Since this mechanism is no different than that for crack healing, it was not investigated independently. Instead, attention was focused on crack healing in this system.

\subsection{2 $96 \% \mathrm{Al}_{2} \mathrm{O}_{3} /$ Sapphire, $1250^{\circ} \mathrm{C}$ Anneal}

The sample annealed at lower temperature displayed substantially different behavior. The majority of the as bonded sample was bonded, but a significant portion of the interface was not. After one hour at $1200^{\circ} \mathrm{C}$ the unbonded regions had been almost completely eliminated, as shown in Figures 30 and 31A,B. 
Successive anneals, up to $33 \mathrm{~h}$, at $1200^{\circ} \mathrm{C}$ failed to produce any significant morphological change, see Figures $30 \mathrm{C}$ and $31 \mathrm{C}$. After up to $60 \mathrm{~h}$ at $1250^{\circ} \mathrm{C}$, there was still no significant change, Figures 30D and 31D. There are, however, regions near crack or channel edges wherein some change in contrast is noticeable. This contrast change appears to reflect local changes in material composition or structure. In the narrow channels ( $4 \mu \mathrm{m}$ wide channels) it appears as though small crystals were growing from the channels like whiskers, see Figure 32.

Unfortunately, only limited information is accessible via optical microscopy. When this sample was annealed $1 \mathrm{~h}$ at $1300^{\circ} \mathrm{C}$, changes similar to those seen in the sample annealed only at $1300^{\circ} \mathrm{C}$ began to take place. However, as seen in Figures $30 \mathrm{E}$ and $31 \mathrm{E}$ the magnitude of the changes was much smaller. We believe that this difference is due to crystallization of the glassy phase.

\subsubsection{6\% $\mathrm{Al}_{2} \mathrm{O}_{3} /$ Sapphire, Glass Chemistry and Crystallization}

As mentioned in Section 2.1.5 referencing [55], the present material is a "high-MgO" material with $\mathrm{MgO}: \mathrm{CaO}$ about 2.5. Hence, when the sample is heated to $1300^{\circ} \mathrm{C}$ for $1 \mathrm{~h}$, no crystallization occurs and the intergranular phase remains viscous, free to flow into the introduced cracks as observed. When this material is annealed at $1200^{\circ} \mathrm{C}$ to $1250^{\circ} \mathrm{C}$, even for almost $100 \mathrm{~h}$, little if any crystallization is expected. Thus, one would expect that the intergranular glass should flow into the cracks, albeit somewhat more slowly than at $1300^{\circ} \mathrm{C}$. The observations in our study indicate different behavior.

As discussed in Section 2.1.5, changes in intergranular glass chemistry may cause its crystallization. Consequently, the lack of crack healing at $1200^{\circ}-1250^{\circ} \mathrm{C}$ may be due to the sapphire interacting with the glass near the $\mathrm{Al}_{2} \mathrm{O}_{3}$ /sapphire 
interface in a manner that promotes the nucleation and/or growth of crystalline phases at these temperatures. When annealed for one hour at $1300^{\circ}$ after the long times at lower temperatures, the crystallized material may remain crystalline or take time to dissolve. A $1 \mathrm{~h}$ anneal at $1500^{\circ} \mathrm{C}$ was found to completely dissolve all crystalline grain boundary phases [55b]. Therefore, $1 \mathrm{~h}$ at $1300^{\circ} \mathrm{C}$ may not be sufficient to dissolve crystallized material. The remaining glass is responsible for the observed small amount of healing during the final $1300^{\circ} \mathrm{C}$ anneal.

A TEM $^{1}$ investigation of this sample after $60 \mathrm{~h}$ at $1250^{\circ} \mathrm{C}$ revealed crystalline phases in some intergranular glass pockets. Figure 33A shows a bright field image of one such pocket. The pocket is a few microns from the $96 \% \mathrm{Al}_{2} \mathrm{O}_{3}$ /sapphire interface, marked on the micrograph. Figures 33B,C,D show selected area diffraction (SAD) patterns from two $\mathrm{Al}_{2} \mathrm{O}_{3}$ grains adjacent to the glass pocket and one centered on the crystal in the pocket, respectively. This enabled the distinction between diffraction spots from the surrounding two grains, labeled G1 and $\mathrm{G} 2 i$, and the crystal in the pocket, labeled $\mathrm{C} i$. Figure 34A shows a higher magnification image of the crystal in this glass pocket. Figures 34B and 34C show centered darkfield images of this crystal using reflections $\mathrm{Cl}$ and $\mathrm{C} 2$, respectively, from the crystal's diffraction pattern in Figure 33D. The SAD pattern in Figure $33 \mathrm{C}$ is of an $\mathrm{Al}_{2} \mathrm{O}_{3}[0001]$ orientation and was used to determine the camera constant of the microscope. The diffraction pattern of the crystal, Figure 33D, was then used to calculate its interplanar spacings. These data were compared to those for various $\mathrm{Al} \cdot \mathrm{Si} \bullet \mathrm{O}, \mathrm{Ca} \cdot \mathrm{Al} \bullet \mathrm{Si} \bullet \mathrm{O}, \mathrm{Mg} \cdot \mathrm{Al} \bullet \mathrm{Si} \bullet \mathrm{O}$, and $\mathrm{Mg} \bullet \mathrm{Al} \bullet \mathrm{O}$ crystalline materials from the Powder Diffraction Files (PDF) [70]. Based on agreements

\footnotetext{
${ }^{1}$ Philips 301 TEM, Philips ...
} 
between interplanar spacings of the unknown crystal and those of the above mentioned materials in the PDF, the unknown crjstal is probably either cordierite, $\mathrm{Mg}_{2} \mathrm{Al}_{4} \mathrm{Si}_{5} \mathrm{O}_{18}$ with an orthorhombic structure, or anorthite, $\mathrm{CaAl}_{2} \mathrm{Si}_{2} \mathrm{O}_{8}$ with a triclinic structure. Interplanar spacings of $\mathrm{Al}_{2} \mathrm{O}_{3}$ do not agree at all with those of this crystal, indicating it is clearly not $\mathrm{Al}_{2} \mathrm{O}_{3}$. Energy dispersive $\mathrm{X}$-ray spectroscopy ${ }^{12}$ (EDS) of this crystal gave the approximate cation composition of the crystal as $\mathrm{Mg} 15.15$ at. \%; $\mathrm{Al} 54.35$ at \%; Si 28.52 at \%; Ca 1.99 at \%. The large ratio of $\mathrm{Mg}$ to $\mathrm{Ca}$ indicates that the crystal is a magnesium aluminosilicate, almost certainly cordierite. The Ca signal may be from a small quantity incorporated in the crystal or from the surrounding glass. The large $\mathrm{Al}$ signal is probably from the surrounding $\mathrm{Al}_{2} \mathrm{O}_{3}$ grains. This shows that there is indeed crystallization of the intergranular glass taking place. This is believed responsible for the drastically reduced rate of crack filling by intergranular glass in the sample annealed at $1200^{\circ} / 1250^{\circ} \mathrm{C}$ compared to that observed in the sample annealed at $1300^{\circ} \mathrm{C}$.

\section{5 $\mathrm{SiO}_{2} /$ Sapphire}

\subsection{1 $\mathrm{SiO}_{2} /$ Sapphire, Behavior During Annealing}

The interface of the bonded $\mathrm{SiO}_{2}$ coated sapphire surfaces was almost completely bonded. Some scratches were visible and there were occasional particulate contaminants which comprised virtually all of the nonbonded surface area, see Figures 35A; 36A, and 37A. As it was desired to avoid crystallization of the $\mathrm{SiO}_{2}$ layer, the anneal temperatures chosen first were only $1250^{\circ} \mathrm{C}$. From

\footnotetext{
${ }^{1}$ Performed by Mahesh Chandramouli, Dept. of Materials Science and Mineral Engineering, University of California at Berkeley

${ }^{2}$ Philips 400 transmission electron micorscope, Kevex ??
} 
Figure 3 the viscosity is about $10^{11.5}$ poise at this temperature. After an accumulated time of $6.5 \mathrm{hr}$ at $1250^{\circ} \mathrm{C}$ the only noticeable changes were formation of closely spaced "islands" in the cracks and the apparent debonding of isolated portions of the interface, particularly near scratches, see Figures 37B. When the temperature was raised to $1300^{\circ} \mathrm{C}$, where the viscosity is about $10^{10.7}$ poise, change was still extremely slow. After accumulating $10 \mathrm{hr}$ at $1300^{\circ}$, the only noticeable change was a coarsening of the islands in cracks noted above, Figures $36 \mathrm{~B}$ and $37 \mathrm{C}$. An additional $10 \mathrm{~h}$ at $1300^{\circ}(20 \mathrm{~h}$ total) produced no further detectable change.

Increasing the temperature to $1400^{\circ} \mathrm{C}$, where the viscosity is about $10^{9.5}$ poise, resulted in substantially increased coarsening of the islands in cracks, but virtually no geometric change in cracks or channels resulted. After $13 \mathrm{~h}$ at $1400^{\circ} \mathrm{C}$ the appearance of occasional long, blade shaped features in some cracks was noted, Figures 35B, 36C, and 37D. As they were definitely facetted with facets along low index directions of the sapphire substrates (see Figure 35F for Laue pattern of crystals), they are believed to be crystalline. Another notable development was the onset of noticeable facetting of the islands bridging cracks. Still, no change in crack or channel geometry had occurred. An additional $10 \mathrm{~h}$ at $1400^{\circ} \mathrm{C}$ ( $23 \mathrm{~h}$ total) produced further coarsening and facetting of the islands, the growth of existing crystals, and the appearance of a few more crystals, Figures 35C, 36D, and 37E. Crystals were now also clearly visible in the regions of the interface where debonding had occurred during annealing. After 20 more

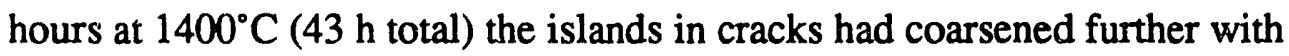
almost all facetted to some degree. More crystals had nucleated and many had 
grown to lengths extending completely across cracks. After all these anneals, however, there has been virtually no significant displacement of crack edges from their original positions, Figures 35D, 36E, and 37F. To this point, all mass bridging crack faces appears to be the result of a crystal nucleation and growth process. The details of this process are not understood at present. It is possibly due contamination, as regions near particulate contamination develop crystals more rapidly than regions distant from the impure regions, see Figure 38.

The anneals at $1620^{\circ} \mathrm{C}$ resulted in substantial crystal growth in "bonded" regions and little growth of crystals in cracks. Most of the islands in cracks disappeared, frequently appearing to leave behind what look like bumps on one face of the crack. Islands that look like crescents or question marks develop. Crack tip regression initiates, see Figures 35E, 36F, and 37G. Crack edges have begun to pull in and appear to be bulged to various degrees, similar in appearance to healing behavior seen in pure sapphire annealed at $1700^{\circ}-1800^{\circ} \mathrm{C}[15,45]$. In this system, glass flow does not appear to have contributed much to the morphological evolution of flaws. Again, channel evolution exhibited the same behavior as crack healing, so was not treated separately.

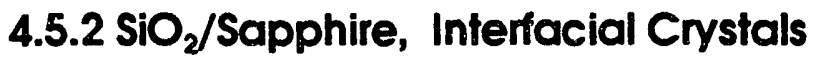

In many regions of the interface with no apparent flaws due to nonbonding or contamination, these blade shaped crystals can still be quite abundant, though hard to see. Figures 39 show bright field reflected (BFR) light and dark field transmitted (DFT) light optical micrographs of such a region. Note that in the BFR image, the only interfacial features present are what look like a few straight 
lines of pores. The DFT inage, however, dramatically brings out interfacial crystals that would otherwise be unseen. The pores in the BFR image do indeed appear to be just that when compared to the same region in the DFT image.

An interesting technique in the optical microscope is that called "Becke lines" mentioned earlier [71]. Using transmitted polarized light, a crystal immersed in a medium of different refractive index is observed and a vertical edge of it is brought into focus. When the sample is moved slightly away from the objective, a line of brighter intensity moves away from the vertical interface and into the material of higher refractive index. When the sample is brought closer, the bright line or "Becke line" moves into the material of lower refractive index. Figures 40 show a series of micrographs of crystals in a well bonded region after accumulating anneal time at the lower temperatures and $43 \mathrm{~h}$ at $1400^{\circ} \mathrm{C}$. The series includes BFR and DFT images and polarized transmitted light images with the sample at, above, and below focus. The results indicate that the refractive index of the crystals is less than that of the surrounding material. Table 9 lists the refractive indices of $\mathrm{Al}_{2} \mathrm{O}_{3}, \mathrm{SiO}_{2}$, and four aluminosilicate minerals; mullite $\left(\mathrm{Al}_{6} \mathrm{Si}_{2} \mathrm{O}_{13}\right)$, andalusite, kyanite, and sillimanite (the latter three being $\mathrm{Al}_{2} \mathrm{SiO}_{5}$ ). The crystal structures of these crystals are also indicated. Given the relative refractive indices between the interfacial crystals and the surrounding material from the Becke line analysis and the data in Table 9, there are probably two possibilities that account for the crystals lower index of refraction. First, the crystals could be quartz surrounded by $\mathrm{Al}_{2} \mathrm{O}_{3}$ or an aluminosilicate. Second, the crystals could be an aluminosilicate surrounded by $\mathrm{Al}_{2} \mathrm{O}_{3}$. The first option seems unlikely since the $\mathrm{SiO}_{2}-\mathrm{Al}_{2} \mathrm{O}_{3}$ phase diagram, Figure 41 , shows substantial 
solubility of $\mathrm{Al}_{2} \mathrm{O}_{3}$ in $\mathrm{SiO}_{2}$ at the $\mathrm{SiO}_{2}$ rich side. Since the $\mathrm{SiO}_{2}$ is only $30-50 \mathrm{~nm}$ thick, it is reasonable to assume that the $\mathrm{Al}_{2} \mathrm{O}_{3}$ content would rise rapidly, moving the composition toward a $\mathrm{SiO}_{2}+$ mullite(ss) miscibility gap. As the $\mathrm{Al}_{2} \mathrm{O}_{3}$ content of the interfacial material can only go up with time, reducing the percent $\mathrm{SiO}_{2}$, and the crystals are growing with time, it is very unlikely that the crystals are quartz (lowest refractive index) surrounded by $\mathrm{Al}_{2} \mathrm{O}_{3}$ or an aluminosilicate. This suggests that the crystals are probably mullite (perhaps off stoichiometry) surrounded by $\mathrm{Al}_{2} \mathrm{O}_{3}$ with some dissolved $\mathrm{SiO}_{2}$. The orientations of these crystals are explained based on interplanar spacing data [70]. The $<110>$ or prismatic planes in $\mathrm{Al}_{2} \mathrm{O}_{3}$, which are normal to the basal plane at the interface, have spacings of $2.379 \AA$ and intersect each other at $60^{\circ}$ or $120^{\circ}$. Their spacing is about $0.5 \%$ smaller than that of the [310] plane in mullite, $2.393 \AA$. Hence, there exists a low energy orientational relation between the two crystals. Microstructures of melt-grown mullite [57] show groups of long, acicular mullite needles not unlike those seen in this $\mathrm{Al}_{2} \mathrm{O}_{3} / \mathrm{SiO}_{2} / \mathrm{Al}_{2} \mathrm{O}_{3}$ interfacial system. 
Table 9.

Refractive Indices

\begin{tabular}{|c|c|c|c|c|c|}
\hline Material & $\mathrm{n}_{\mathbf{z}}$ & $\mathbf{n}_{b}$ & $\mathbf{n}_{\mathbf{z}}$ & Crust.Str. & Refer \\
\hline \multirow[t]{2}{*}{$\mathrm{Al}_{2} \mathrm{O}_{3}$} & 1.767 & $1.759-$ & & Rhomb & [72] \\
\hline & 1.772 & 1.763 & & & \\
\hline \multirow[t]{2}{*}{$\mathrm{SiO}_{2}$} & $1.594(\alpha)$ & $1.553(\alpha)$ & & $\alpha$ or $\beta$ quartz & $"$ \\
\hline & $1.459(\beta)$ & & & & \\
\hline Mullite & 1.637 & 1.641 & 1.652 & Orthorhomb & [73] \\
\hline \multirow[t]{2}{*}{ Andalusite } & 1.629 & $1.633-$ & $1.638-$ & Orthorhomb & [72] \\
\hline & 1.64 & 1.644 & 1.65 & & \\
\hline \multirow[t]{2}{*}{ Kyanite } & 1.712 & $1.721-$ & 1.727 & Tricl & $"$ \\
\hline & 1.718 & 1.723 & 1.734 & & \\
\hline \multirow[t]{2}{*}{ Sillimanite } & 1.654 & $1.658-$ & 1.637 & Orthorhomb & $"$ \\
\hline & 1.661 & 1.662 & 1.683 & & \\
\hline
\end{tabular}

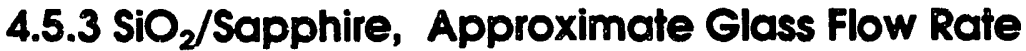

Recall the calculation for the "flow rate" for a fluid between two plates into a crack from section 2.1.4. If we now use values of the parameters appropriate to the $\mathrm{SiO}_{2} /$ sapphire system and its geometry we can obtain an idea of the time scales to expect. For $b=200 \mu \mathrm{m}$ (crack length), $h=50 \mathrm{~nm}, a \cong 1 / 2 \mathrm{~h}=25 \mathrm{~nm}, \mu=10^{9}$ poise $\left(\mathrm{T} \approx 1500^{\circ} \mathrm{C}\right)$, and $p_{i}=\mathrm{K} \gamma=\frac{1}{a} \gamma=1.2 \times 10^{8} \mathrm{dyne} / \mathrm{cm}^{2}, \mathrm{Q}_{\max }$ is about $10^{-14} \mathrm{~cm}^{3} / \mathrm{s}$. This value is very small compared to the crack volume, $4 \times 10^{-9} \mathrm{~cm}^{3}$. At this rate it would take over $50 \mathrm{~h}$ to half fill a crack. However, as the crack begins to fill, $a$ will increase. Since $Q \propto \frac{1}{a^{2}}$, the rate will drop quickly, becoming about an order of magnitude less when the radius equals the film thickness. This calculation is crude, but gives an upper bound for the volume flow rate to fill cracks. For the 
given film thickness and a viscosity corresponding to a higher temperature than used in these experiments, this rate is still very slow. Hence, the lack of significant healing by viscous flow is not inconsistent with the constraints placed on this mechanism by the current geometry and material properties. 


\section{Summary and Conclusions}

The morphological evolution of cylindrical pores or "channels" and crack-like cavities in glass and glass containing ceramics at elevated temperatures was studied. The systems studied were: Corning 7056 alkali borosilicate glass, a soda-lime glass, a commercially available Coors $96 \% \mathrm{Al}_{2} \mathrm{O}_{3}$ electronic substrate material with $\approx 5-10 \%$ intergranular glass, $96 \% \mathrm{Al}_{2} \mathrm{O}_{3}$ bonded to sapphire, and a model sapphire/glass/sapphire system fabricated by diffusion bonding etched and unetched pieces of sapphire onto which 15-25 nm of $\mathrm{SiO}_{2}$ had been sputter deposited. These systems s an a broad range of glass contents and permit observation of healing behavior with varying glass content. The results were compared with analytical models and results of similar studies in completely crystalline systems.

For the 7056 glass at $610^{\circ} \mathrm{C}-650^{\circ} \mathrm{C}, 96 \% \mathrm{Al}_{2} \mathrm{O}_{3}$ at $1150^{\circ} \mathrm{C}$, and the $96 \%$ $\mathrm{Al}_{2} \mathrm{O}_{3} /$ sapphire at $1300^{\circ} \mathrm{C}$ behavior was in agreement with expectations for mass transport by viscous flow. In the soda-lime glass, bloating dominated morphological evolution. Gas evolution from fining agents led to $\approx 10 \times$ increases in feature volume. In the 7056 glass, there is no kinetically favored wavelength for channel breakup. Hence, perturbation wavelengths and pore spacings do not occur at any special values. Instead, end effects and processing defects appear to predispose the channels to evolve as they do. Mean node spacing/channel radius values typically fall in the range of 20-50, with values below $2 \pi$ and up to $\approx 100$ not uncommon. Cracks evolve by the crack cross sections becoming elliptical; the aspect ratio decreases with increasing anneal time. In the $96 \%$ $\mathrm{Al}_{2} \mathrm{O}_{3}$, initial healing occured by the flow of intergranular glass during anneals at $1150^{\circ} \mathrm{C}$. However, difficulty breaking samples open to inspect morphological changes prohibited following the process beyond the very initial stages. For the $96 \%$ 
$\mathrm{Al}_{2} \mathrm{O}_{3} /$ sapphire at $1300^{\circ} \mathrm{C}$, the interfacial glass flows into and fills cracks and channels. After only one hour at $1300^{\circ} \mathrm{C}$, most large cracks were reduced to pores with sizes and shapes similar the native porosity of the $\mathrm{Al}_{2} \mathrm{O}_{3}$.

$96 \% \mathrm{Al}_{2} \mathrm{O}_{3}$ /sapphire samples annealed initially for one hour at $1200^{\circ} \mathrm{C}$. This did not produce any morphological change in the cracks or channels, but nonbonded regions in the interface disappeared, resulting in an essentially completely bonded interface. Successive anneals at this temperature, up to 33 hours total, produced no further changes. Successive anneals at $1250^{\circ} \mathrm{C}$, up to 60 hours total, failed to produce any noticeable changes as well. However, around the edges of some cracks and particularly the narrower channels $(\sim 4-6 \mu \mathrm{m})$ changes in contrast developed which may be different phases crystallizing out of the glass. Finally, the sample was annealed for one hour at $1300^{\circ} \mathrm{C}$ which resulted in changes similar to those observed in the sample annealed only at $1300^{\circ} \mathrm{C}$, but much less in magnitude. Studies on the crystallization of the intergranular glass in this material indicate that this may be occurring, preventing the glass from flowing into the interfacial flaws. A TEM investigation on this sample revealed the glass had begun to crystallize.

In the $\mathrm{SiO}_{2} /$ sapphire system, anneals at $1250^{\circ} \mathrm{C}$ produced very little change after times totalling 6.5 hours. The only noticeable change was the formation of small islands in cracks and wider channels. These appear to be more frequent near areas with particulate contamination introduced during processing. Anneals at $1300^{\circ} \mathrm{C}$ totalling 20 hours produced virtually no change as well. However, the islands mentioned above were seen to begin to vanish in the channels, and coarsen in the cracks. Still, the channel and crack shapes and sizes were essentially the same as in the as processed sample. When the annealing temperature was increased to $1400^{\circ} \mathrm{C}$, morphological changes began to occur. 
However, rather than healing or channel breakup, further coarsening and facetting of the islands in the cracks, their disappearance, and also nucleation and growth of blade-shaped crystals were observed. These crystals, expected to be mullite, were the primary changes that were observed. They could be seen to grow across porous, poorly bonded regions and across cracks and channels or nucleating and growing within cracks. They grew with very specific orientations. Their long directions were at $60^{\circ}$ or $120^{\circ}$ to each other and along the low index directions of the basal sapphire crystals.

Occasionally, intercrystal angles were approximately $90^{\circ}$, but this was rather infrequent. The edges of the cracks and channels still had not moved by any noticeable amount. The phase diagram for the $\mathrm{Al}_{2} \mathrm{O}_{3} / \mathrm{SiO}_{2}$ system indicates a liquid phase in the $\mathrm{Al}_{2} \mathrm{O}_{3}$ rich region of the system at about $1600^{\circ}-1620^{\circ}$. To investigate if these crystals would melt and flow into the flaws, the sample was annealed for a total of 45 minutes at $1620^{\circ} \mathrm{C}$. Although the crystals did not appear to melt, the facetted edges and comers rounded and gave the appearance that they may have actually been very viscous. After these anneals, it appeared that the crack edges finally started to change, but further analysis is required. In this system, the glass does not contribute appreciably to healing.

This work has attempted to provide some insight toward understanding the healing of internal flaws in materials in which mass transport is governed by viscous flow. In addition to studying pure glass for comparison with analytic models of viscous materials, glass-ceramic material systems with varying glass contents were also studied in order to investigate how the role of glass depends on the amount of glass present. It is hoped that theoreticians will appreciate some of these results which they might find useful in refining their models. Additionally, those interested in strength recovery or joining in real engineering ceramic materials may hopefully find other portions of this work helpful 
as a starting point for applied research and/or development. 


\section{References}

1. Lord Rayleigh, "On the Instability of Jets", Proc. London Math. Soc. 10 4-13, 14 Nov. 1878

2. Lord Rayleigh, "On the Instability of a Cylinder of Viscous Liquid under Capillary Force", Phil. Mag. S. 5., 34 (207), Aug. 1892, 145-154

3. Lord Rayleigh, "On the Instability of Cylindrical Fluid Surfaces", ibid 177-180

4. S. Chandrasekhar, Hydrodynamic and Hydromagnetic Stability, Copyright 1961, Oxford University Press; Dover Publications, Inc. New York, New York

5. F.A. Nichols and W.W. Mullins, "Surface-(Interface-) and Volume-Diffusion Contributions to Morphological Changes Driven by Capillarity", Trans. Met. Soc. AIME 233 1840-1848 (1965)

6. T.K. Gupta, "Instability of Cylindrical Voids in Alumina", J. Am. Ceram. Soc. 61 (5-6) 191-195 (1978)

7. J. Rödel and A.M. Glaeser, "Morphological Evolution of Pore Channels in Alumina", in Sintering of Advanced Ceramics, edited by C.A. Handwerker, J.E. Blendell, and W.A. Kaysser, (Ceramic Transactions, 7, The American Ceramic Society, Westerville, OH 1990) 243-257

8. S.-Y. Shieh and J.W. Evans, "The stability of cylindrical voids and of cylinders subject to closure by viscous flow or evaporation/condensation", J. Appl. Phys. 70 (6) 2968-2972 (1991)

9. J.L. Boling and W.W. Dolan, "Blunting of Tungsten Needles by Surface Diffusion", J. Appl. Phys. 29 (3) 556-559 (1958)

10. F.A. Nichols and W.W. Mullins, "Morphological Changes of a Surface of Revolution due to Capillarity-Induced Surface Diffusion", J. Appl. Phys. 36 (6) 1826-1835 (1965)

11. F.A. Nichols, "On the spheroidization of rod-shaped particles of finite length", J. Mat. Sci. 11 1077-1082 (1976)

12. W.C. Carter and A.M. Glaeser,"The effect of finite amplitude perturbations on the stability of continuous phases", Mat. Sci. and Eng. 89 LA1-L45 (1987)

13. W.C. Carter and A.M. Glaeser, "The Morphological Stability of Continuous Intergranular Phases:Thermodynamic Considerations", Acta Metall. 35 (1) 237-245 (1987)

14. H.P. Stüwe and O. Kolednik, "Shape Instability of Thin Cylinders", Acta. Metall. 36 (7) 1705-1708 (1988)

15. J. Rödel,Application of Controlled Interfacial Pore Structures to Pore Perturbation and Pore Drag in Alumina, Ph.D. Thesis, University of California at Berkeley, (1986)

16. C.F. Yen and R.L.Coble, "Sheroidization of Tubular Voids in $\mathrm{Al}_{2} \mathrm{O}_{3}$ Crystals at High Temperatures", J. Am. Ceram. Soc. 55 (10) 507-509 (1972) 
17. F.P. Mallinder and B.A. Proctor, "Preparation of High-strength Sapphire Crystals", Proc. Brit. Ceram. Soc. 6 9-16 (1966)

18. A.H. Heuer and J.P. Roberts, "The Influence of Annealing on the Strength of Corundum Crystals", ibid 17-27

19. F.F. Lange and T.K. Gupta, "Crack Healing by Heat Treatment", J. Am. Ceram. Soc. 53 (1) 54-55 (1970)

20. F.F. Lange and K.C. Radford, "Healing of Surface Cracks in Polycrystalline $\mathrm{Al}_{2} \mathrm{O}_{3}$ ", J. Am. Ceram. Soc. 53 (7), 420-421 (1970)

21. F.F. Lange, "Healing of Surface Cracks in SiC by Oxidation", J. Am. Ceram. Soc. 53 (5) 290 (1970)

22. S.M. Wiederhorn and P.R. Townsend, "Crack Healing in Glass", J. Am. Ceram. Soc. 53 (9) 486-489 (1970)

23. J.T.A. Roberts and B.J. Wrona, "Crack Healing in $\mathrm{UO}_{2}$ ", J. Am. Ceram. Soc. 56 (6) 297-299 (1973)

24. R. Raj, W. Pavinich, and C.N. Ahlquist, "On the Sintering Rate of Cleavage Cracks", Acta Metall. 23 399-403 (1975)

25. B.J. Hockey and B.R. Lawn, "Electron microscopy of microcracking about indentations in aluminum oxide and silicon carbide", J. Mat. Sci. 10 1275-1284 (1975)

26. T.K. Gupta, "Crack Healing and Strengthening of Thermally Shocked Alumina", $J$. Am. Ceram. Soc. 59 (5-6) 259-262 (1976)

27. G. Bandyopadhyay and J.T.A. Roberts, "Crack Healing and Strength Recovery in $\mathrm{UO}_{2}{ }^{\prime}$, J. Am. Ceram. Soc. 59 (9-10) 415-419 (1976)

28. T.K. Gupta, "Kinetics of Strengthening of Thermally Shocked $\mathrm{MgO}$ and $\mathrm{Al}_{2} \mathrm{O}_{3}$ ", $J$. Am. Ceram. Soc.- Disc. and Notes, 59 (9-10) 448-449 (1976)

29. G. Bandyopadhyay and C.R. Kennedy, "Isothermal Crack Healing and Strength Recovery in $\mathrm{UO}_{2}$ Subjected to Varying Degrees of Thermal Shock", J. Am. Ceram. Soc. 60 (1-2) 48-50 (1977)

30. A.G. Evans and E.A. Charles, "Strength Recovery by Diffusive Crack Healing", Acta Metall. 25 919-927 (1977)

31. S.M. Park and D.R. O'Boyle, "Observations of crack healing in sodium chloride single crystals at low temperatures", J. Mat. Sci. 12 840-841 (1977)

32. R.N. Singh and J.L. Routbort, "Fracture and Crack Healing in (U,Pu)C", J. Am. Ceram. Soc. 62 (3-4) 128-133 (1979)

33. T.K. Gupta, "Crack Healing in $\mathrm{Al}_{2} \mathrm{O}_{3}, \mathrm{MgO}$, and Related Materials", $A d v$. in Ceramics, edited by W.D. Kingery, 750-766 (1984)

34. J. Rödel and A.M. Glaeser, "Production of Controlled-Morphology Pore Arrays: Implications and Opportunities", J. Am. Ceram. Soc., 70 (8) C172-C175 (1987)

35. S.H. Hickman and B. Evans, "Influence of Geometry upon Crack Healing Rate in Calcite", Phys. Chem. Minerals 15 91-102 (1987) 
36. P. Hrma, W.T. Han, and A.R.Cooper, "Thermal Healing of Cracks in Glass", J. Non-Cryst. Sol. 102 88-94 (1988)

37. J. Rödel and A.M. Glaeser, "Application of Controlled Interfacial Pore Structures to Kinetic Studies in Alumina", in Interfacial Structures. Properties, and Design, edited by M.H. Yoo, W.A.T. Clark, and C.L. Braint, (Mater. Res. Soc. Proc., 122, Pittsburgh, PA, 1988) 485-490

38. J. Rödel and A.M. Glaeser, "High-Temperature Healing of Lithographically Introduced Cracks in Sapphire", J. Am. Ceram. Soc. 73 (3) 593-601 (1990)

39. A.J. Forty and C.T. Forwood, "The Healing of Cleavage Cracks in Alkali Halide Crystals", Trans. Brit. Ceram. Soc. $62715-724$ (1963)

40. T.K. Gupta, "Effect of Healing on Thermal Stress Fracture", in Thermal Stresses in Severe Environments, edited by D.P.H. Hasselman and R.A. Heller, Plenum Publishing, New York, NY (1980)

41. Y.V. Murty, J.E. Morral, T.Z. Kattamis, and R. Mehrabian, "Initial Coarsening of Manganese Sulfide Inclusions in Rolled Steel During Homogenization", Metall. Trans. A 6A 2031-2035 (1975)

42. Y.V. Murty, T.Z. Kattamis, R.Mehrabian, and M.C. Flemings, "Behavior of Sulfide Inclusions During Thermomechanical Processing of AISI 4340 Steel", Metall. Trans. A 8A 1275-1282 (1977)

43. F.F. Lange and D.R. Clarke, "Morphological Changes of an Intergranular Thin Film in a Polycrystalline Spinel", J. Am. Ceram. Soc. 65 (10) 502-506 (1982)

44. C. Herring, "Effect of Change of Scale on Sintering Phenomena", J. Appl. Phys., 21 301-303 (1950)

45. A. Nickles, J. Powers, and A.M. Glaeser, "Crack Healing in Sapphire", Presented at the 92nd Annual Meeting of the American Ceramic Society, Dallas, TX, April 22-26, 1990

46. P. Bross and H.E. Exner, "Computer Simulation of Sintering Process", Acta Metall. 27 1013-1020 (1979)

47. C. Herring, in Structure and Properties of Solid Surfaces, edited by R. Gomer and C.S. Smith, University of Chicago Press, Chicago, IL (1952)

48. C. Herring, J. App. Phys. 21437 (1950)

49. A.S. Nickles, Master of Science Thesis, Department of Materials Science and Mineral Engineering, University of California at Berkeley, (1992)

50. A. Jagota and P.R. Dawson, "Simulation of the Viscous Sintering of Two Particles", J. Am. Ceram. Soc., 73 (1) 173-177 (1990)

51. D.C. Cassidy and N.A. Gjostein, "Capillarity-Induced Smoothing of Glass Surfaces by Viscous Flow", J. Am. Ceram. Soc. 53 (3) 161-168 (1970)

52. R.M. German, Liquid Phase Sintering, Plenum Press, (1985)

53. F.M. White, Fluid Mechanics. 2nd Ed, McGraw-Hill Book Co. (1986) 
54. S.P. Timoshenko and J.N. Goodier, Theory of Elasticity. 3rd Ed, McGraw-Hill Book Co. (1970)

55a.C.A. Powell-Dogan and A.H. Heuer, "Microstructure of 96\% Alumina Ceramics: I, Characterization of the As-Sintered Materials", J. Am. Ceram. Soc. 73 (12) 3670-3676 (1990)

55b.C.A. Powell-Dogan and A.H. Heuer, "Microstructure of $96 \%$ Alumina Ceramics: II, Crystallization of High-Magnesia Boundary Glasses", ibid 3677-3683

55c.C.A. Powell-Dogan and A.H. Heuer, "Microstructure of 96\% Alumina Ceramics: III, Crystallization of High-Calcia Boundary Glasses", ibid 3684-3691

56. F.E. Wagstaff and K.J. Richards, "Kinetics of Crystallization of Stoichiometric $\mathrm{SiO}_{2}$ Glass in $\mathrm{H}_{2} \mathrm{O}$ Atmospheres", J.Am. Ceram. Soc. 49 (3) 118-121 (1966)

57. I.A. Aksay and J.A. Pask, "Stable and Metastable Equilibria in the System $\mathrm{SiO}_{2}-\mathrm{Al}_{2} \mathrm{O}_{3}$ ", J. Am. Ceram. Soc. 58 (11-12) 507-512 (1975)

58. M.D. Sacks, N. Bozkurt, and G.W. Schieffele, "Fabrication of Mullite and Mullite-Matrix Composites by Transient Viscous Sintering of Composite Powders", J.Am. Ceram.Soc. 74 (10) 2428-2437 (1991)

59. J.W. Cahn, "Stability of Rods with Anisotropic Surface Free Energy", Scripta MET 13 (11) 1069-1071 (1979)

60. S.-Y. Shieh, private communication

61. W.W. Mullins, "Solid Surface Morphologies Governed by Capillarity", in Metal Surfaces: Structure, Energetics, and Kinetics, Seminar of the ASM and Metallurgical Society of AIME, Oct. 27-28, 1962

62. J.S. Stölken and A.M. Glaeser, "The Morphological Evolution of Cylindrical Rods with Anisotropic Surface Free Energy via Surface Diffusion", Scripta MET et MAT 27 (4) 449-454 (1992)

63. J.-H. Choy, S.A. Hackney, and J.K.Lee, "Non-Linear Stability Analysis of the Diffusional Spheroidization of Rods", as yet unpublished

64. J. Stölken and H. Ackler, unpublished research

65. 1991 Annual Book of ASTM Standards. Volume 3.01, ASTM, Philadelphia, PA (1991)

66. Daniel Kuchta, private communication

67. R.D. Black, E.L. Hall, N. Lewis, R.S. Gilmore, S.D. Arthur, R.D. Lillquist, "Silicon and Silicon Dioxide Thermal Bonding", Mat. Res. Soc. Symp. Proc. 107 495-500 (1988)

68. CRC Standard Math Tables, 26ed, Edited by W.H. Beyer, CRC Press, Inc. (1981)

69. R.H. Doremus, Glass Science, John Wiley and Sons, (1973)

70. JCPDS Powder Diffraction Files (to be clarified later)

71. N.H. Hartshorne and A. Stuart, Practical Optical Crystallography, American Elsevier Publishing Co, New York, New York (1964) 
72. Handbook of Chemistry and Physics, 53rd.Ed, edited by R.C. Weast, The Chemical Rubber Co. (1972)

73. Winchell, referenced in [70] 


\section{Figure Captions}

Figure 1. Calculated undercutting during initial stage sintering at an interparticle neck with mass transport by surface diffusion only (top) and surface and grain boundary diffusion (bottom). (From Bross and Exner,[46]\}

Figure 2. The development of an interparticle neck during sintering with mass transport by viscous flow only. \{Jagota and Dawson,[50]\}

Figure 3. The viscosity of $\mathrm{SiO}_{2}$ vs. temperature \{from Doremus [69]\}.

Figure 4. Schematic cross section of the sapphire/SiO $/$ sapphire interface.

Figure 5. Schematic diagram of fluid flow between two parallel plates [from White [53]\}.

Figure 6. A: Normalized growth rate, $\sigma\left(\sigma=\frac{\dot{\alpha}}{\alpha}\right)$, vs. $\mathrm{x}\left(\mathrm{x}=\mathrm{kr}_{\mathrm{o}}\right)$ for 1$)$ a liquid jet and 2) a hollow jet in a fluid of low viscosity. B: Normalized growth rate vs. $x$ for a jet of highly viscous fluid. The numbers on the curves are the values of a parameter $J$ where $J=\frac{\gamma a}{p^{2}}, \rho$ being the density of the glass, see [4].\{From Chandrasekhar, [4]\}

Figure 7. Normalized growth rate, $\sigma\left(\sigma=\frac{\dot{\alpha}}{\alpha}\right)$, vs. $\mathrm{x}$ for a hollow cylindrical cavity in a fluid of very high viscosity. \{From Shieh and Evans, [8]\}

Figure 8. Schematic plot of $r(z)$ vs. $z$ (top) and $\kappa(s)$ vs. $s$ (bottom) for trial solution of cylinder end perturbation. \{From Stölken and Ackler,[64]\}

Figure 9. Mask 1, used in Corning 7056 glass samples.

Figure 10. Mask JDP7, used in $96 \% \mathrm{Al}_{2} \mathrm{O}_{3} /$ Sapphire and $\mathrm{SiO}_{2} /$ Sapphire samples.

Figure 11. Cross section of crack in Corning 7056 glass, mask $2 \mathrm{~L}$, after 13 hr. at $650^{\circ} \mathrm{C}$.

Figure 12. Cracks in Corning 7056 glass, $610^{\circ}$ sample. A: As bonded; B: $30 \mathrm{hr}$ at $610^{\circ} \mathrm{C} ; \mathrm{C}: 45 \mathrm{hr}$ at $610^{\circ} \mathrm{C}$. 
Figure 13. Cracks in Corning 7056 glass, mask 2L. A: As bonded; B: $3 \mathrm{hr}$ at $650^{\circ} \mathrm{C} ; \mathrm{C}: 6 \mathrm{hr}$ at $650^{\circ} \mathrm{C}$; D: $13 \mathrm{hr}$ at $650^{\circ} \mathrm{C}$.

Figure 14. Cracks in Corning 7056 glass, mask 2N. A: As bonded; B: $3 \mathrm{hr}$ at $650^{\circ} \mathrm{C} ; \mathrm{C}: 6 \mathrm{hr}$ at $650^{\circ} \mathrm{C} ; \mathrm{D}: 13 \mathrm{hr}$ at $650^{\circ} \mathrm{C}$.

Figure 15. Viscosity, $\eta$, vs. temperature, T, of Corning 7056 glass.

Figure 16. Node spacing/ $\mathrm{r}_{0}$ values for Corning 7056 glass $610^{\circ}$ sample, 30 $\mathrm{hr}$ at $610^{\circ} \mathrm{C}$.

A: Channel 6, mean $=65.32$

B: " $5, "=47.73$

C: " $4, "=35.90$

D: $" 3, "=25.99$

$\mathrm{E}:$ " $2, "=18.66$

F: $" 1, "=23.92$

G: Cumulative values, mean $=31.64$

Figure 17. Node spacing/ $\mathrm{r}_{0}$ values for Corning 7056 glass $610^{\circ}$ sample, 45 hr at $610^{\circ} \mathrm{C}$.

A: Channel 6, mean $=25.59$

B: $" 5, "=27.94$

C: $" 4, "=35.18$

D: " 3, " $=45.21$

E: " $2, "=64.30$

F: " $1, "=112.90$

G: Cumulative values, mean $=39.39$

Figure 18. Node spacing $/ \mathrm{r}_{0}$ values for Coming 7056 glass, masks $2 \mathrm{~N}$ and $2 \mathrm{~L}, 3 \mathrm{hr}$ at $650^{\circ} \mathrm{C}$.

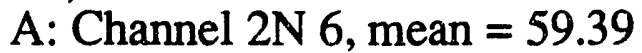

B: " $" 5, "=41.94$

C: " $" 4, "=40.55$

D: " $" 3, "=33.89$

E: " $" 2, "=33.12$

F: " $" 1, "=30.07$

G: " $2 \mathrm{~L} 6, "=49.03$

$\mathrm{H}: \quad " \quad 5, "=59.15$

I: " $" 4, "=53.89$

J: Cumulative values, mean $=41.19$ 
Figure 19. Node spacing/ $\mathrm{r}_{0}$ values for Corning 7056 glass, masks $2 \mathrm{~N}$ and $2 \mathrm{~L}, 6 \mathrm{hr}$ at $650^{\circ} \mathrm{C}$.

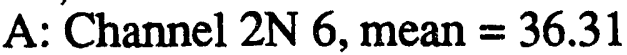
B: " $" 5, "=36.05$
C: " $" 4, "=42.09$
D: " $" 3, "=50.06$
E: " $" 2, "=76.17$
F: $" \quad " 1, "=115.4$
G: " 2L 6, " $=42.95$
$\mathrm{H}: " \quad$ " 5 , " $=39.49$
I: " $" 4, "=36.95$

J: Cumulative values, mean $=47.31$

Figure 20. Channels in Corning 7056 glass $610^{\circ}$ sample.
A: As bonded.
B: $30 \mathrm{hr}$ at $610^{\circ} \mathrm{C}$.
C: $45 \mathrm{hr}$ at $610^{\circ} \mathrm{C}$.

Figure 21. Channels in Corning 7056 glass, mask 2L.
A: As bonded.
B: $3 \mathrm{hr}$ at $650^{\circ} \mathrm{C}$.
C: $6 \mathrm{hr}$ at $650^{\circ} \mathrm{C}$.
D: $13 \mathrm{hr}$ at $650^{\circ} \mathrm{C}$.

Figure 22. Channels in Corning 7056 glass, mask $2 \mathrm{~N}$.
A: As bonded.
B: $3 \mathrm{hr}$ at $650^{\circ} \mathrm{C}$.
C: $6 \mathrm{hr}$ at $650^{\circ} \mathrm{C}$.
D: 13 hr at $650^{\circ} \mathrm{C}$.

Figure 23. Soda-lime glass sample
A: As-bonded cracks and short channels.
B: Cracks and short channels after $15 \mathrm{~min}$ at $650^{\circ} \mathrm{C}$.

Figure 24. As-bonded crack and short channels in an exposed surface from the fractured interface in a $96 \% \mathrm{Al}_{2} \mathrm{O}_{3}$ sample.

Figure 25. Crack and short channels in an exposed surface from the fractured interface in a $96 \% \mathrm{Al}_{2} \mathrm{O}_{3}$ sample after $1 \mathrm{~h}$ at $1150^{\circ} \mathrm{C}$.

Figure 26. Crack and short channels in an exposed surface from the fractured interface in a $96 \% \mathrm{Al}_{2} \mathrm{O}_{3}$ sample after $3.5 \mathrm{~h}$ at $1150^{\circ} \mathrm{C}$. 
Figure 27. Ends of short channels in an exposed surface from the fractured interface in a $96 \% \mathrm{Al}_{2} \mathrm{O}_{3}$ sample after $3.5 \mathrm{~h}$ at $1150^{\circ} \mathrm{C}$. Figures $27 \mathrm{~A}$, $27 \mathrm{~B}$, and $27 \mathrm{C}$ correspond to channels $\mathrm{A}, \mathrm{B}$, and $\mathrm{C}$, respectively, in Figure 27.1

Figure 28. Etched $96 \% \mathrm{Al}_{2} \mathrm{O}_{3}$ surface for grain size measurement.

Figure 29. Cracks in $96 \% \mathrm{Al}_{2} \mathrm{O}_{3} /$ Sapphire.

A: As bonded rectangles and circles.

B: One hour at $1300^{\circ} \mathrm{C}$ anneal, rectangles and circles.

Figure 30. Long cracks in $96 \% \mathrm{Al}_{2} \mathrm{O}_{3} /$ Sapphire.
A: As bonded.
B: $1 \mathrm{hr}$ at $1200^{\circ} \mathrm{C}$.
C: $20 \mathrm{hr}$ at $1200^{\circ} \mathrm{C}$.
$\mathrm{D}: 60 \mathrm{hr}$ at $1250^{\circ} \mathrm{C}$.
E: $1 \mathrm{hr}$ at $1300^{\circ} \mathrm{C}$.

Figure 31. Cracks in $96 \% \mathrm{Al}_{2} \mathrm{O}_{3} /$ Sapphire.
A: As bonded.
B: $1 \mathrm{hr}$ at $1200^{\circ} \mathrm{C}$.
C: $20 \mathrm{hr}$ at $1200^{\circ} \mathrm{C}$.
$\mathrm{D}: 60 \mathrm{hr}$ at $1250^{\circ} \mathrm{C}$.
E: 1 hr at $1300^{\circ} \mathrm{C}$.

Figure 32. Channels in $96 \% \mathrm{Al}_{2} \mathrm{O}_{3} /$ Sapphire with "whiskers" at edges of channels.
A: $60 \mathrm{hr}$ at $1250^{\circ} \mathrm{C}$.
B: $1 \mathrm{hr}$ at $1300^{\circ} \mathrm{C}$.

Figure 33. A glass pocket near the $96 \% \mathrm{Al}_{2} \mathrm{O}_{3}$ /sapphire interface after $60 \mathrm{~h}$ at $1250^{\circ} \mathrm{C}$. The interface is marked between the carrots.

A: Bright field image of crystal, $C$, in glass pocket between grains.

B: SAD pattern from grain $G 1$ in $A$.

$\mathrm{C}$ : SAD pattern from grain $\mathrm{G} 2$ in $\mathrm{A}$. Zone axis is [0001], $e=[10 \overline{1} 0]$, $\mathbf{g}=[1 \overline{1} \overline{2} 0]$.

D: SAD pattern from crystal in pocket. 
Figure 34. Higher magnification bright and dark field images of crystal in $33 \mathrm{~A}$.

A: Bright field image of crystal in glass pocket, $102 \mathrm{kX}$.

B: Centered dark field image of crystal using beam $\mathrm{Cl}$ from its diffraction pattern in 33D, $102 \mathrm{kX}$.

C: Centered dark field image of crystal using beam C2 from its diffraction pattern in 33D, 102KX.

Figure 35. Cracks in $\mathrm{SiO}_{2} /$ Sapphire.

A: As bonded.

B: $13 \mathrm{hr}$ at $1400^{\circ} \mathrm{C}$.

C: $23 \mathrm{hr}$ at $1400^{\circ} \mathrm{C}$.

D: $43 \mathrm{hr}$ at $1400^{\circ} \mathrm{C}$.

E. $0.75 \mathrm{hr}$ at $1620^{\circ} \mathrm{C}$.

F: Laue pattern of sapphire crystals oriented with respect to sample.

Figure 36. Cracks in $\mathrm{SiO}_{2} /$ Sapphire.
A: As bonded.
B: $10 \mathrm{hr}$ at $1400^{\circ} \mathrm{C}$.
C: $13 \mathrm{hr}$ at $1400^{\circ} \mathrm{C}$.
$\mathrm{D}: 23 \mathrm{hr}$ at $1400^{\circ} \mathrm{C}$.
E: $43 \mathrm{hr}$ at $1400^{\circ} \mathrm{C}$.
F: $0.75 \mathrm{hr}$ at $1620^{\circ} \mathrm{C}$.

Figure 37. Cracks in $\mathrm{SiO}_{2} /$ Sapphire.
A: As bonded.
$\mathrm{B}: 6.5 \mathrm{hr} 1250^{\circ} \mathrm{C}$.
C: $10 \mathrm{hr}$ at $1300^{\circ} \mathrm{C}$.
D: $13 \mathrm{hr}$ at $1400^{\circ} \mathrm{C}$.
E: $23 \mathrm{hr}$ at $1400^{\circ} \mathrm{C}$.
F: $43 \mathrm{hr}$ at $1400^{\circ} \mathrm{C}$.
G: $0.75 \mathrm{hr}$ at $1620^{\circ} \mathrm{C}$.

Figure 38. Features in contaminated interfacial region in $\mathrm{SiO}_{2} /$ Sapphire sample.
A: $23 \mathrm{hr}$ at $1400^{\circ} \mathrm{C}$.
B: $43 \mathrm{hr}$ at $1400^{\circ} \mathrm{C}$.
C: $0.75 \mathrm{hr}$ at $1620^{\circ} \mathrm{C}$.

Figure 39. Interfacial crystals in $\mathrm{SiO}_{2} / \mathrm{Sapphire}$ sample, $43 \mathrm{hr}$ at $1400^{\circ} \mathrm{C}$.

A: Bright field reflected light (BFR).

B: Dark field transmitted light (DFT). 
Figure 40. Becke line series.
A: Bright field reflected light.
B: Dark field transmitted light.
C: Bright field polarized transmitted light (BFPT), sample at focus.
Note position of crystal edge, see arrows "E".
C.1: Schematic of 40C, showing crystal edges (full lines).
D: BFPT, sample raised from focus. Note that bright lines, or "Becke lines" have moved into the crystals, see arrows "BL".
D.1: Schematic of 40D, showing crystal edges (full lines) and Becke lines (dashed lines).
E: BFPT, sample lowered from focus. Note that Becke lines have moved into material surrounding crystals, see arrows "BL".
E.1: Schematic of 40E, showing crystal edges (full lines) and Becke lines (dashed lines).

Figure 41. $\mathrm{SiO}_{2} / \mathrm{Al}_{2} \mathrm{O}_{3}$ phase diagram. $\{$ From Aksay and Pask,[57]\} 


\section{Figures}



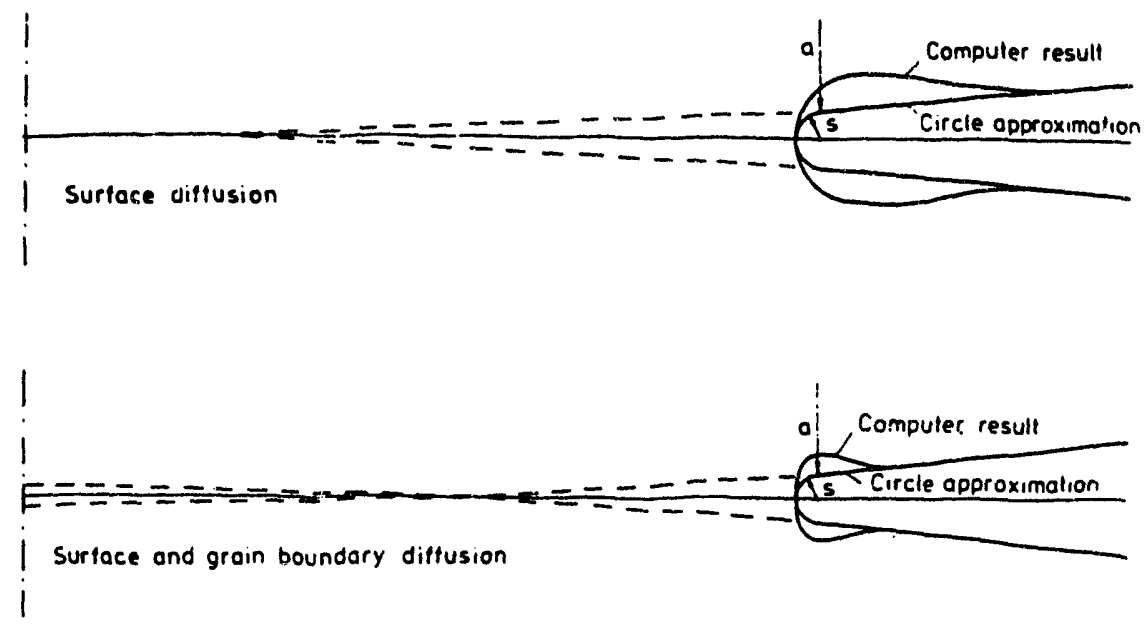

Figure 1

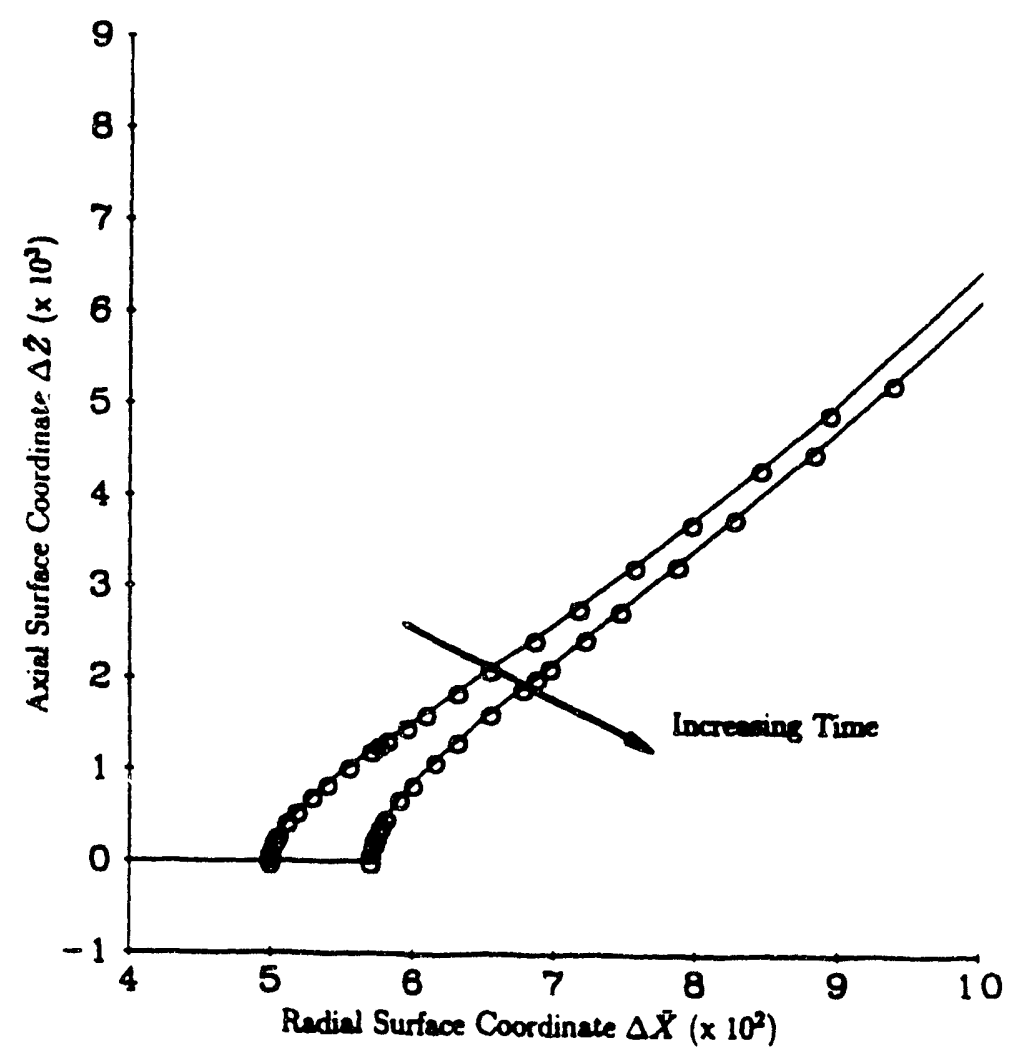

figure 2 


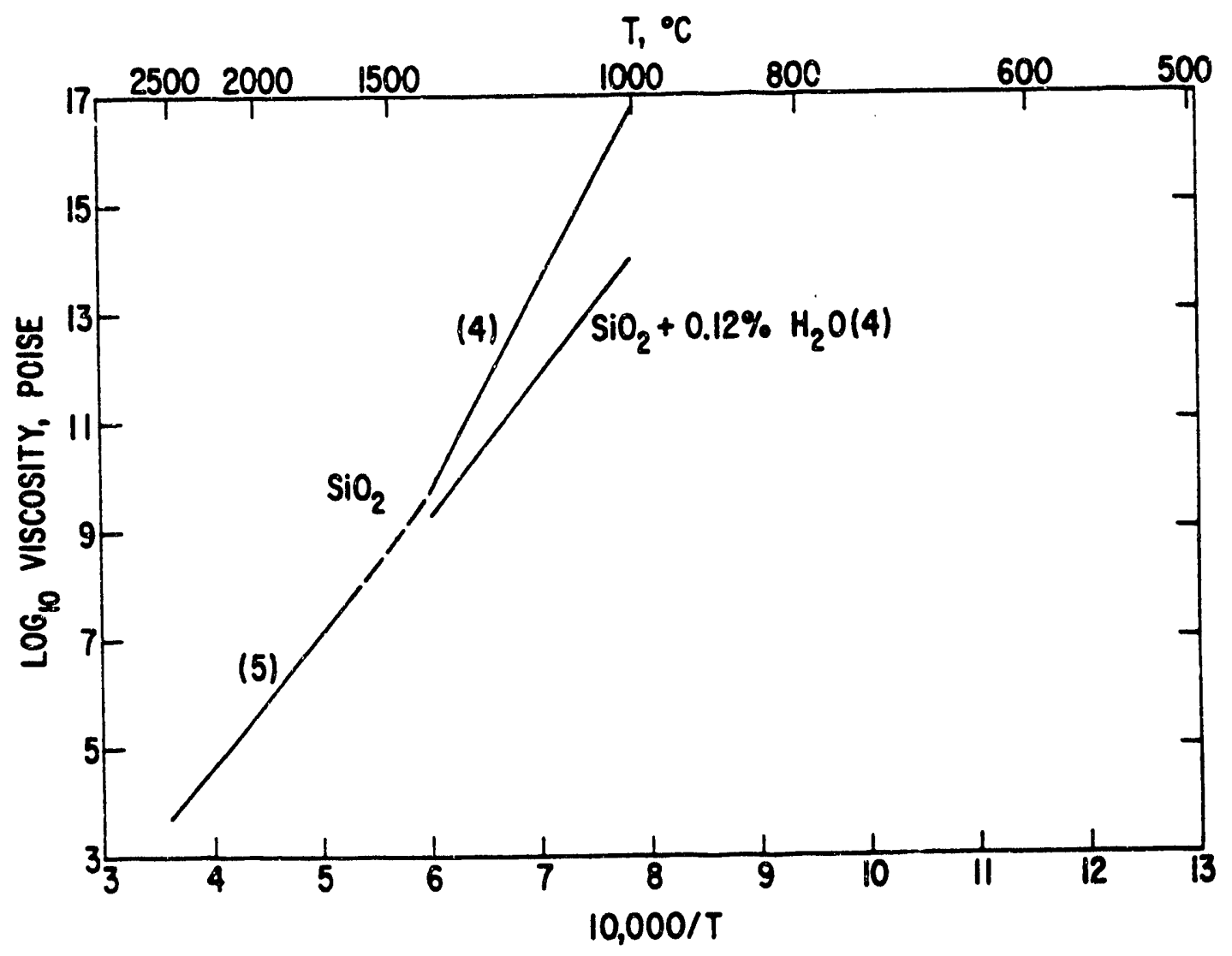

Figure 3

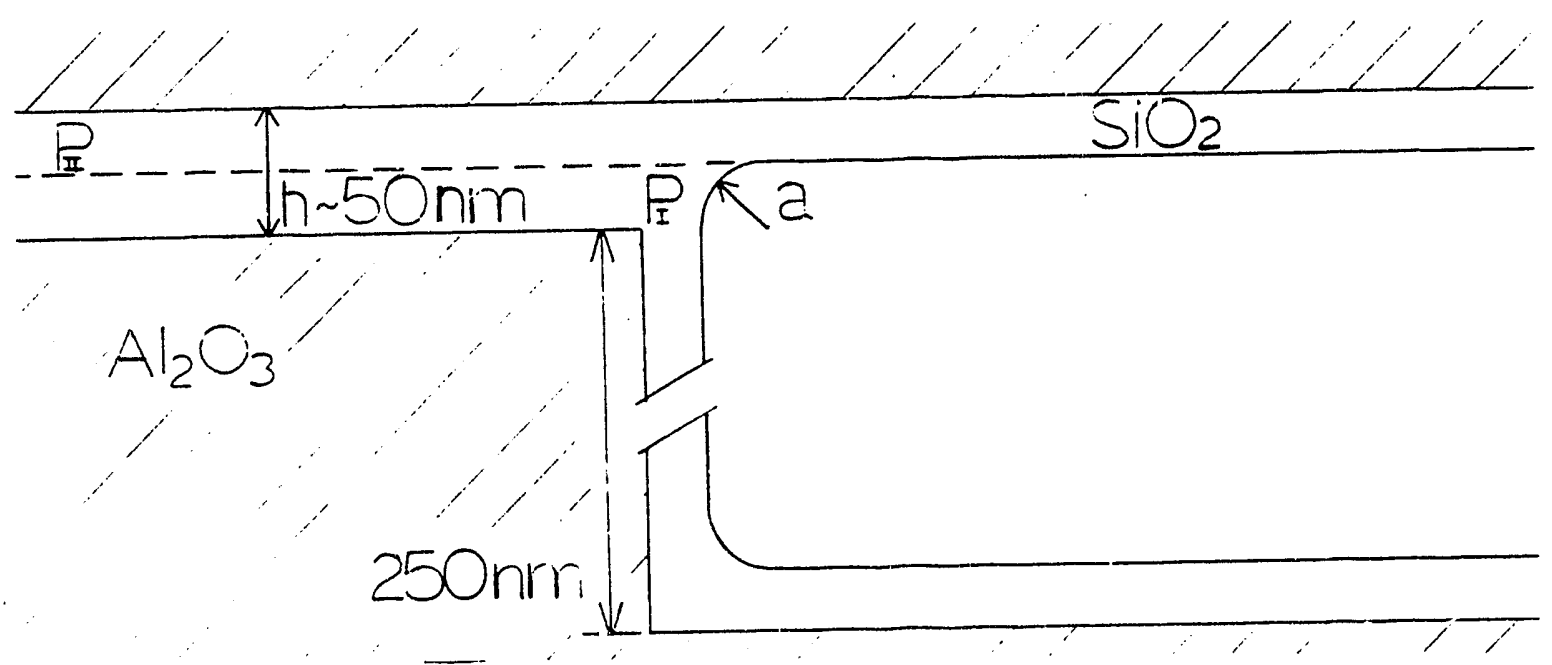

Figure 4 


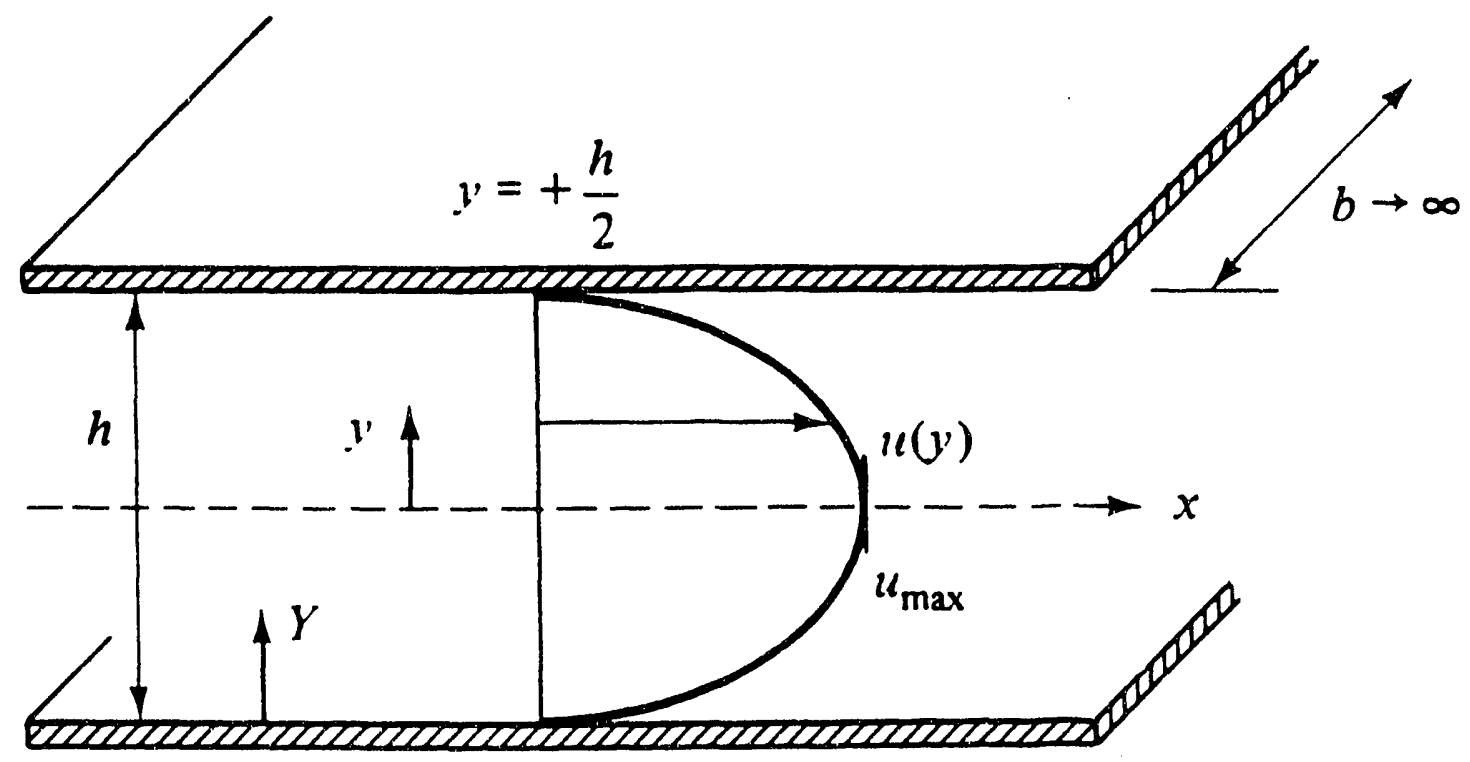

$$
y=-\frac{h}{2}
$$

Figure 5 


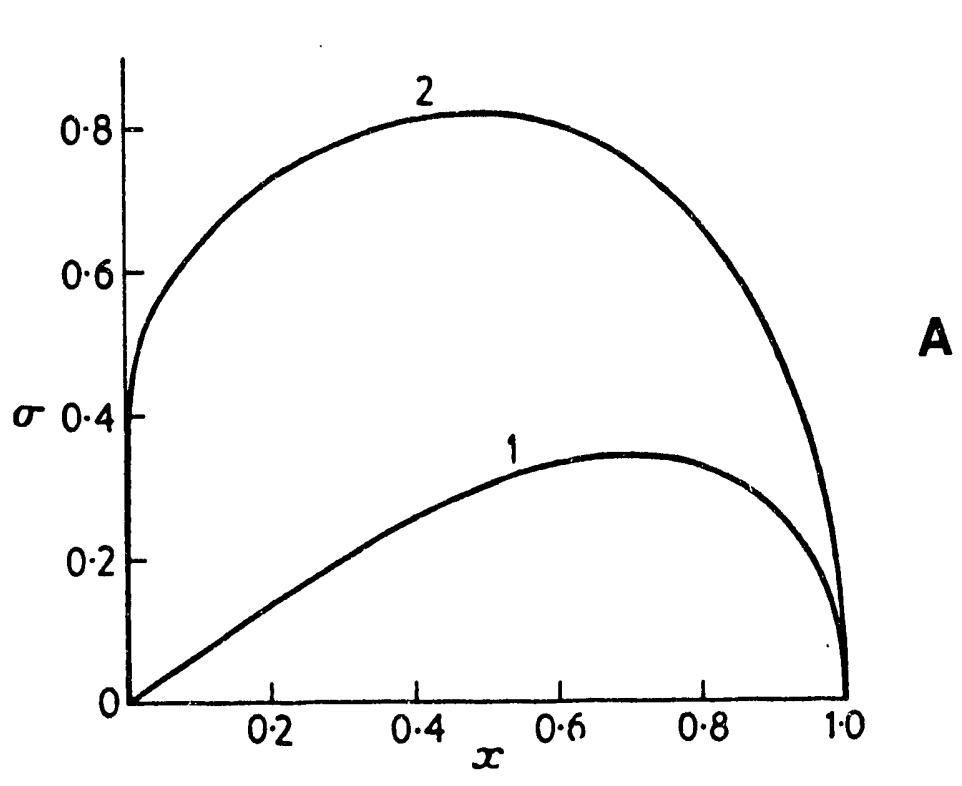

80

Figure 6
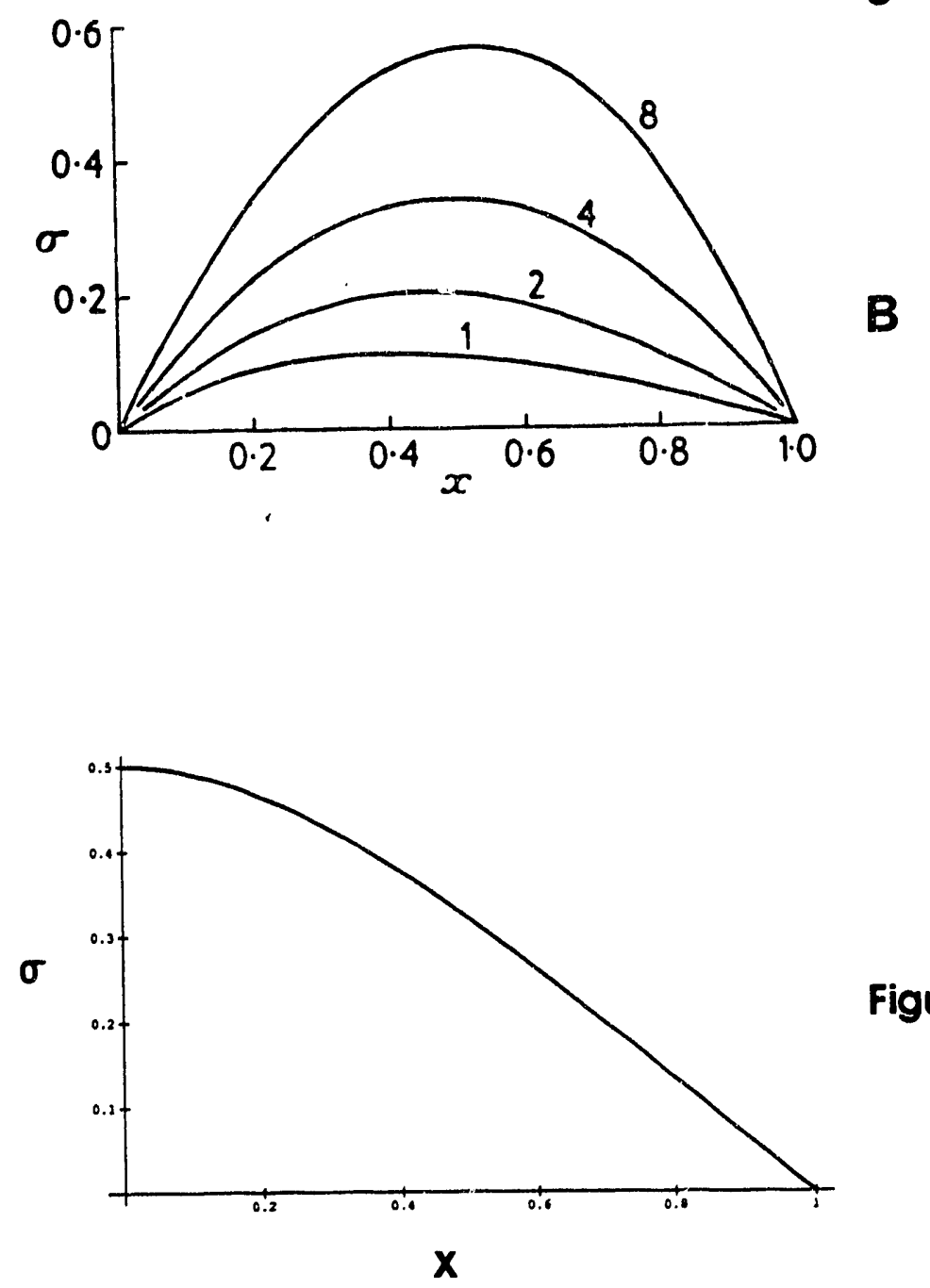

Figure 7 


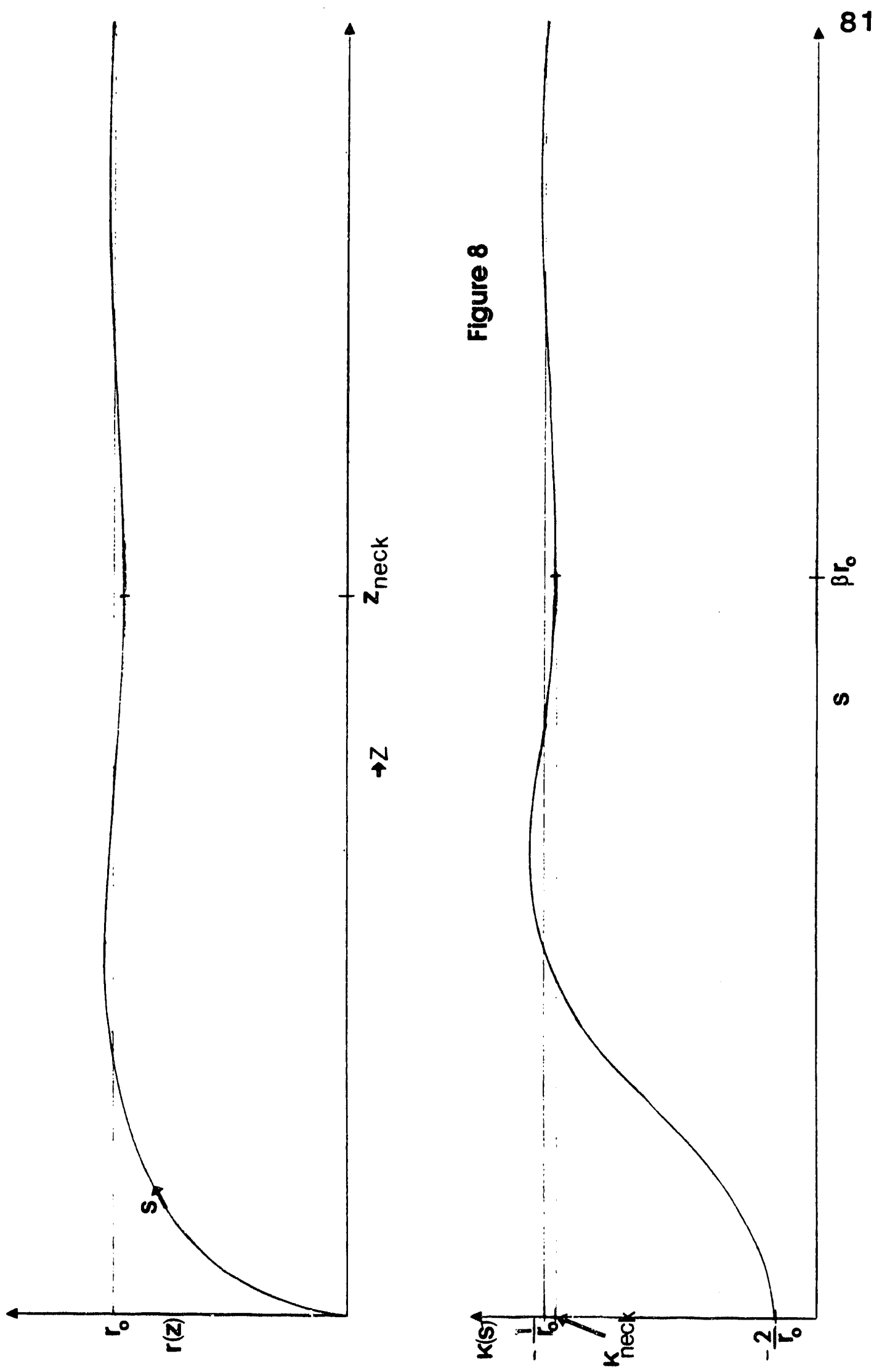




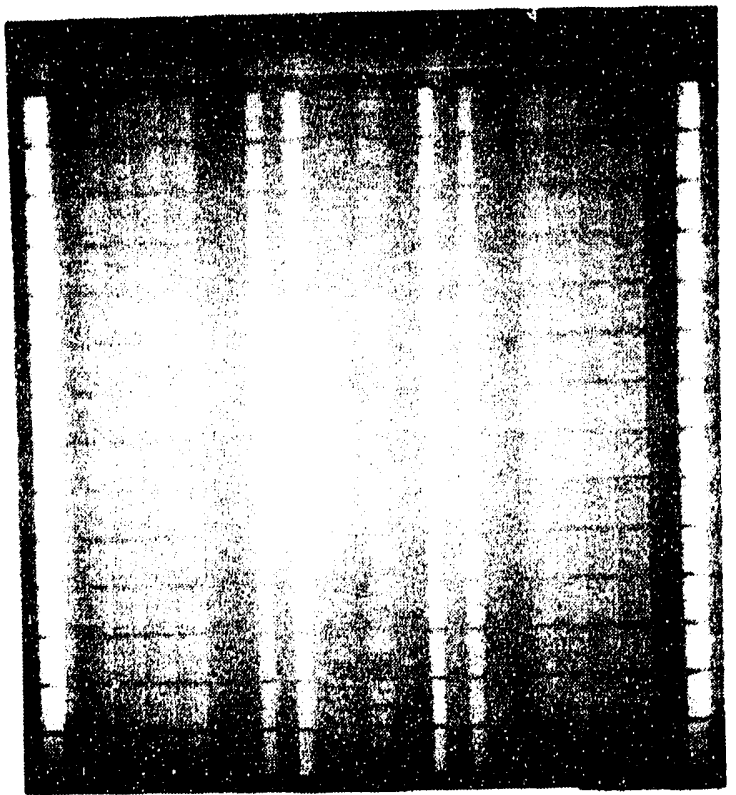

Figure 9

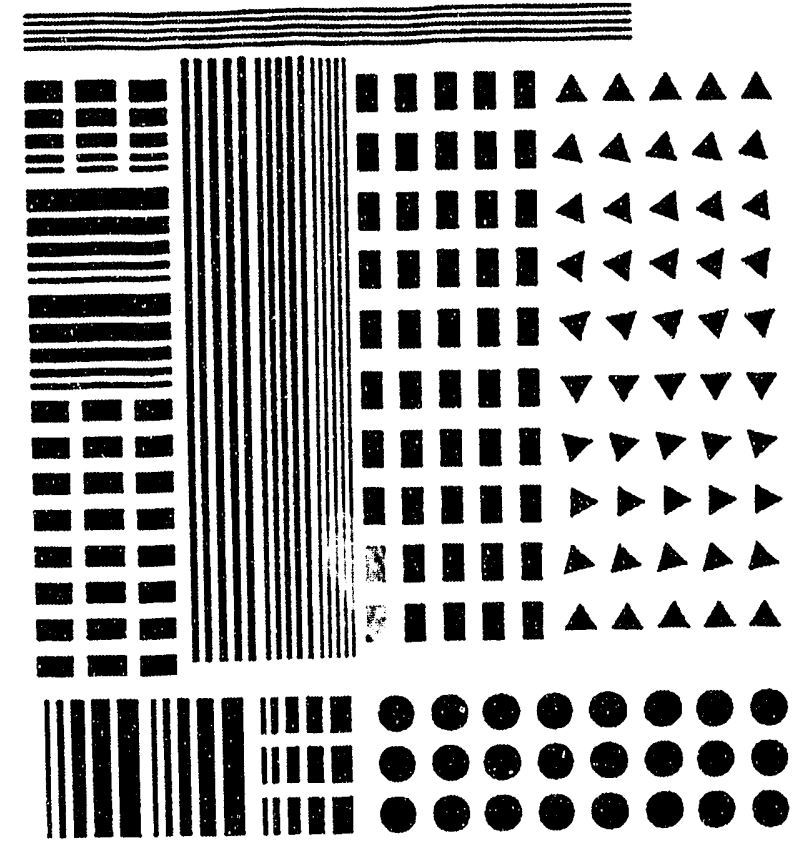

Figure 10 


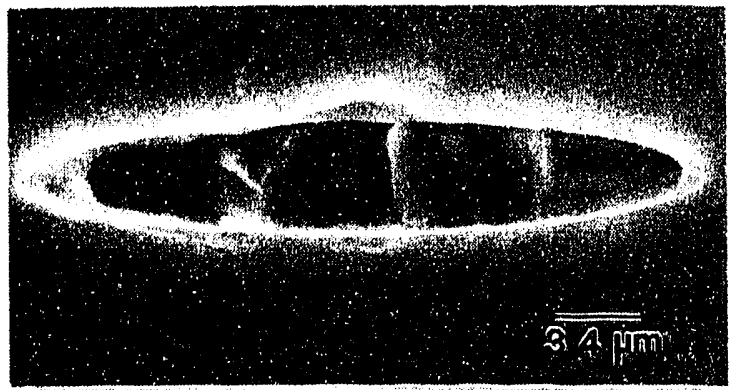

Figure 11

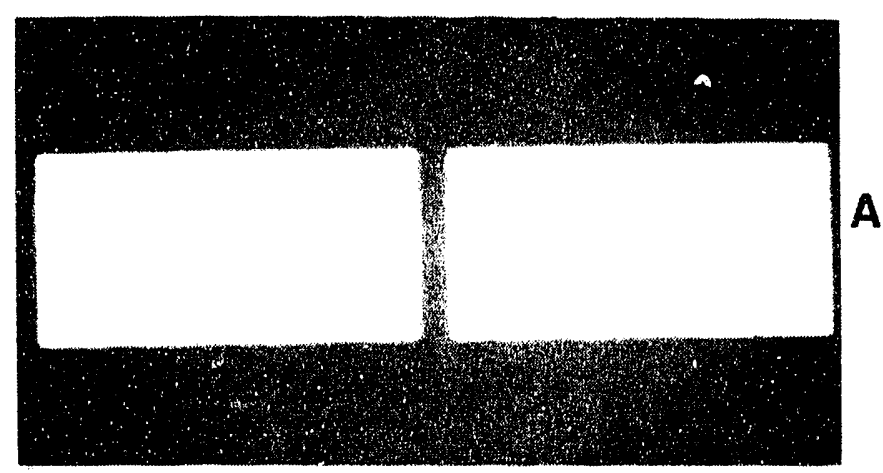

Figure 12
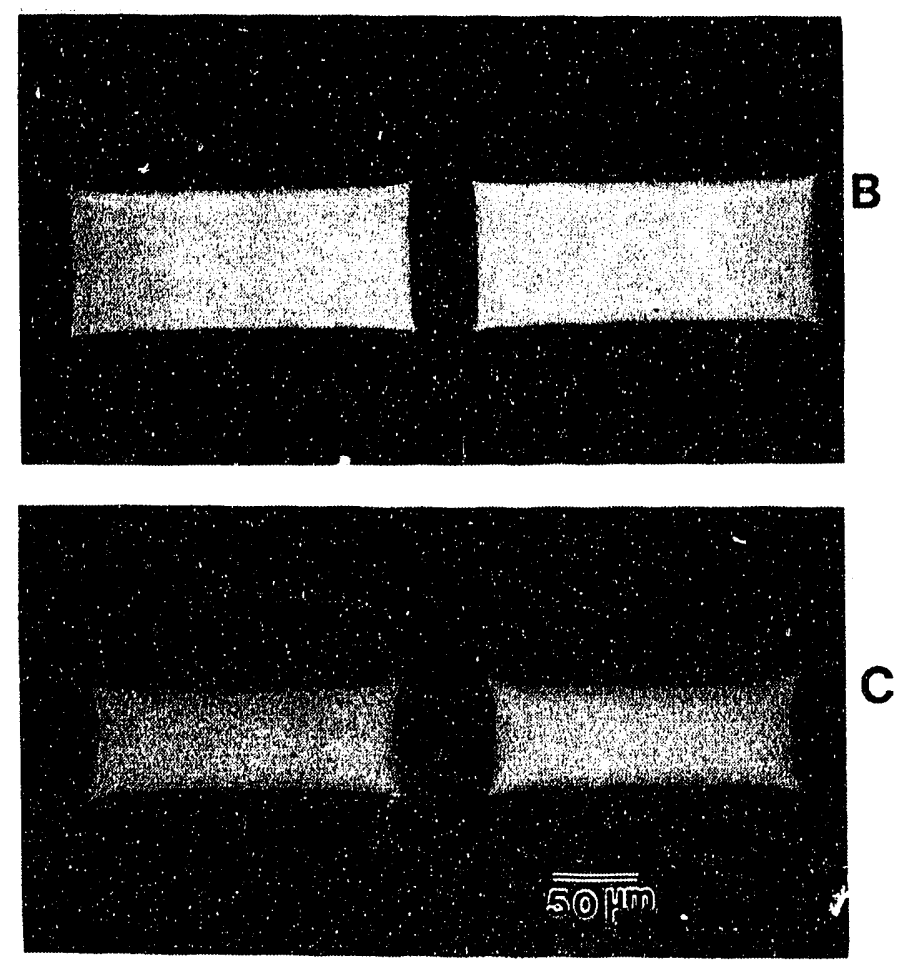

XBB 920-10218 
34
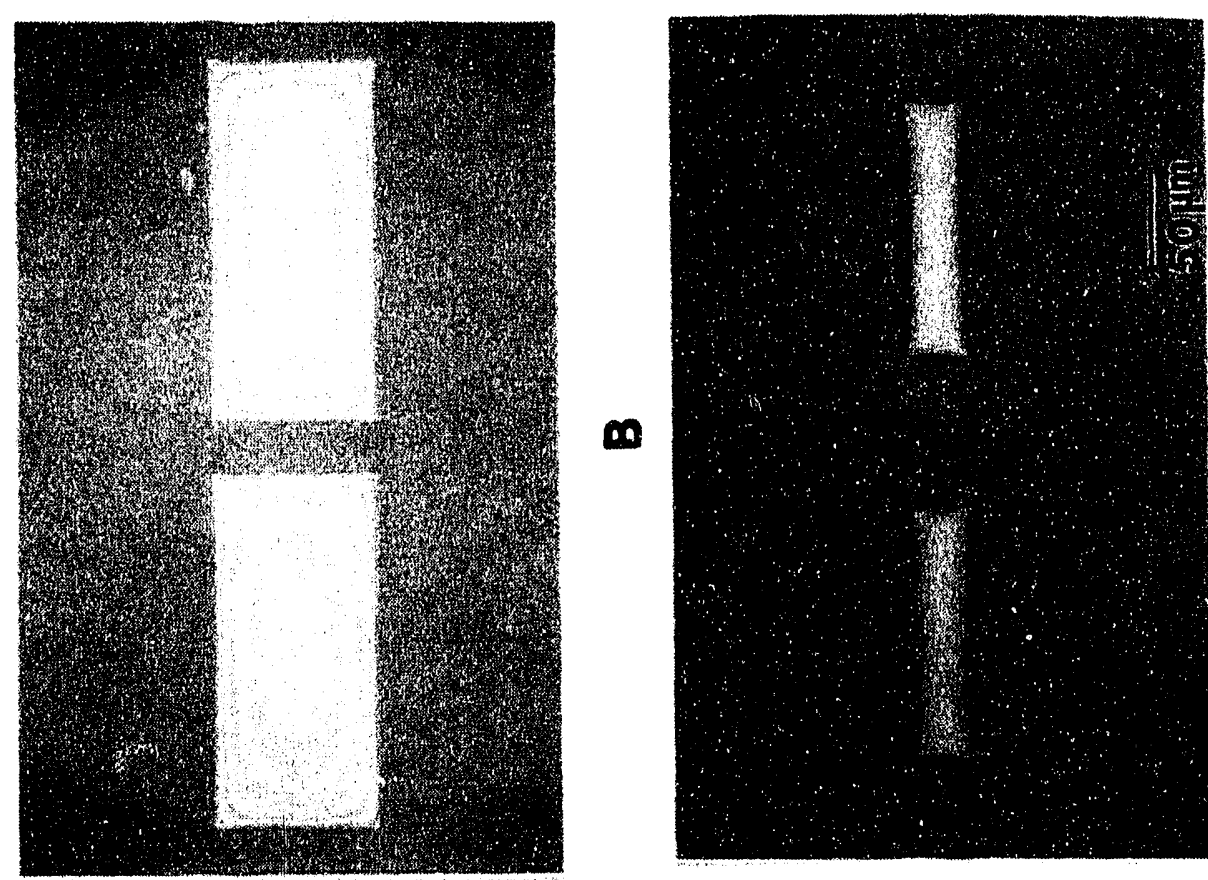

$\frac{0}{01}$
$\frac{0}{1}$
$\dot{\delta}$
$o$
$\infty$
0
$x$
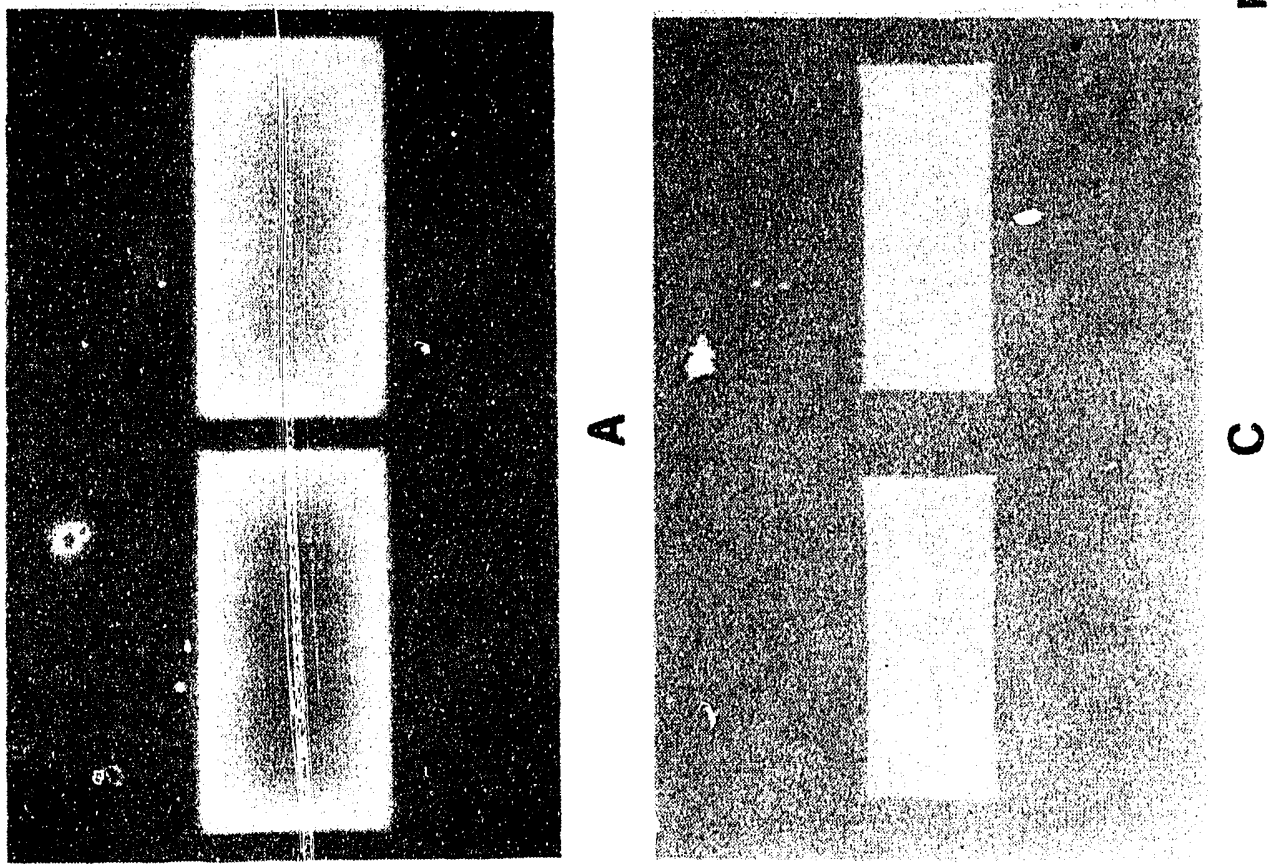

$\frac{2}{\frac{9}{5}}$

0 


\section{5}
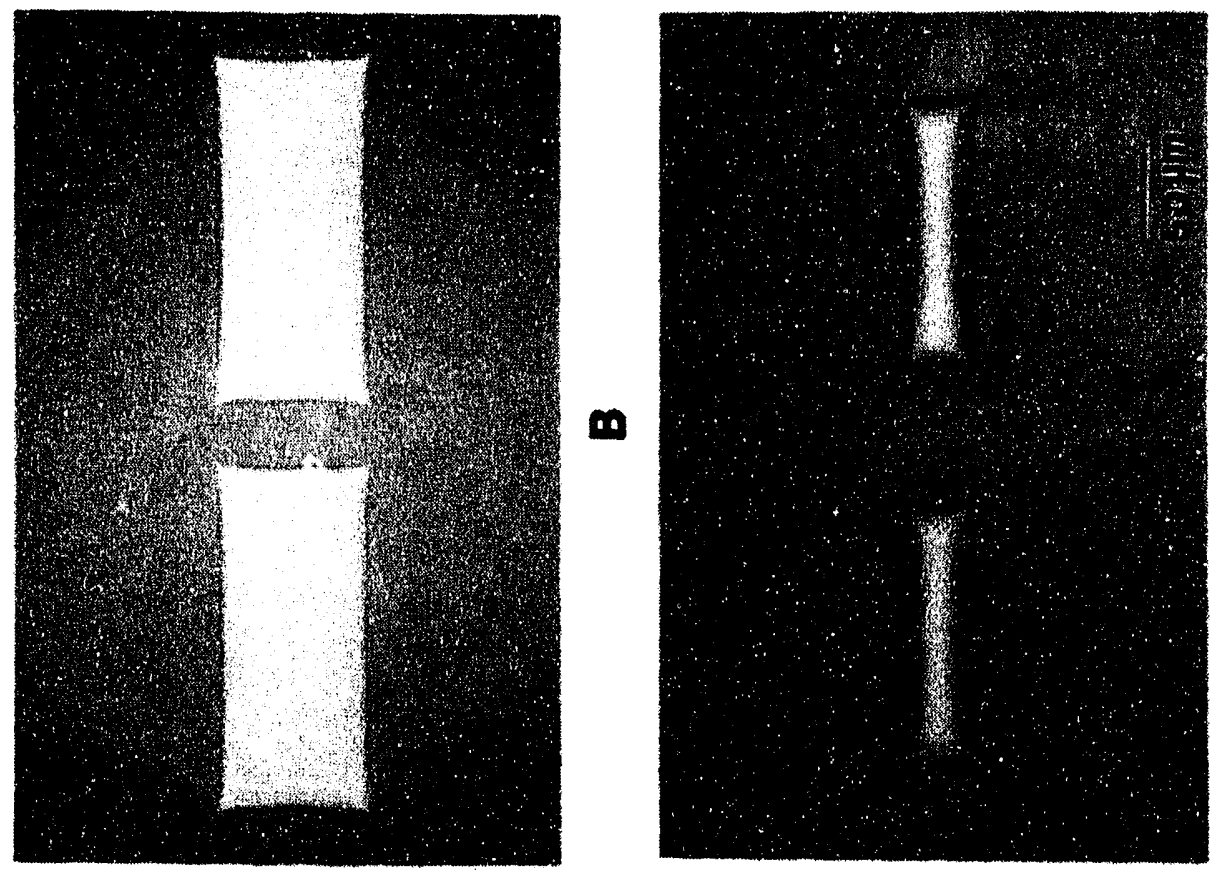

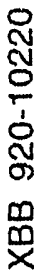

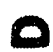

$\frac{9}{3}$
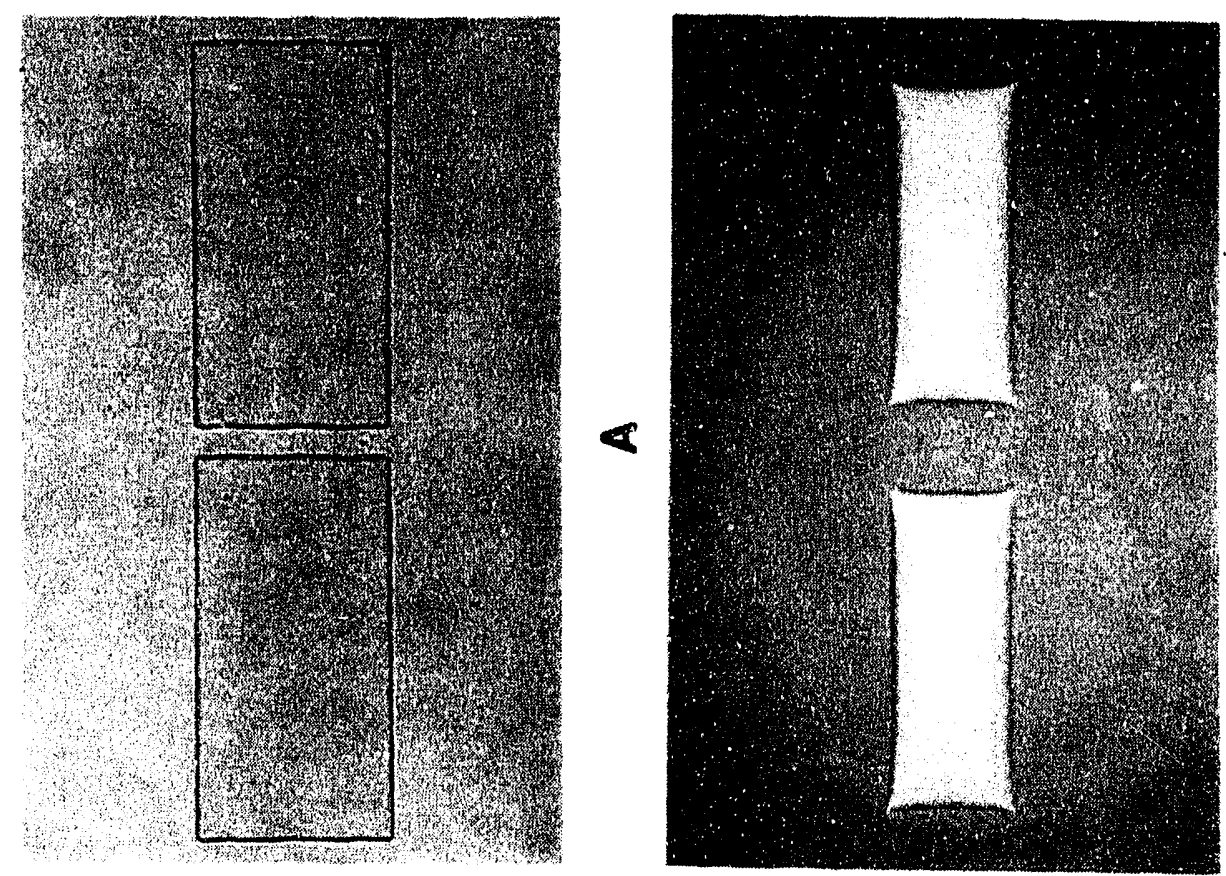

0 
86

\section{VISCOSITY}

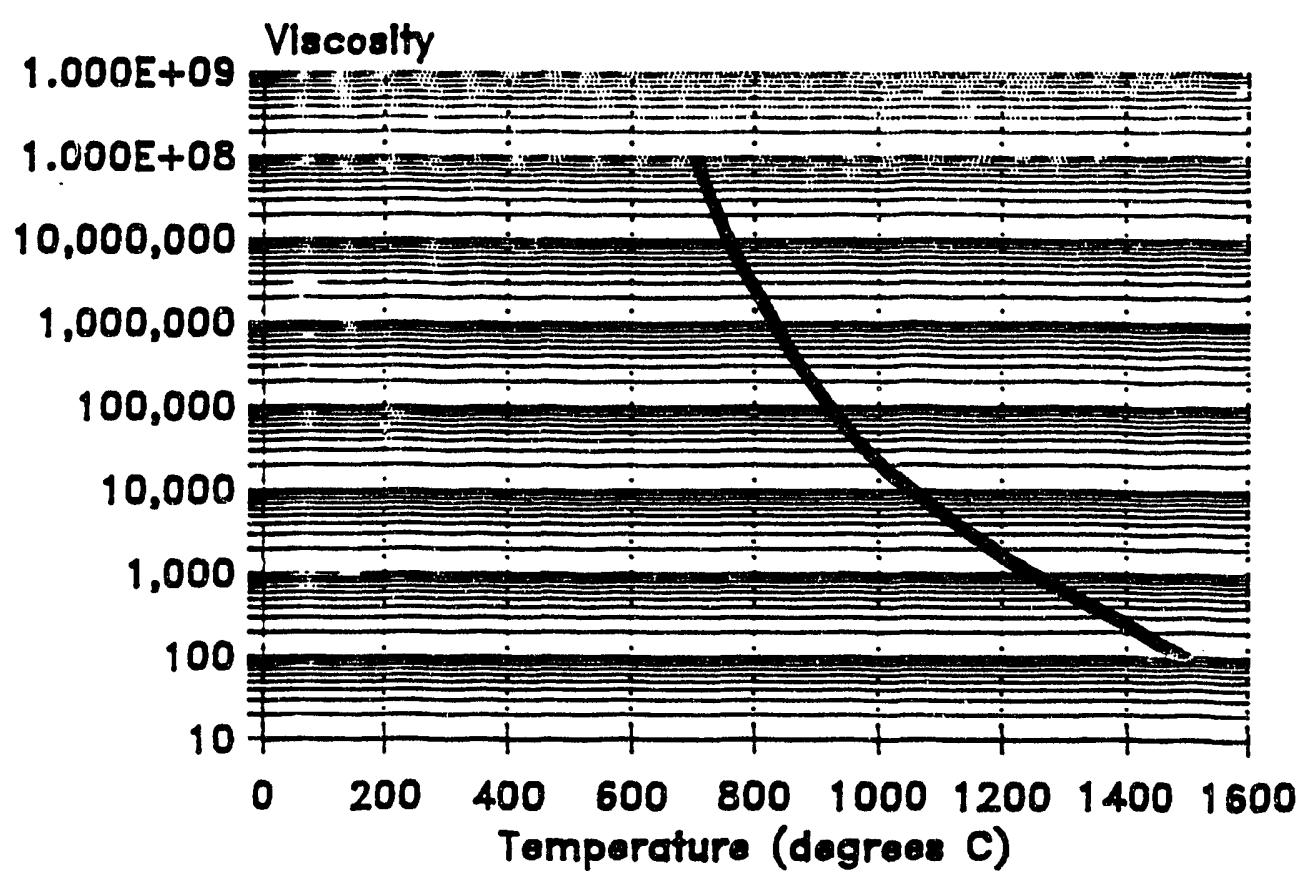

Figure 15 

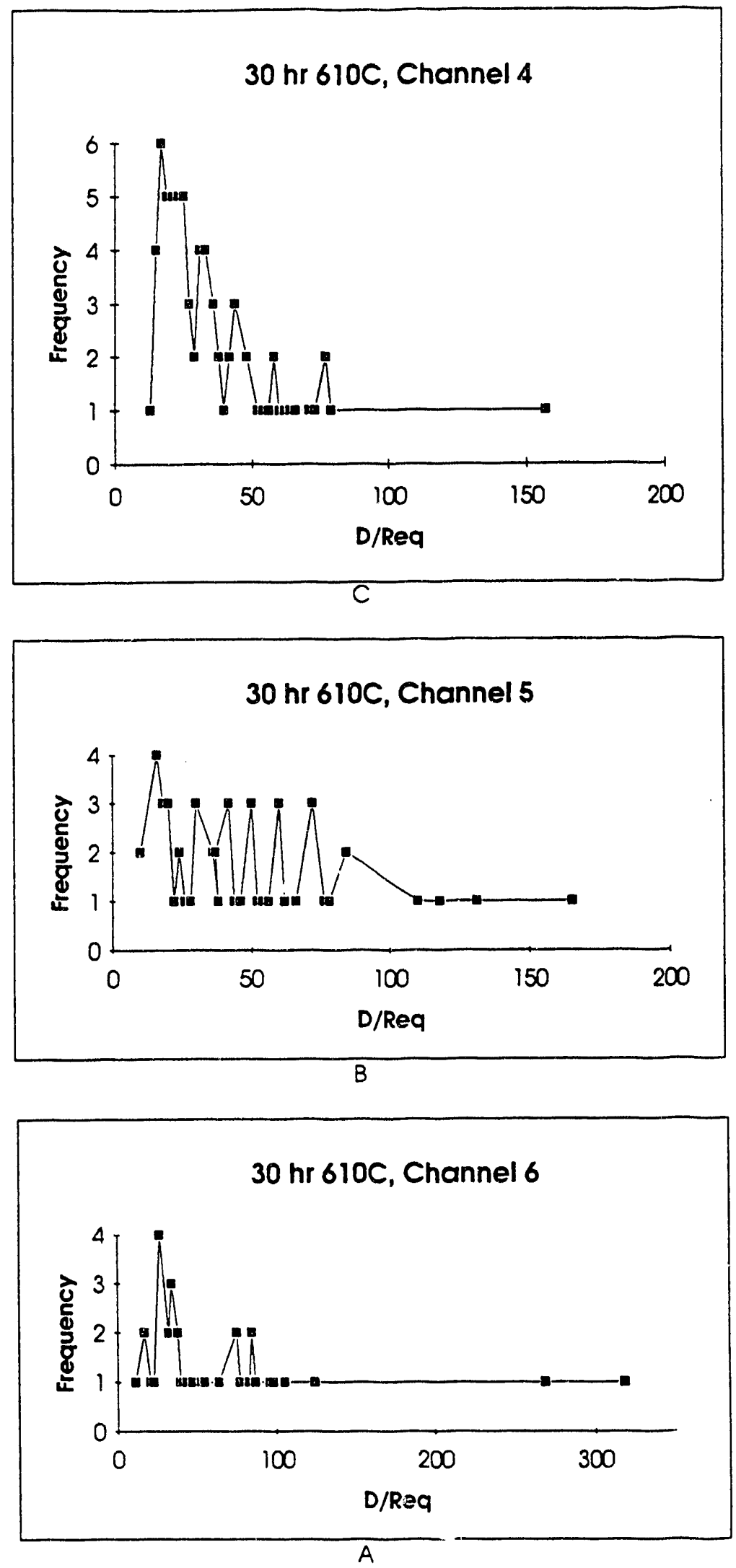

Figure 16 
88

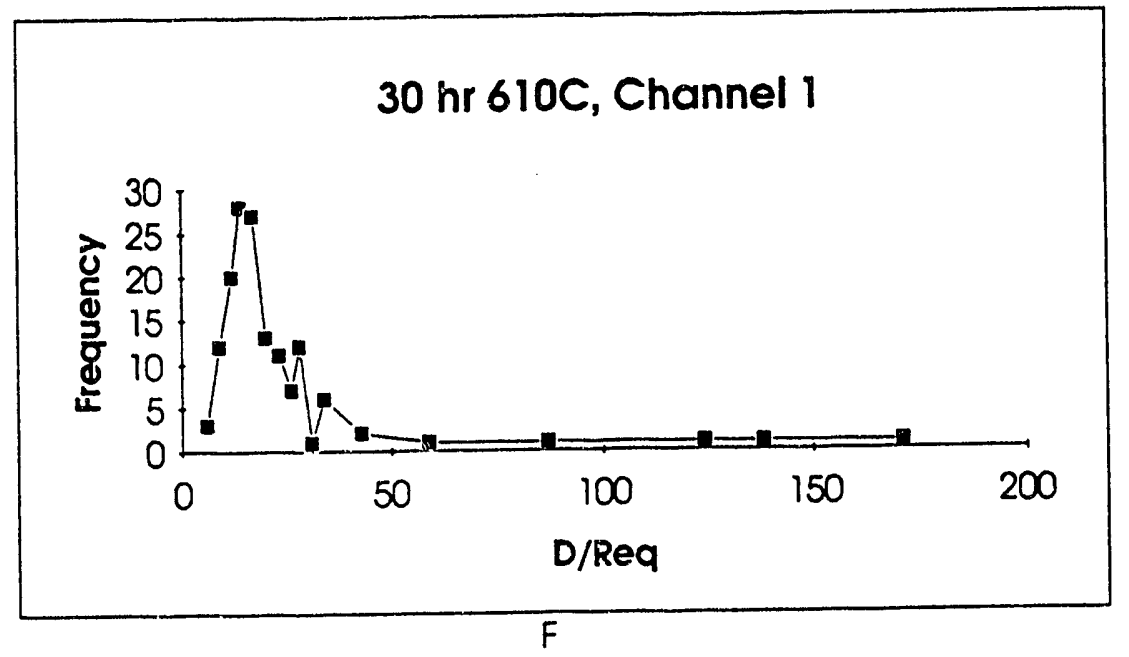

30 hr 610C, Channel 2

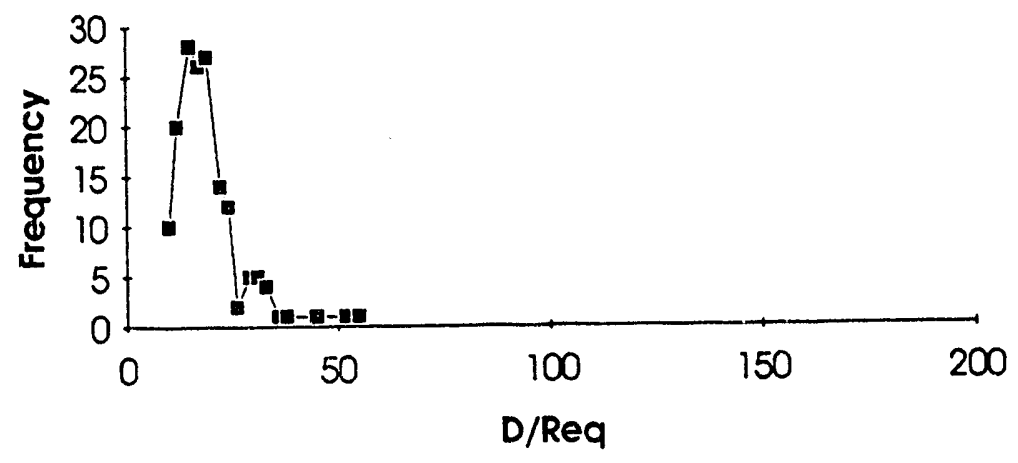

E

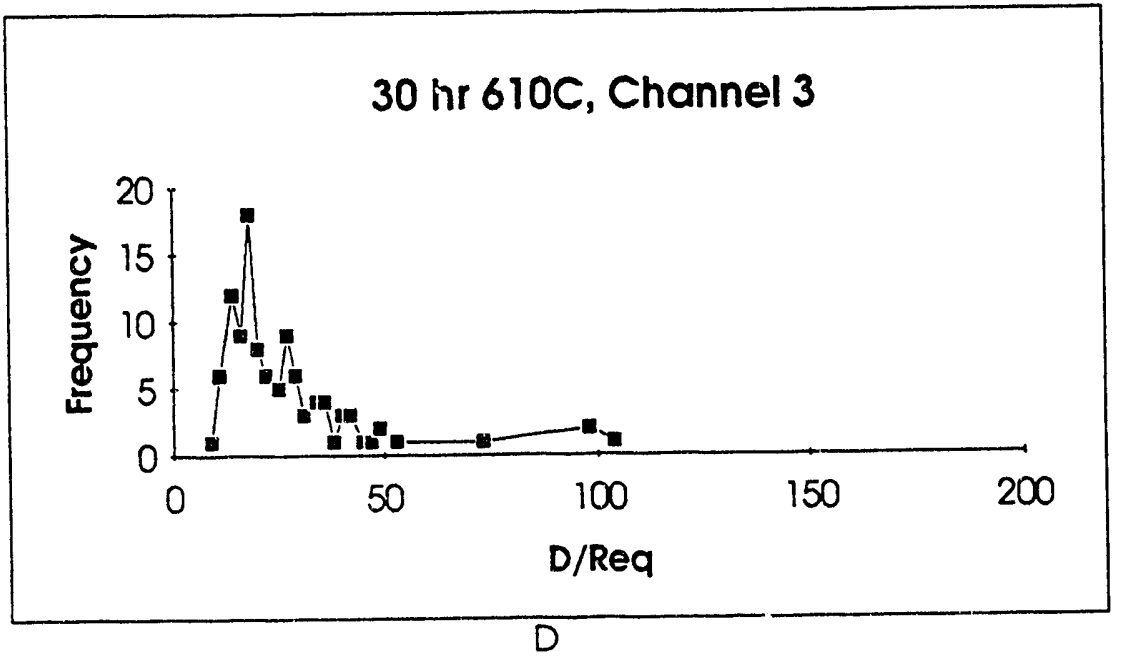

Figure 16, continued 
89

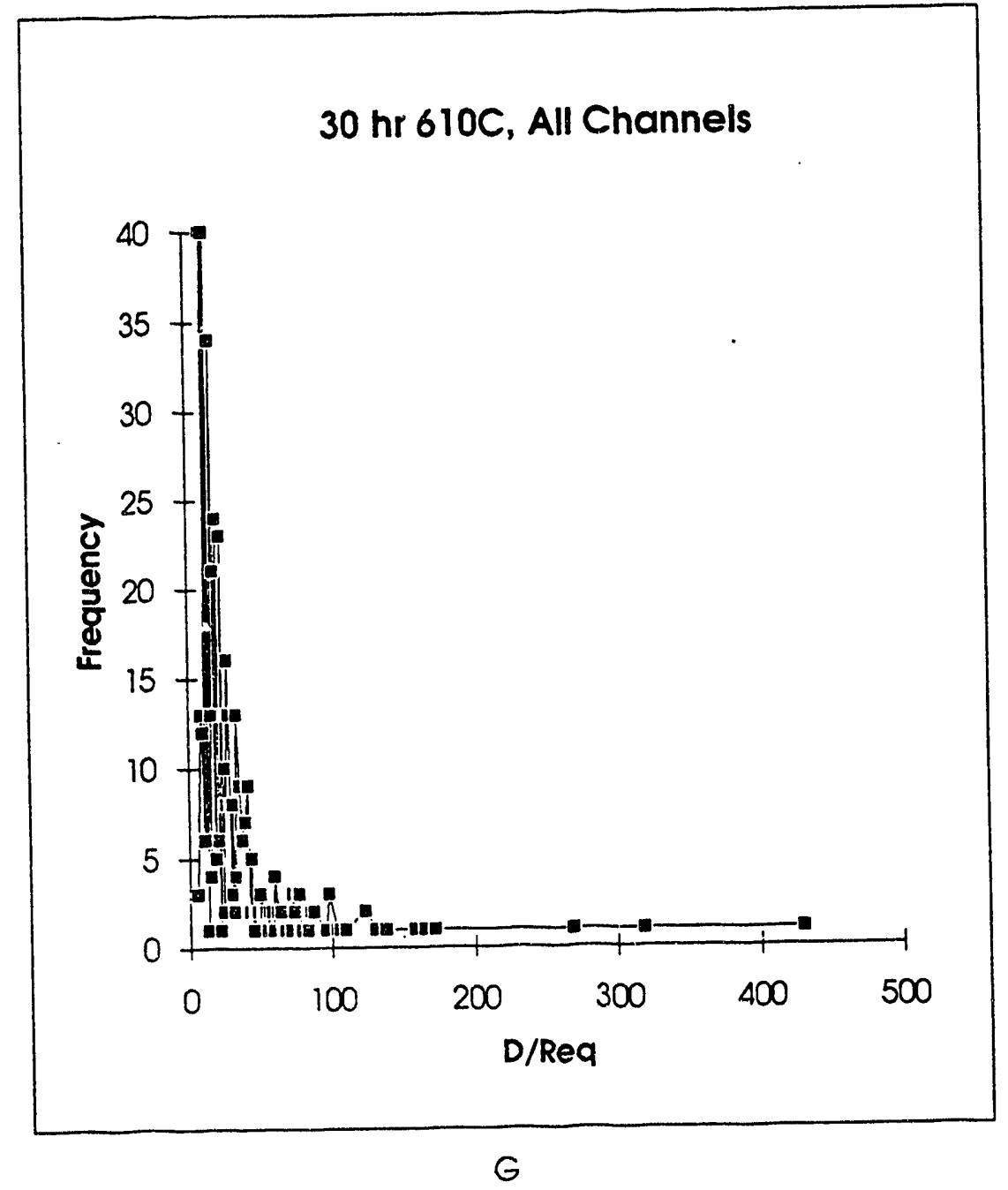

Figure 16, continued 


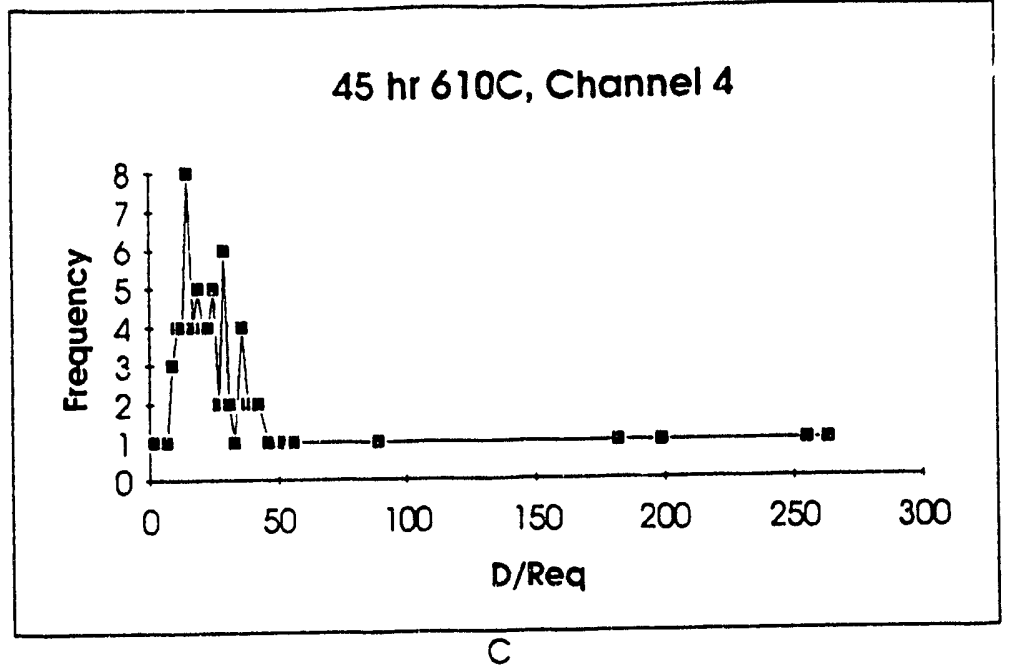

90

$45 \mathrm{hr} 610 \mathrm{C}$, Channel 5

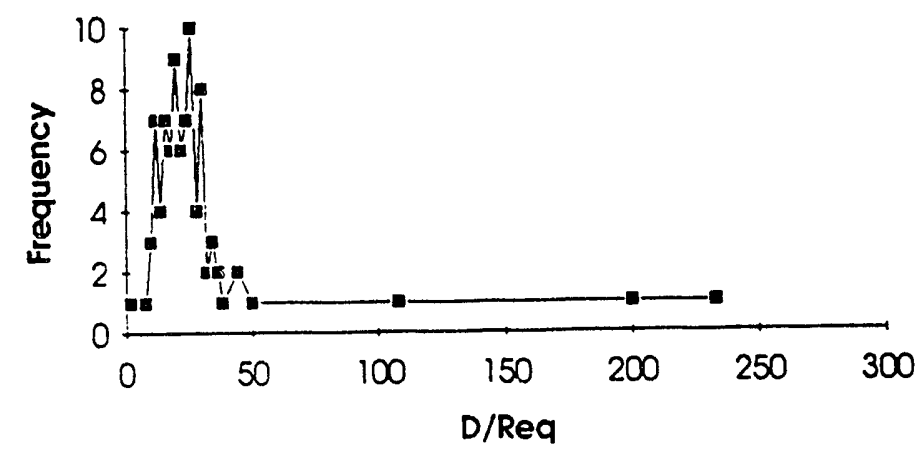

$B$

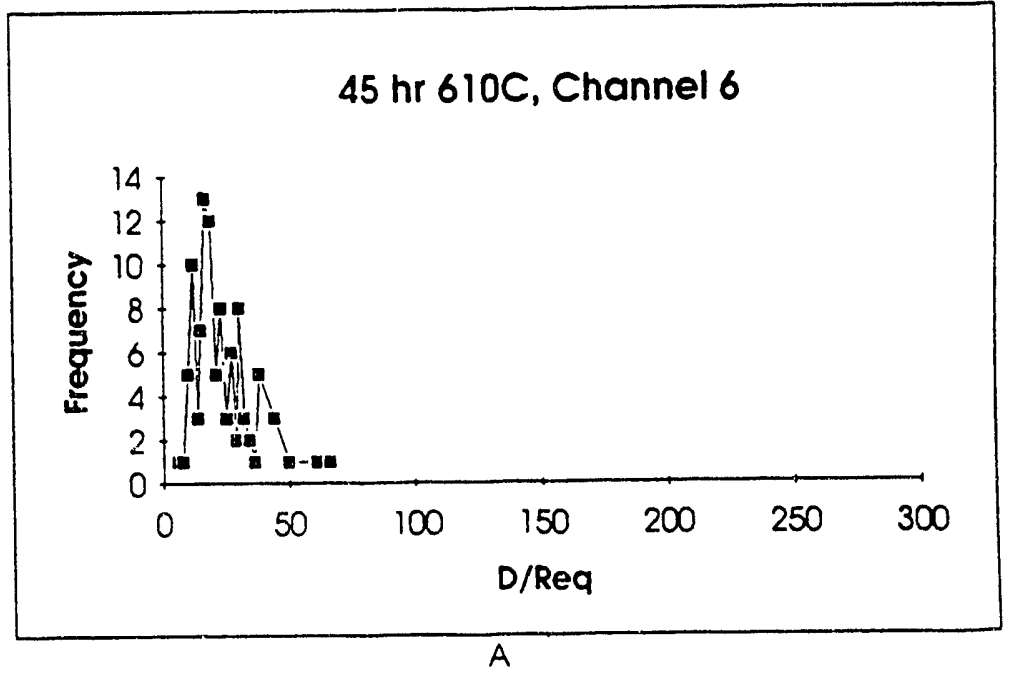

Figure 17 

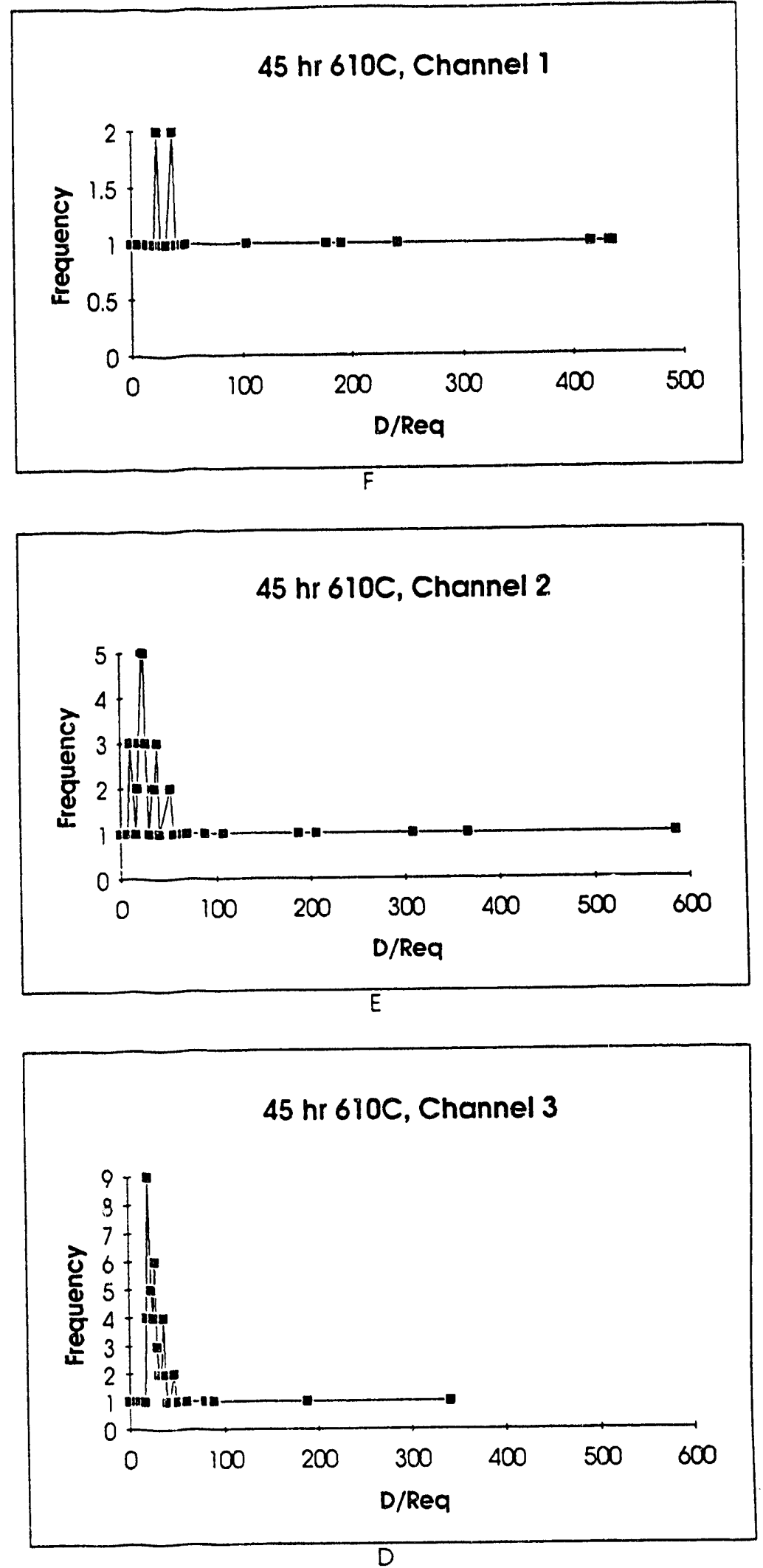

Figure 17, continued 
92

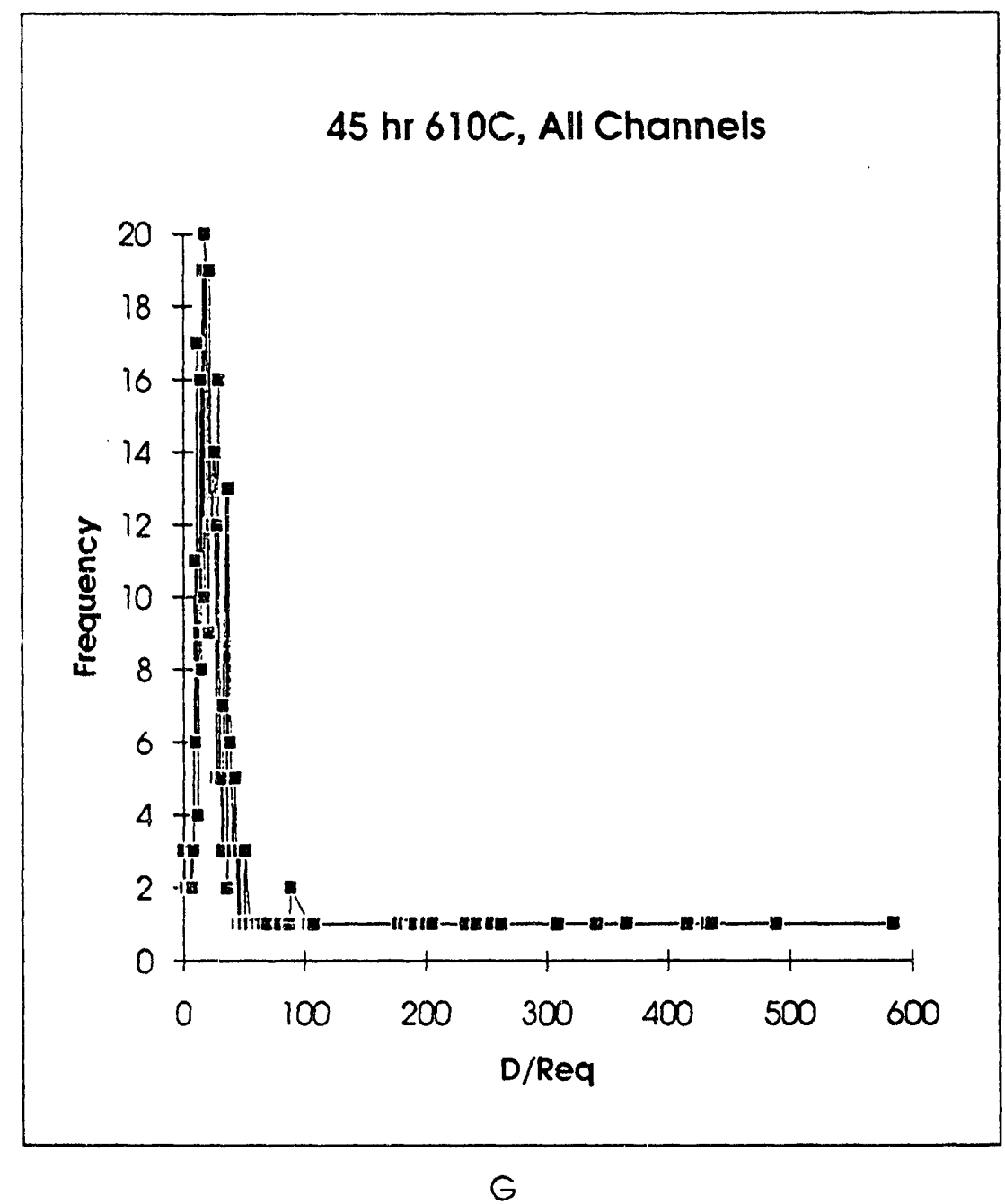

Figure 17, continued 

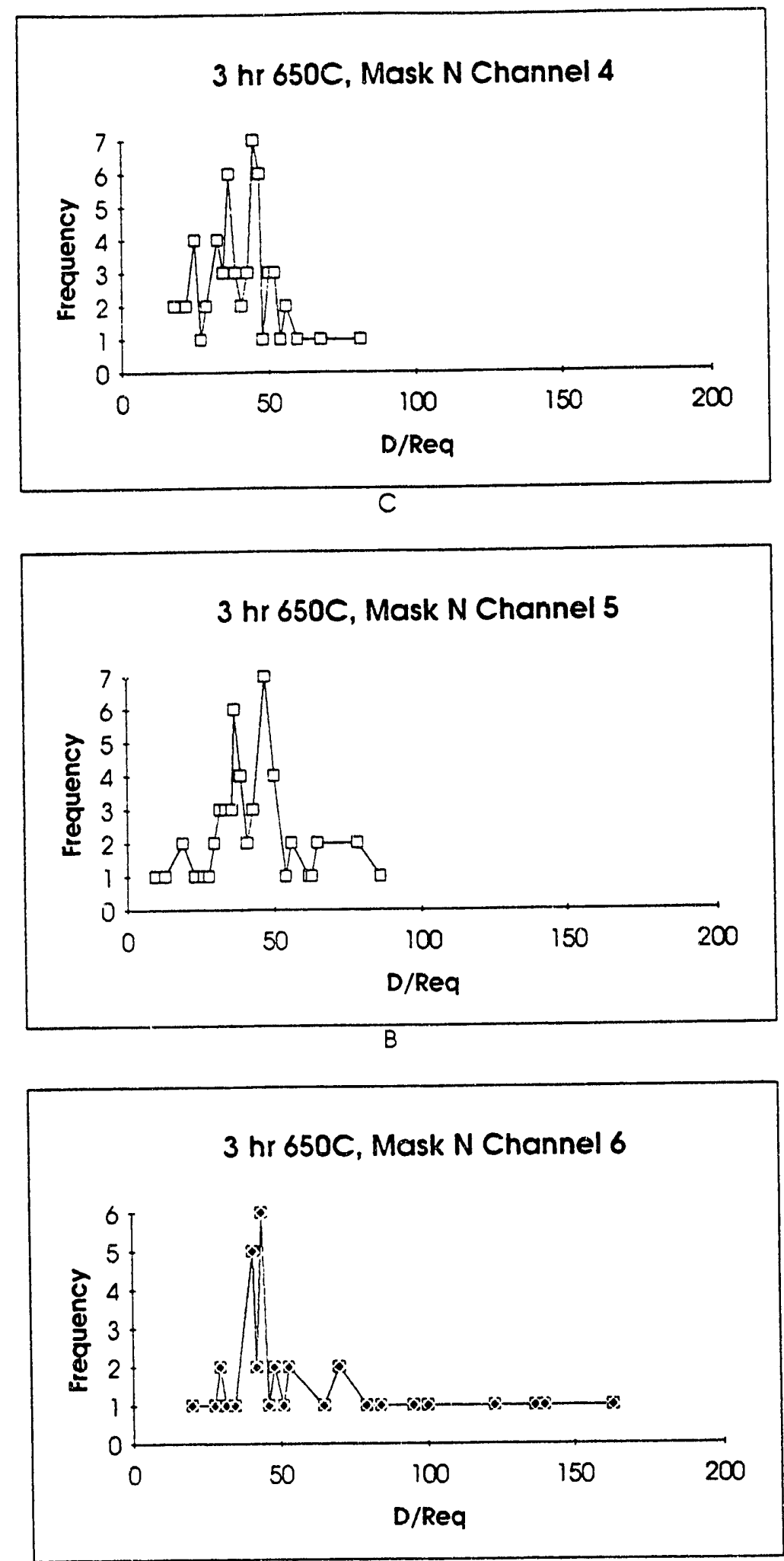

A

Figure 18 


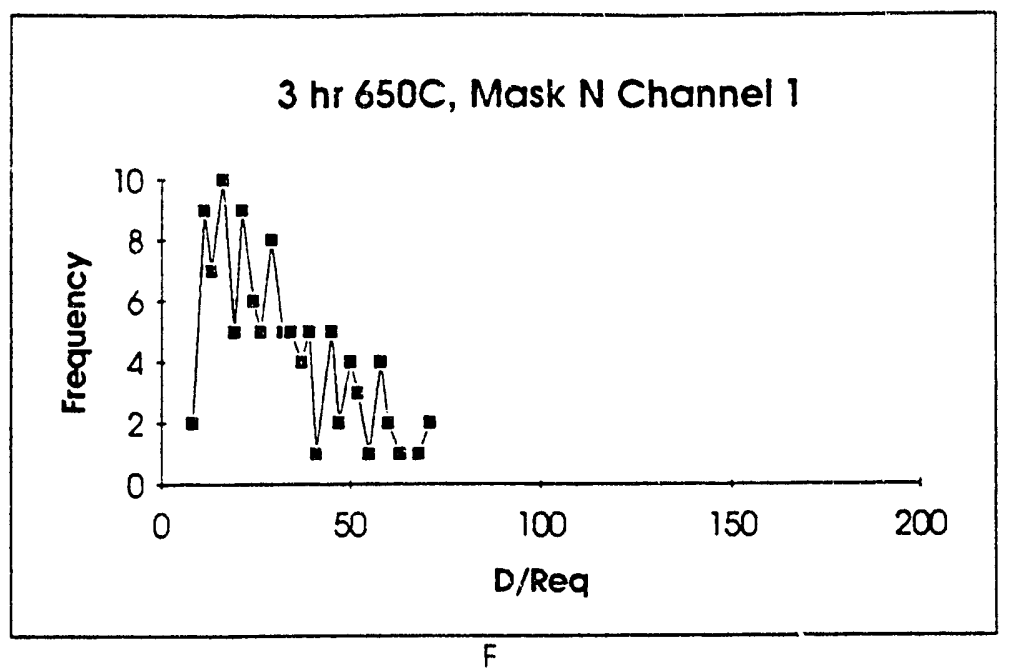

94
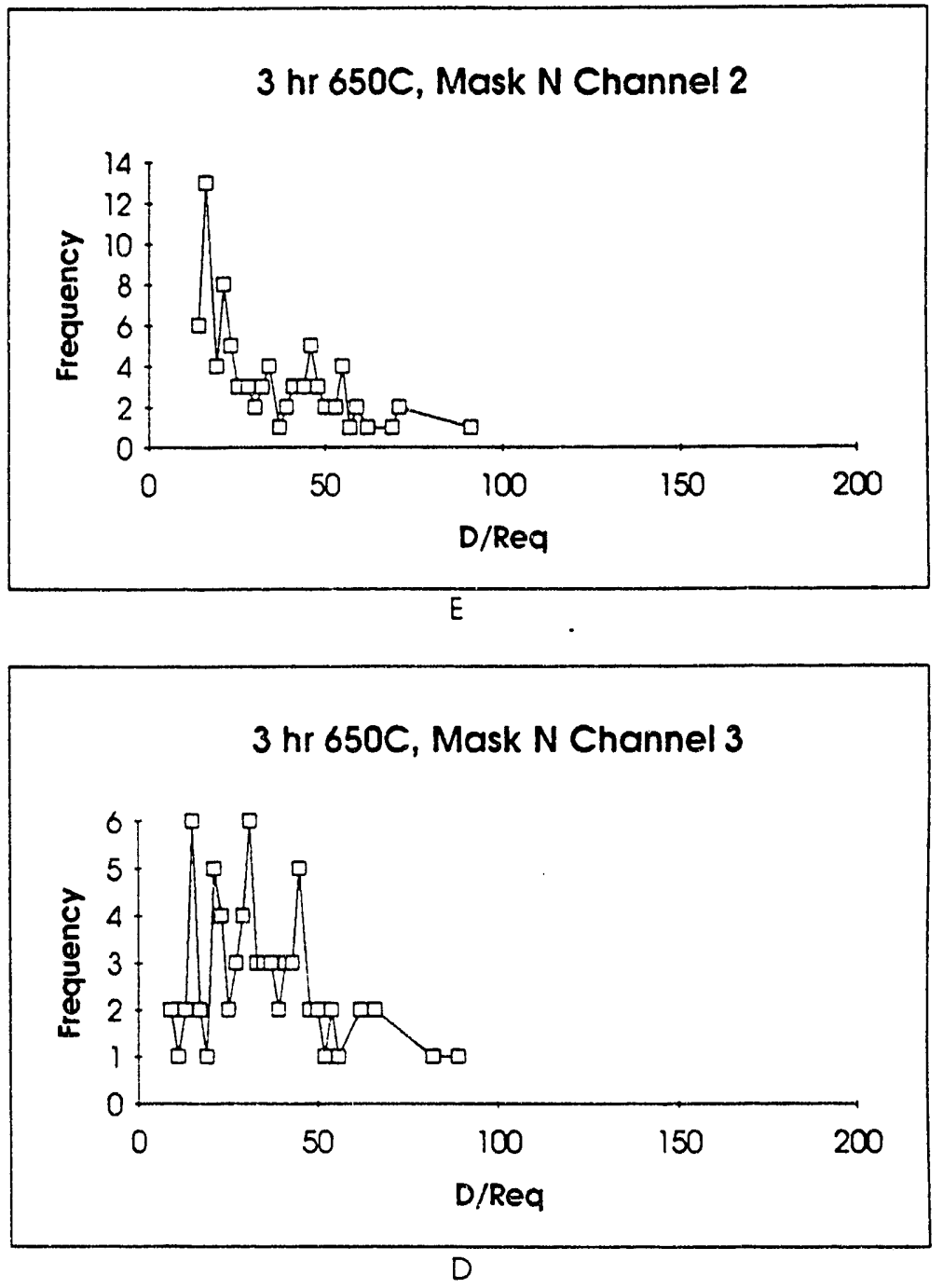

Figure 18, continued 

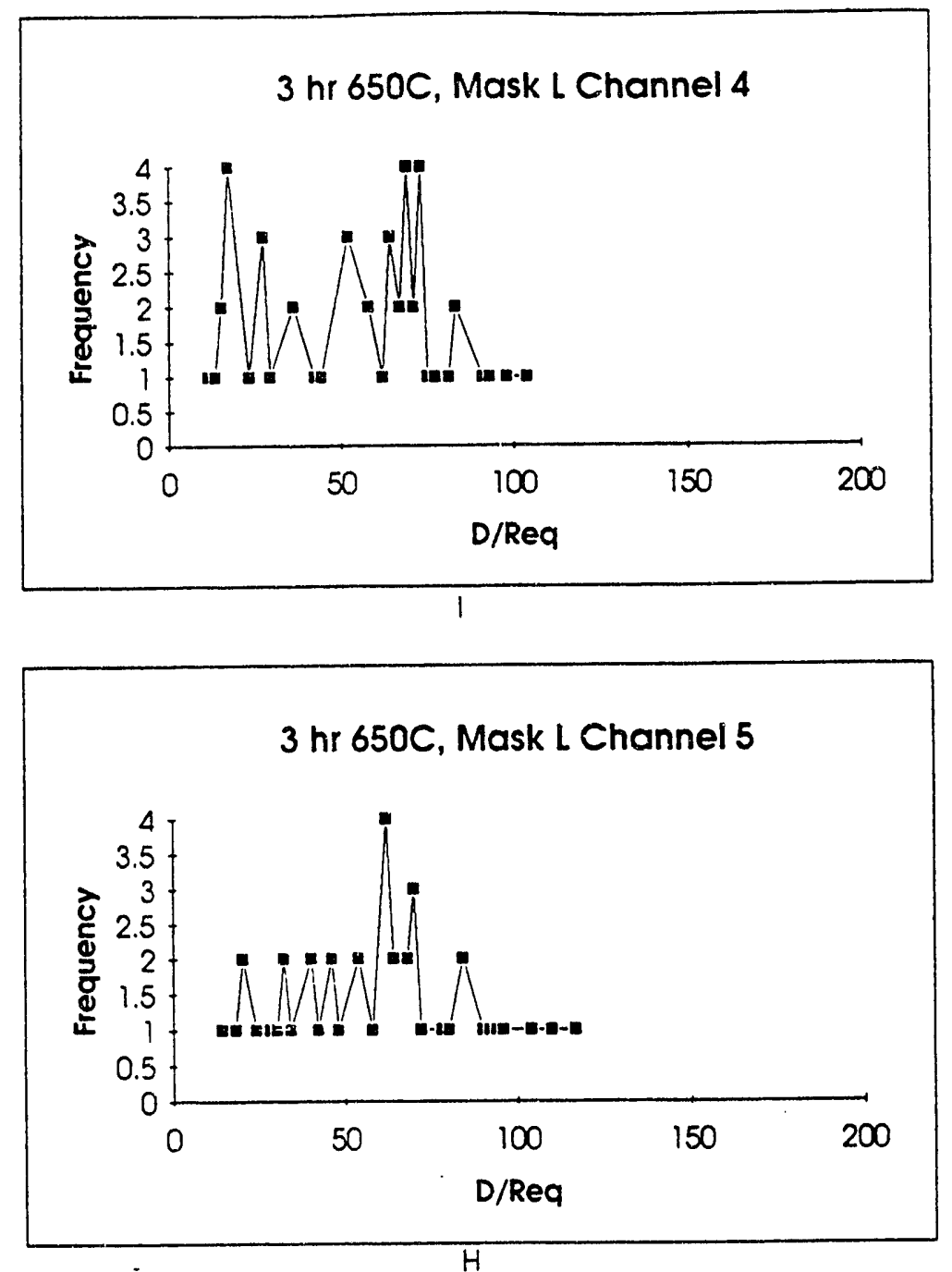

H

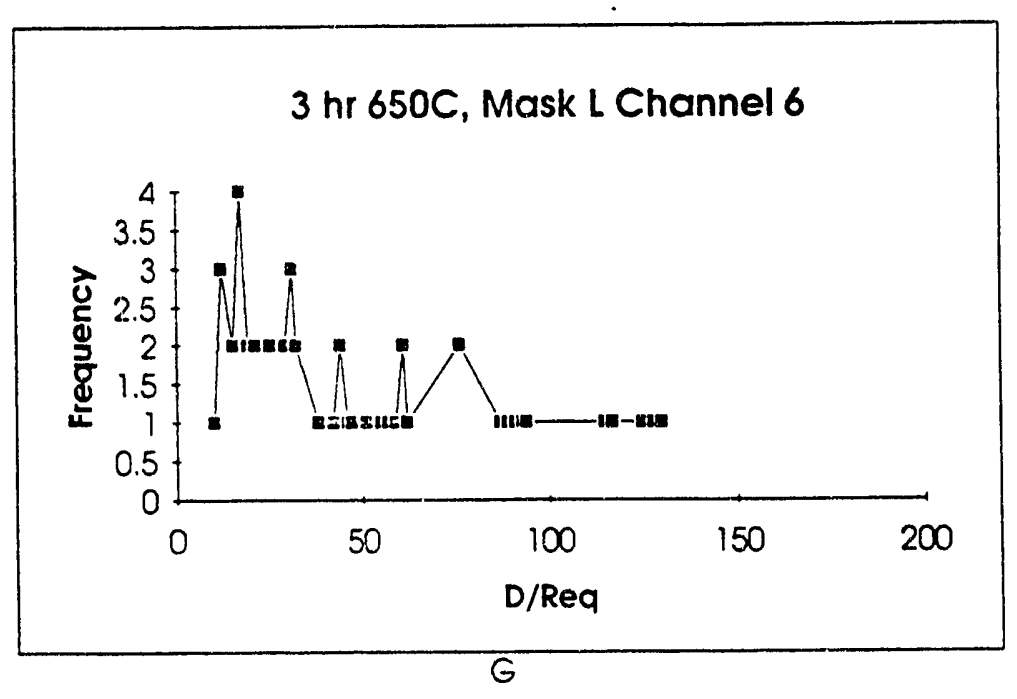

Figure 18, continued 
96

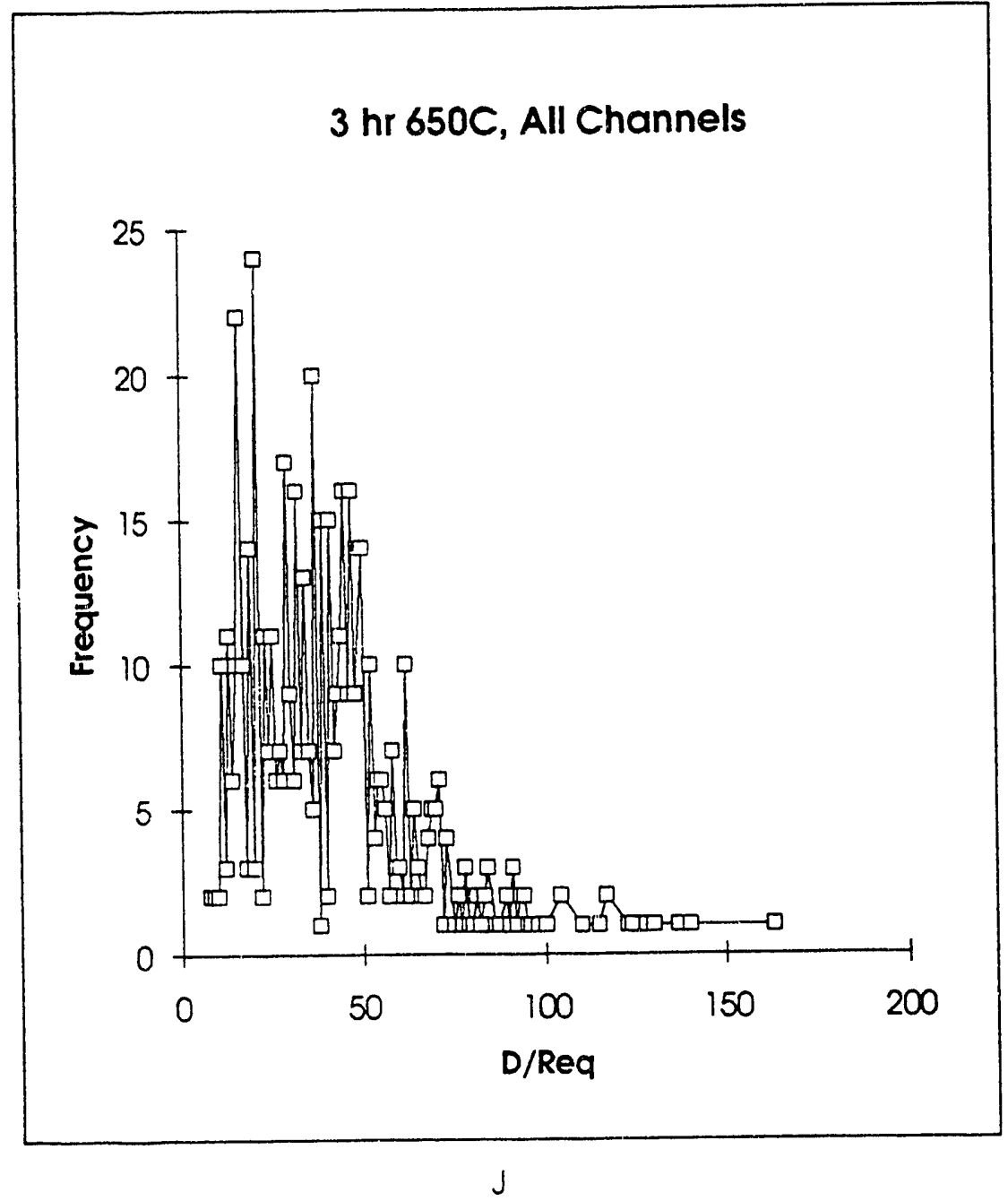

Figure 18, continuẹd 

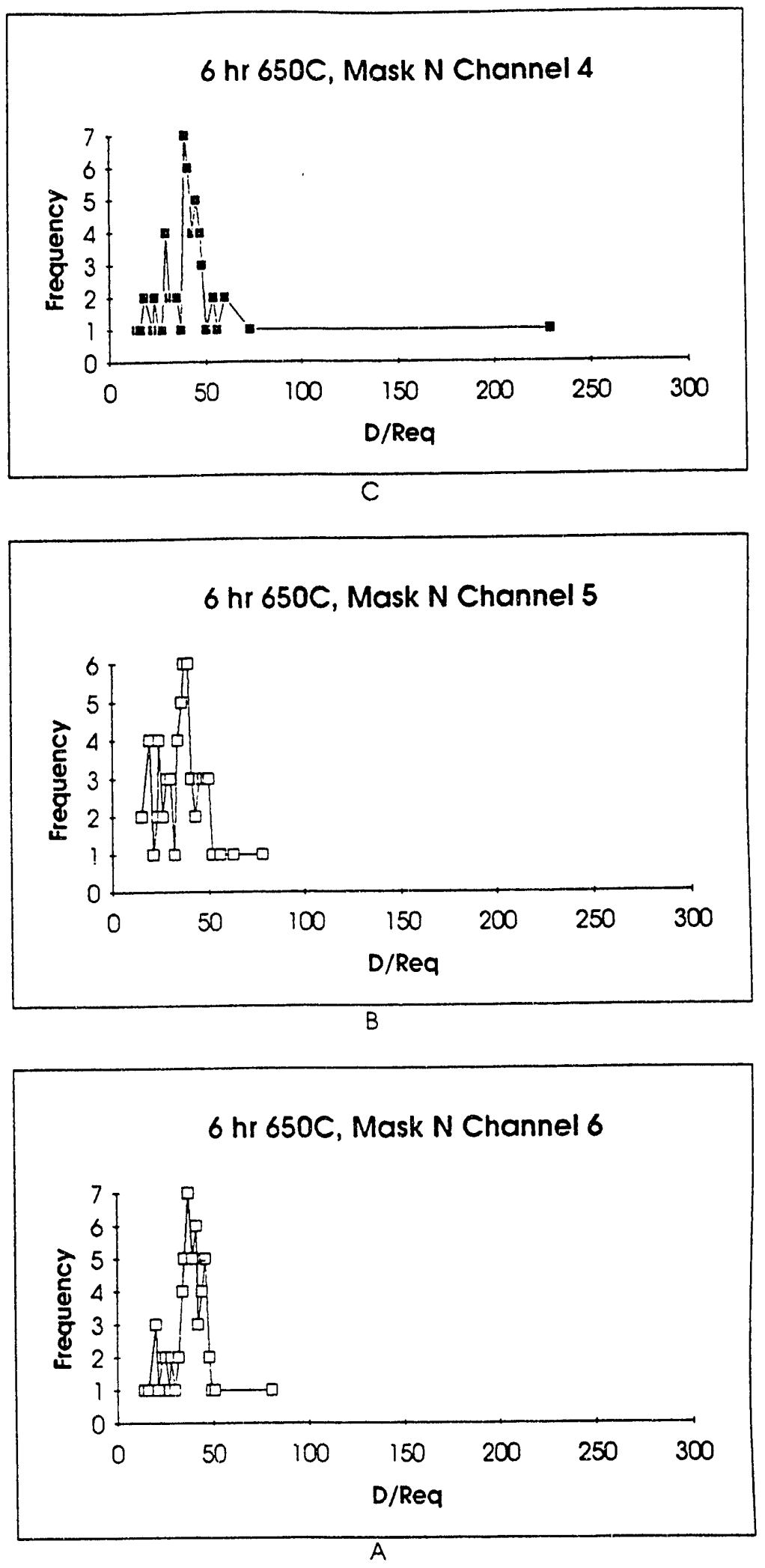

Figure 19 

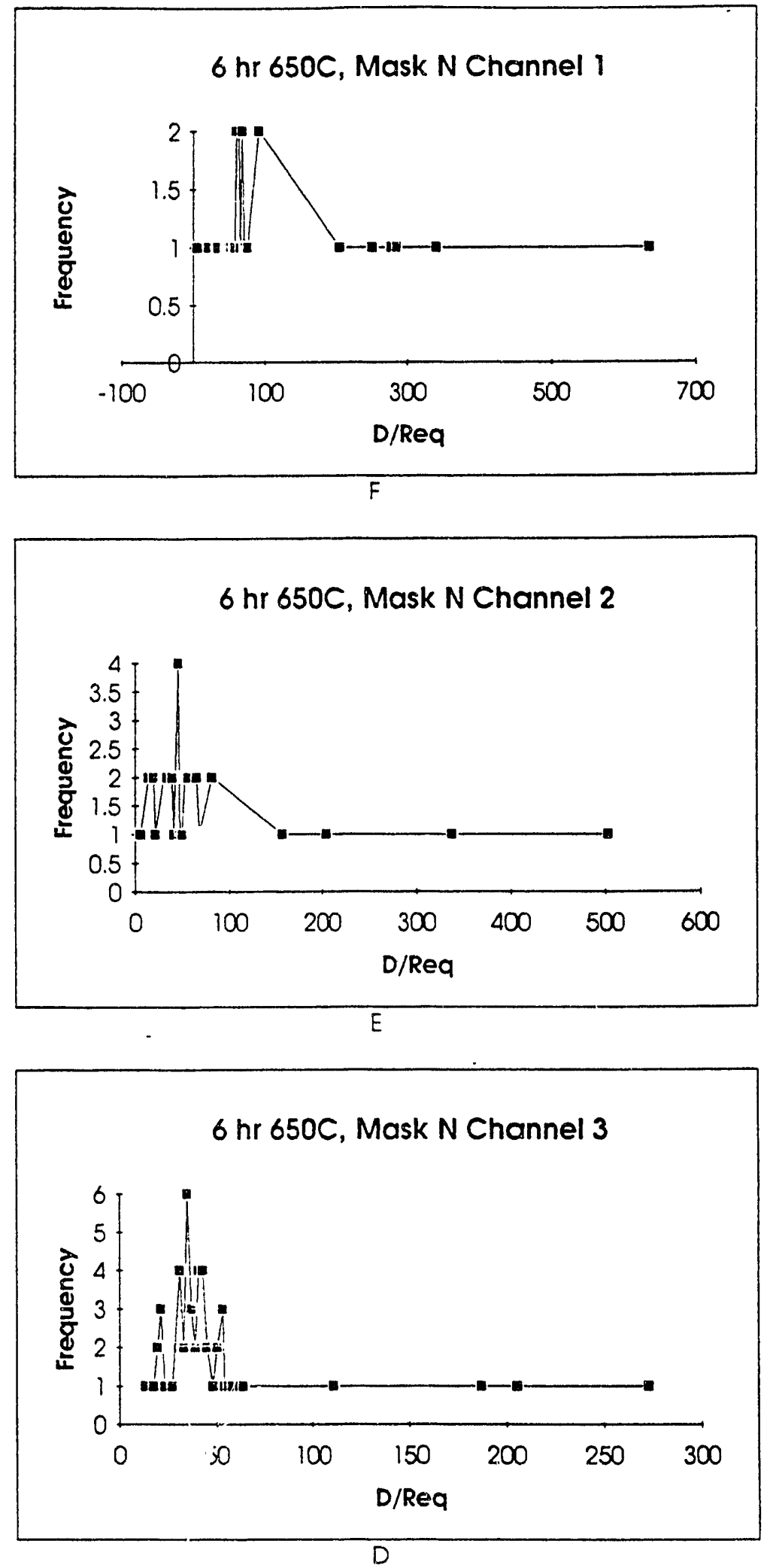

Figure 19 ,continued 

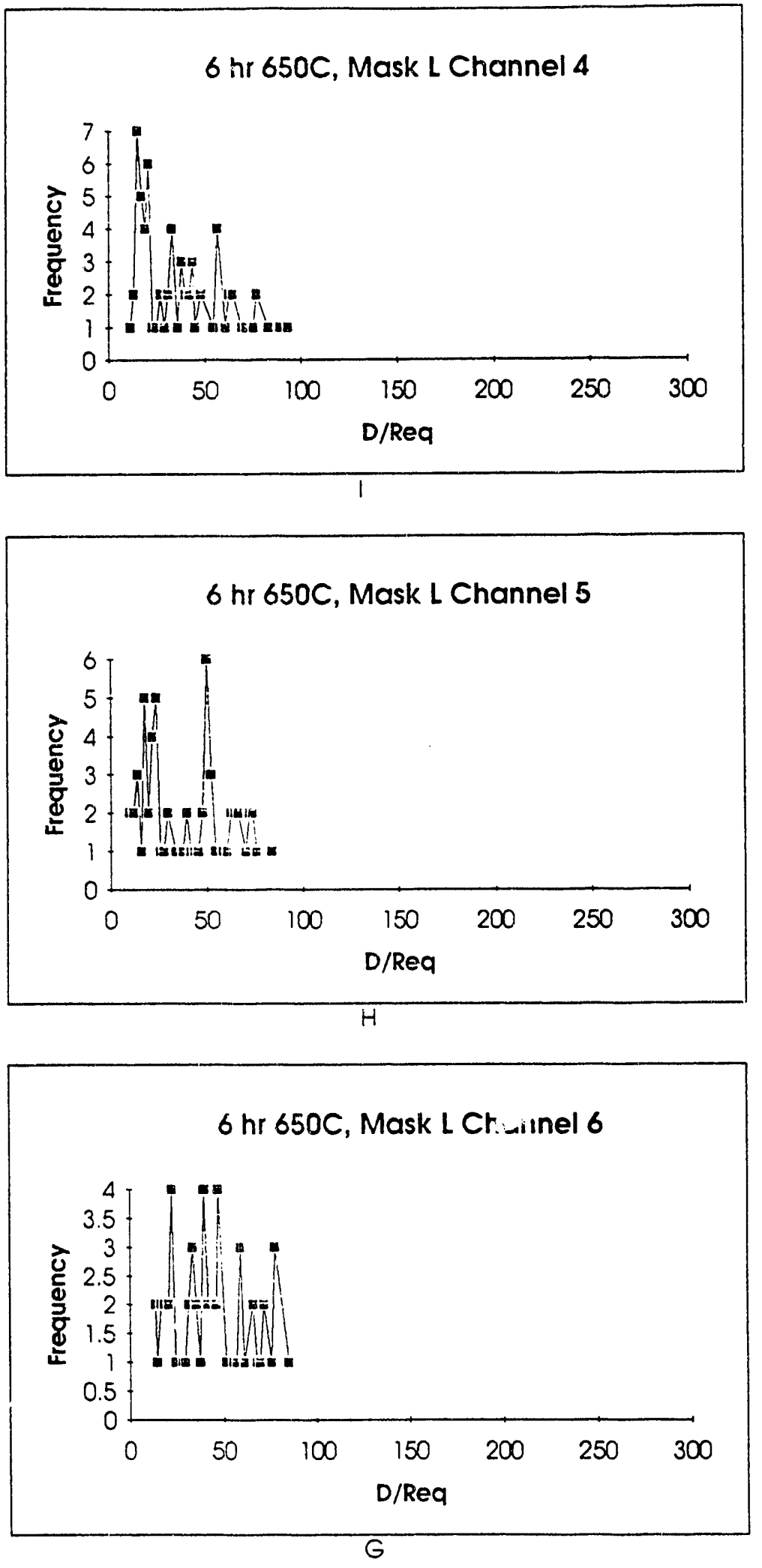

Figure 19 ,continued 
100

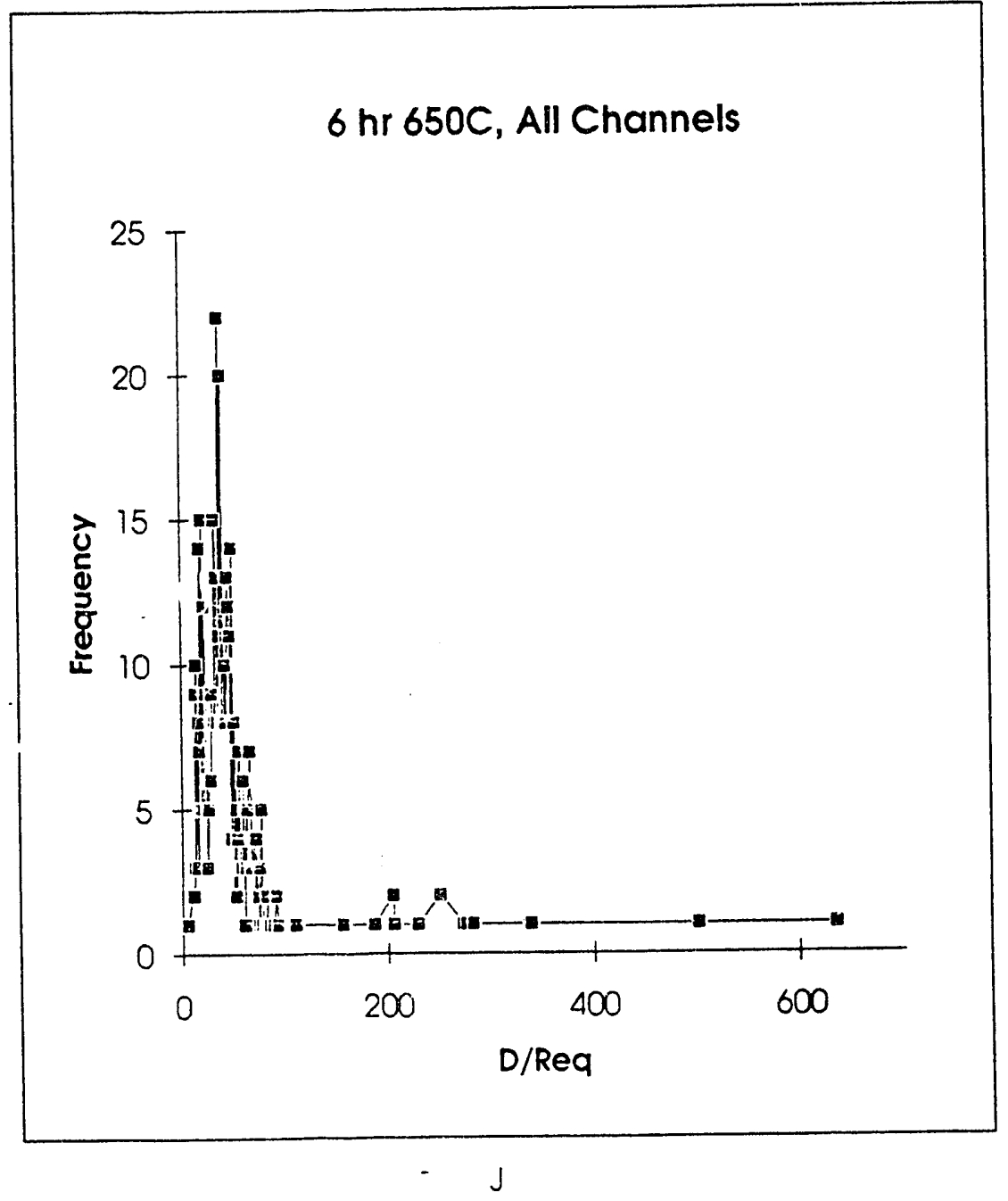

Figure 19, continued 
101
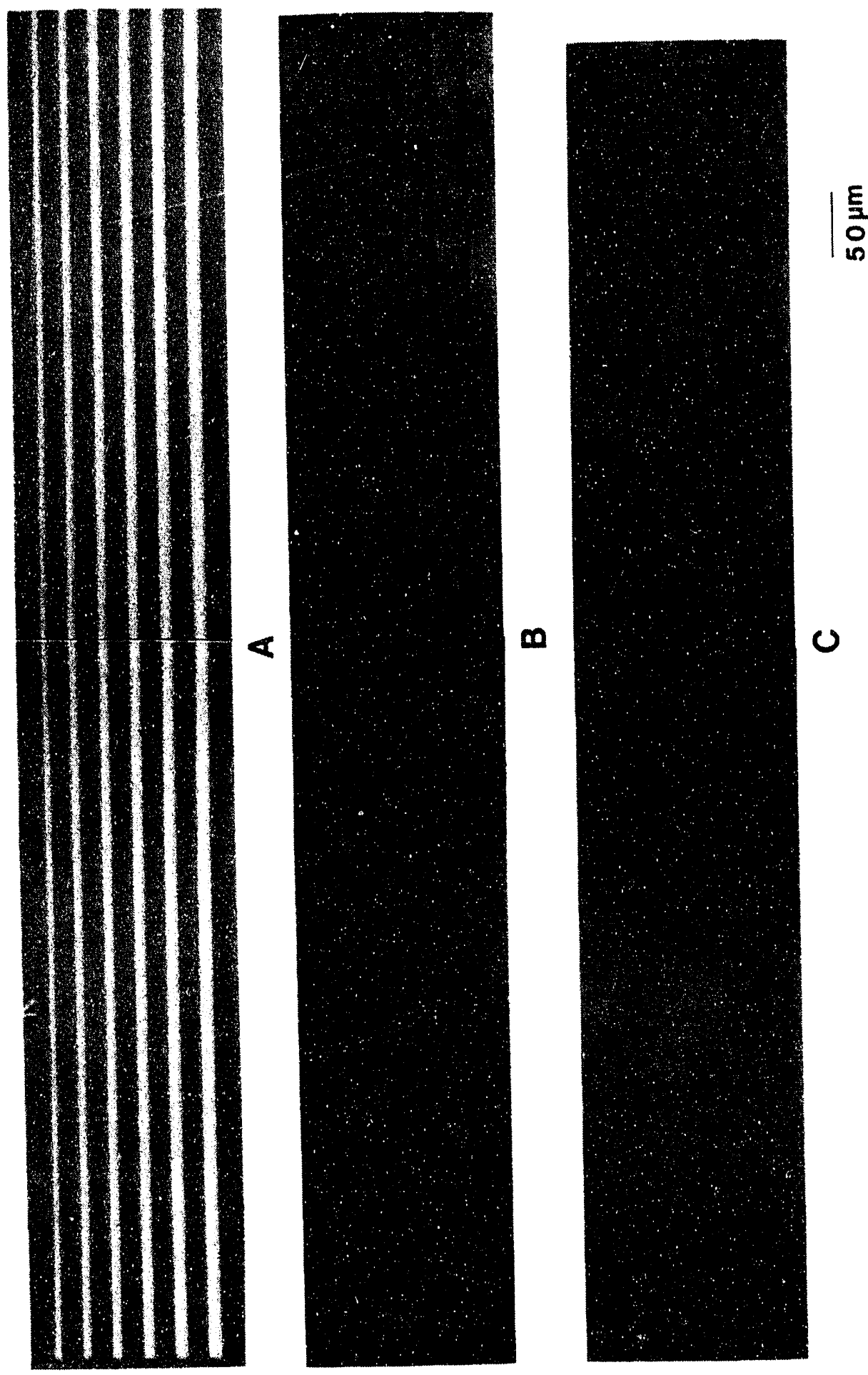

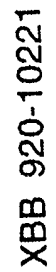

온
온
윤 
102
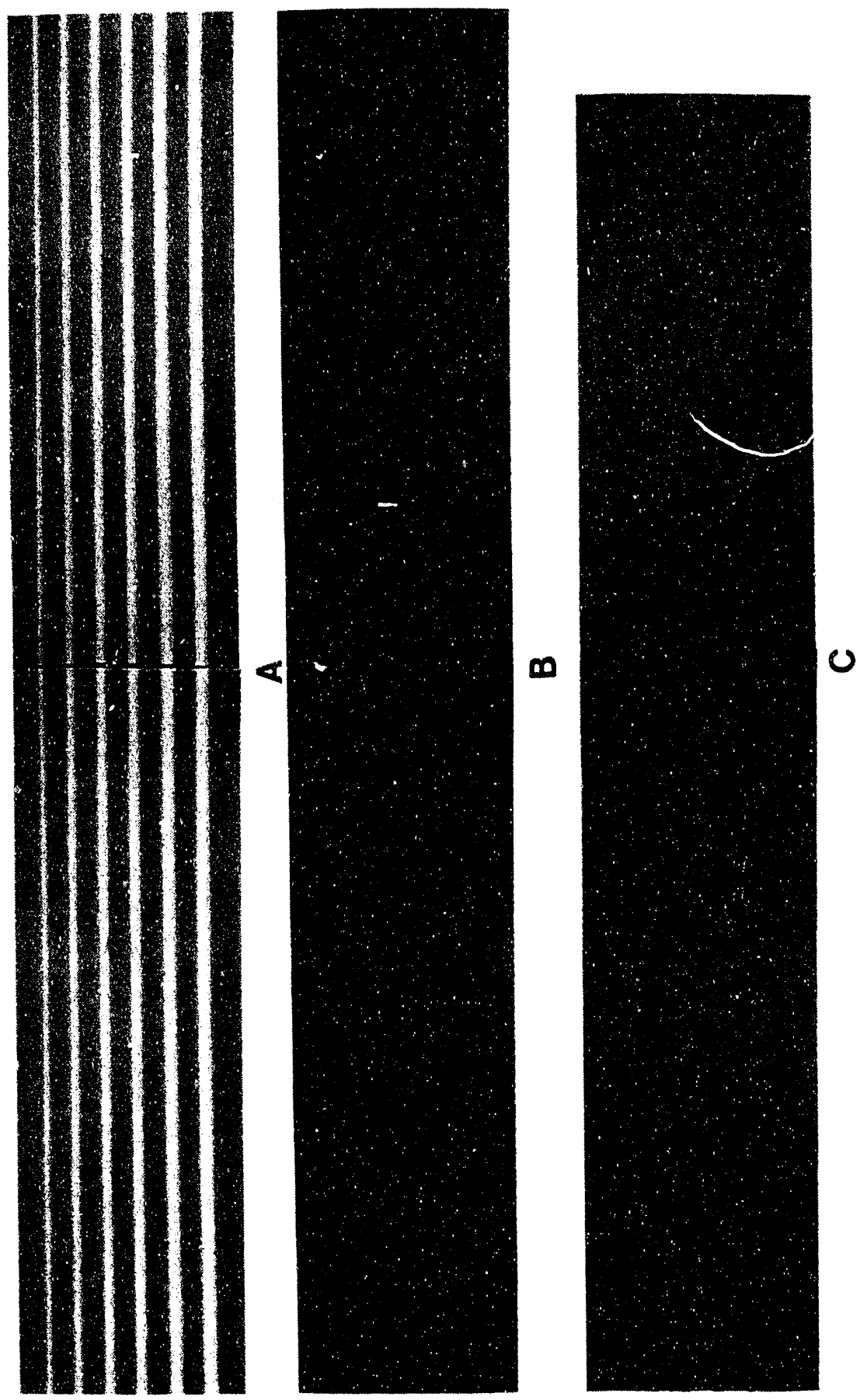

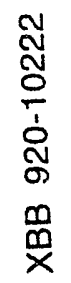

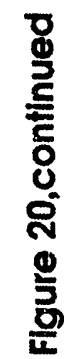




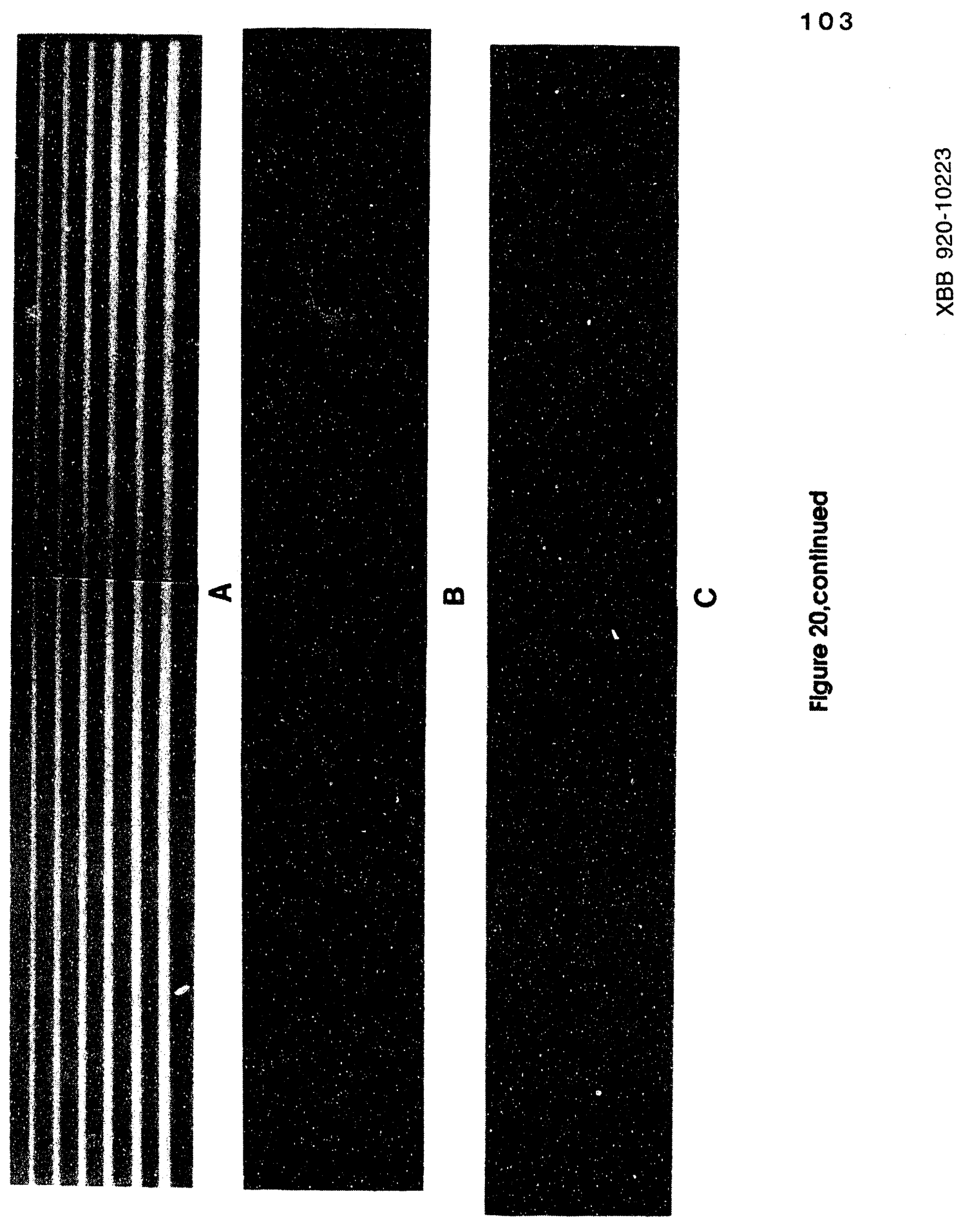




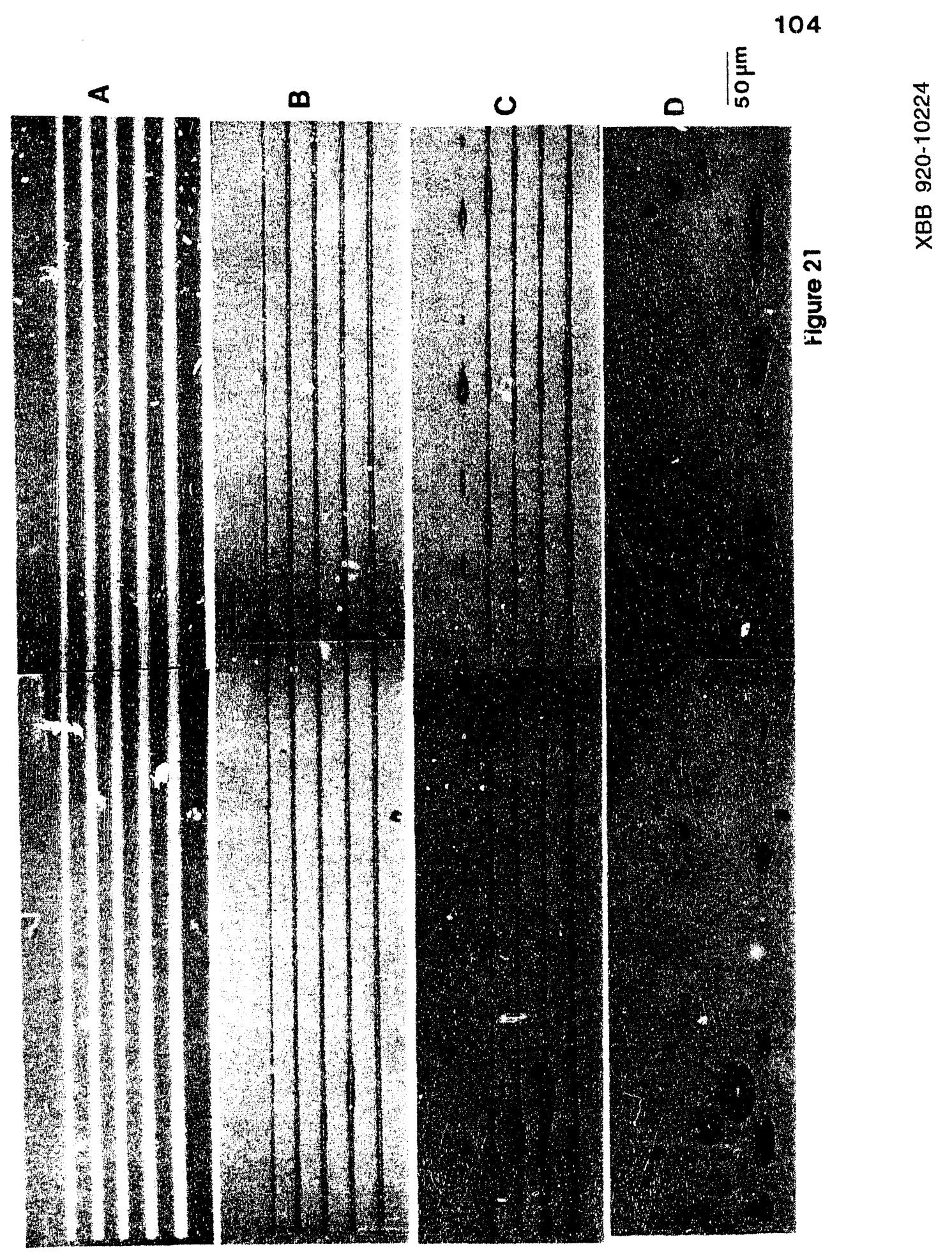


105

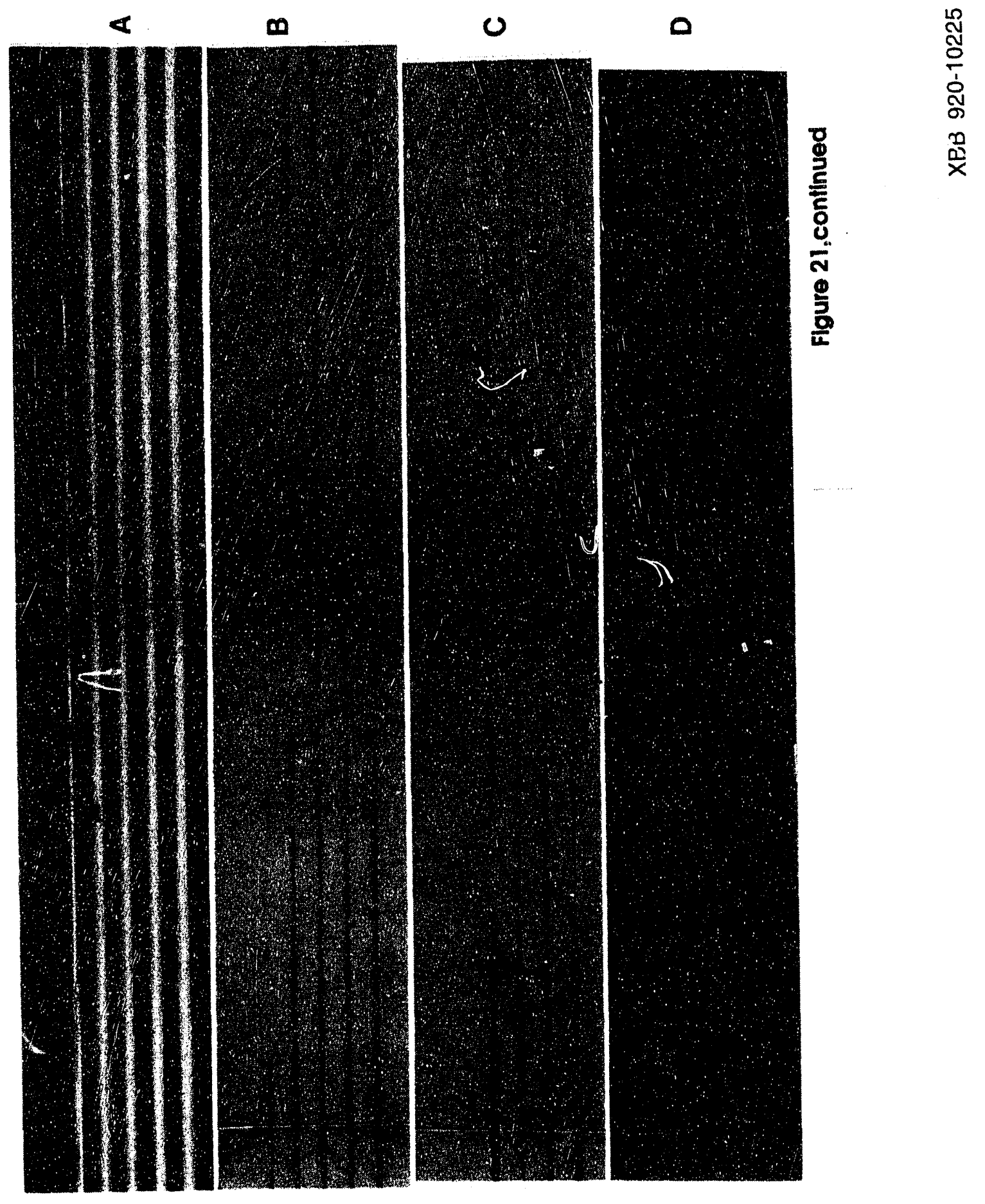


106

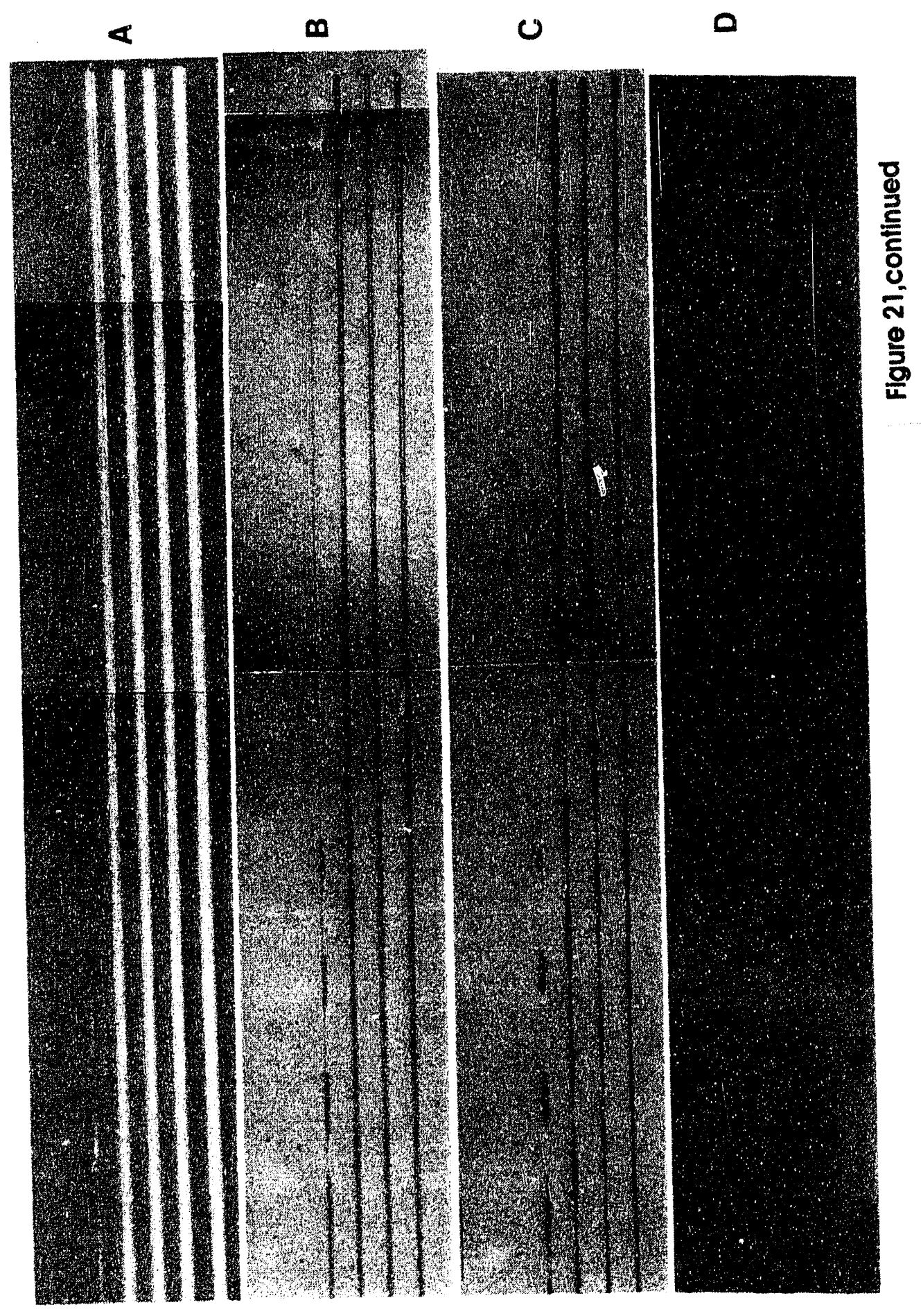

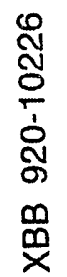




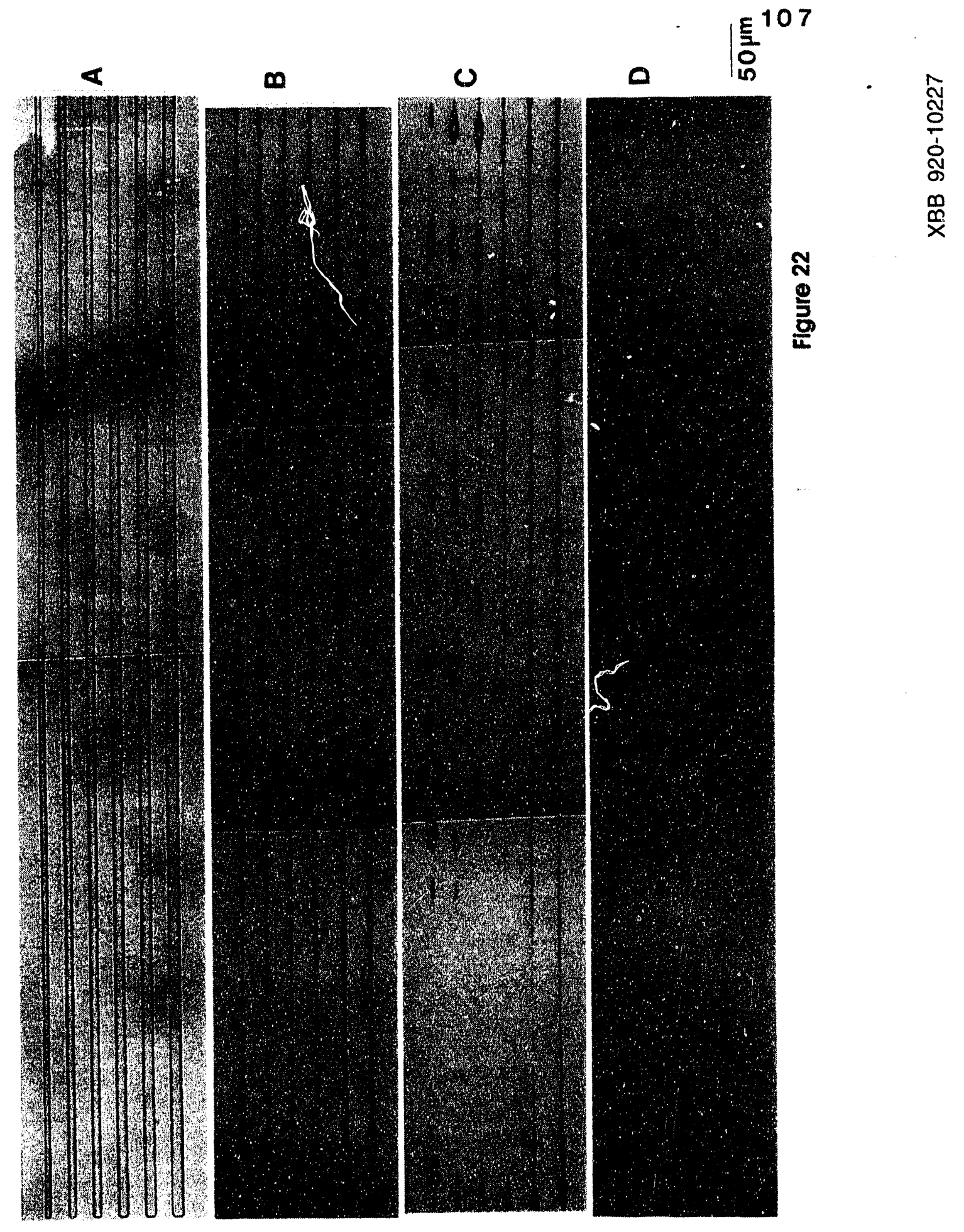


108

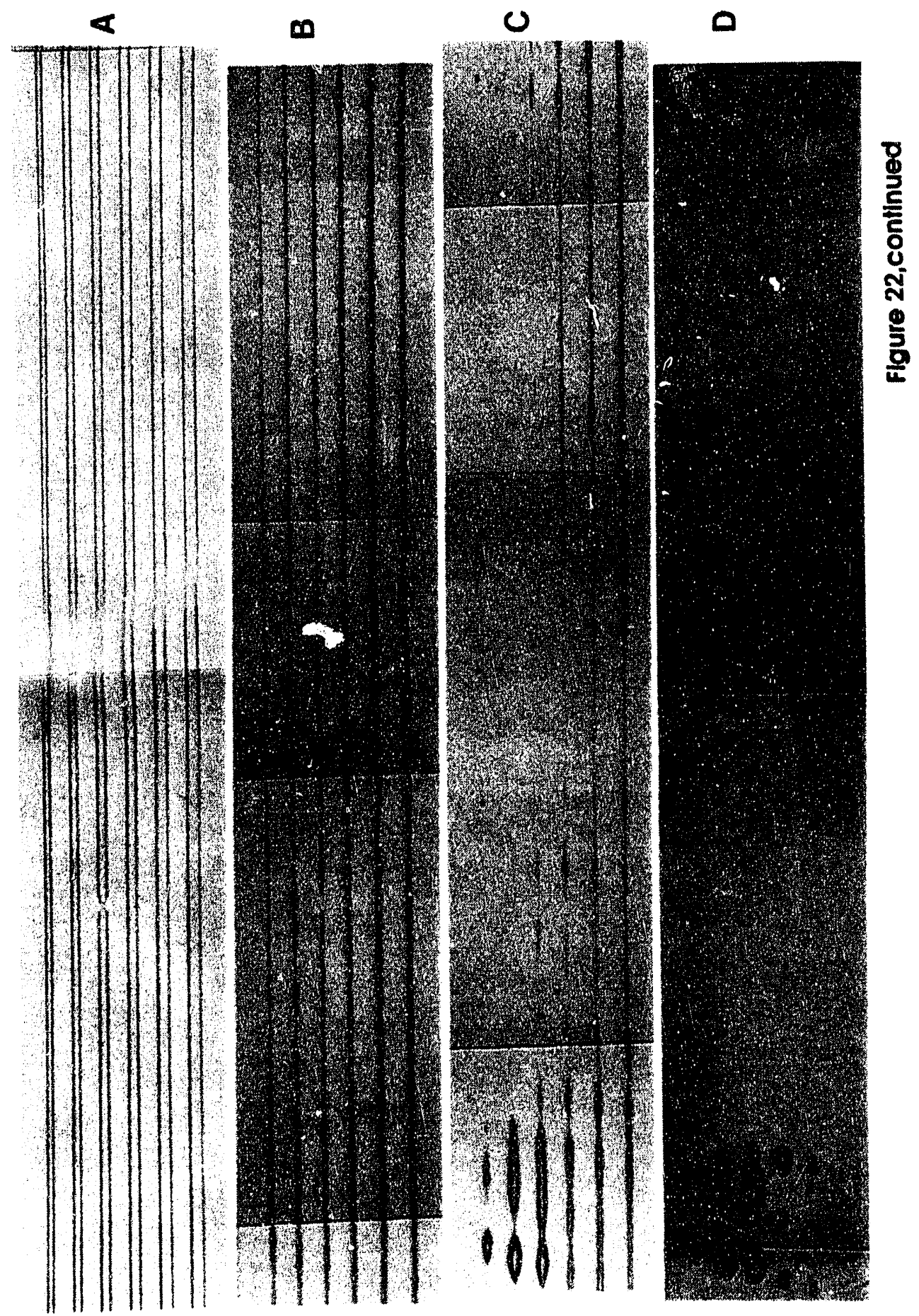

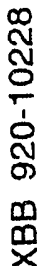


109

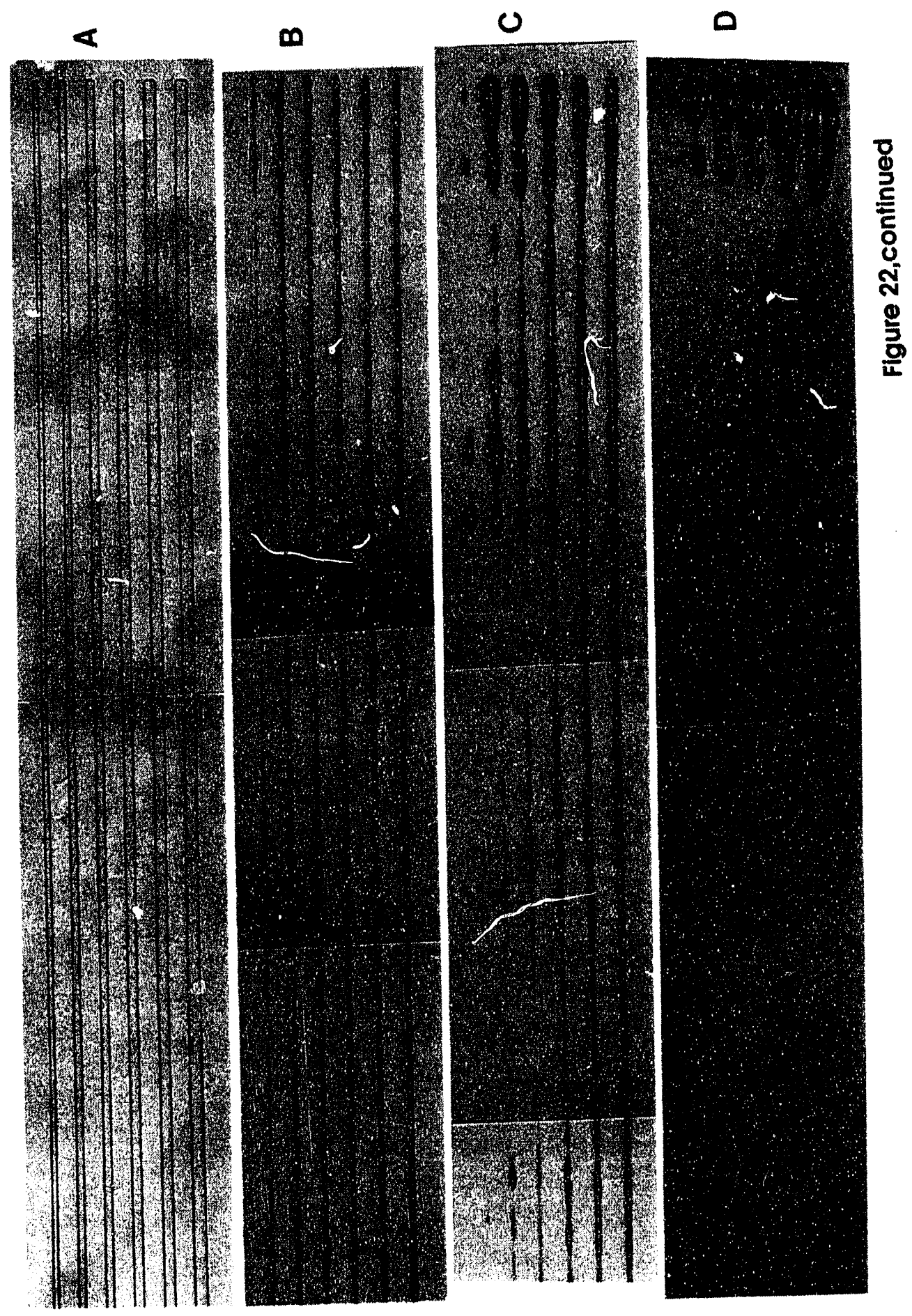

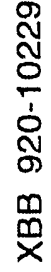



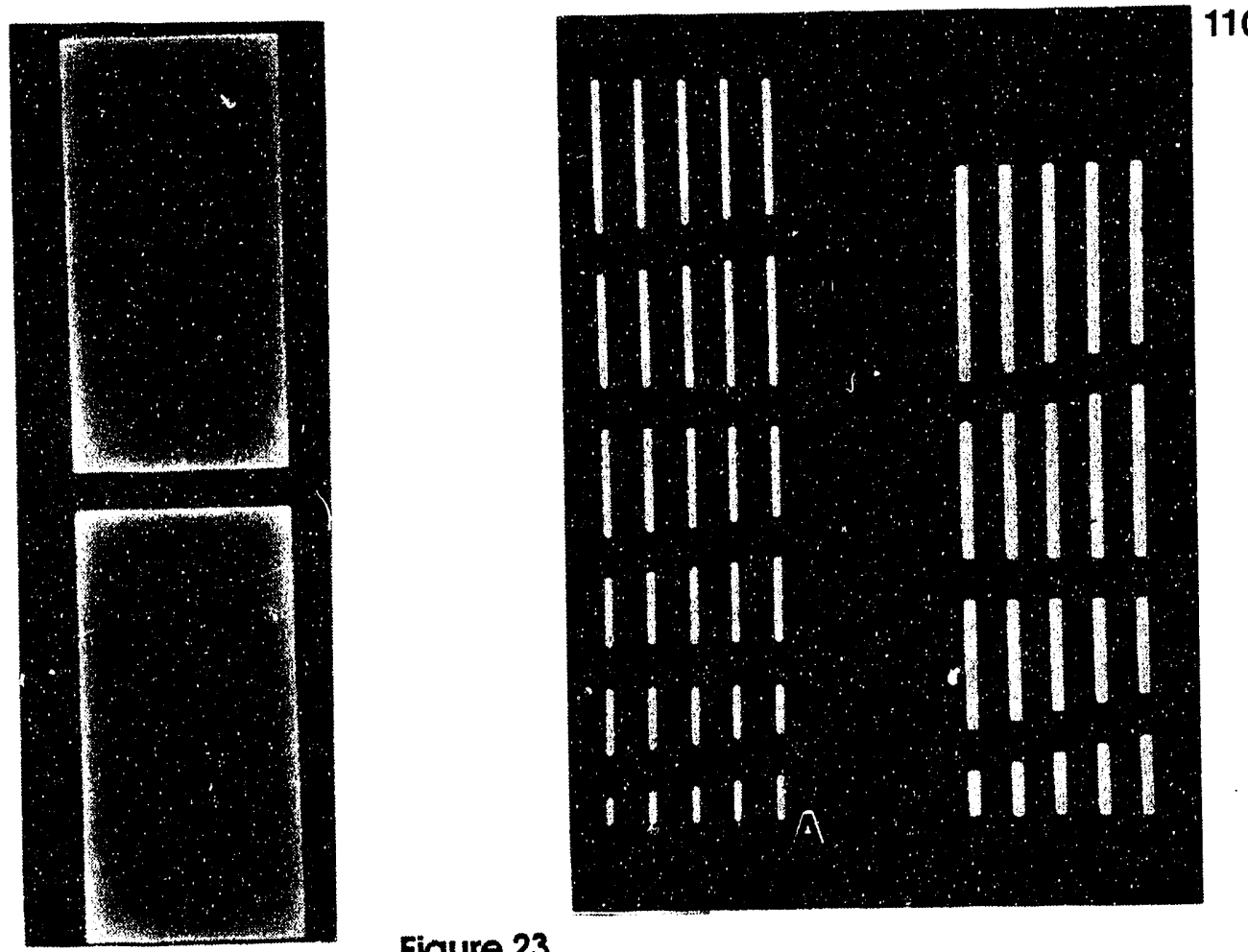

Figure 23
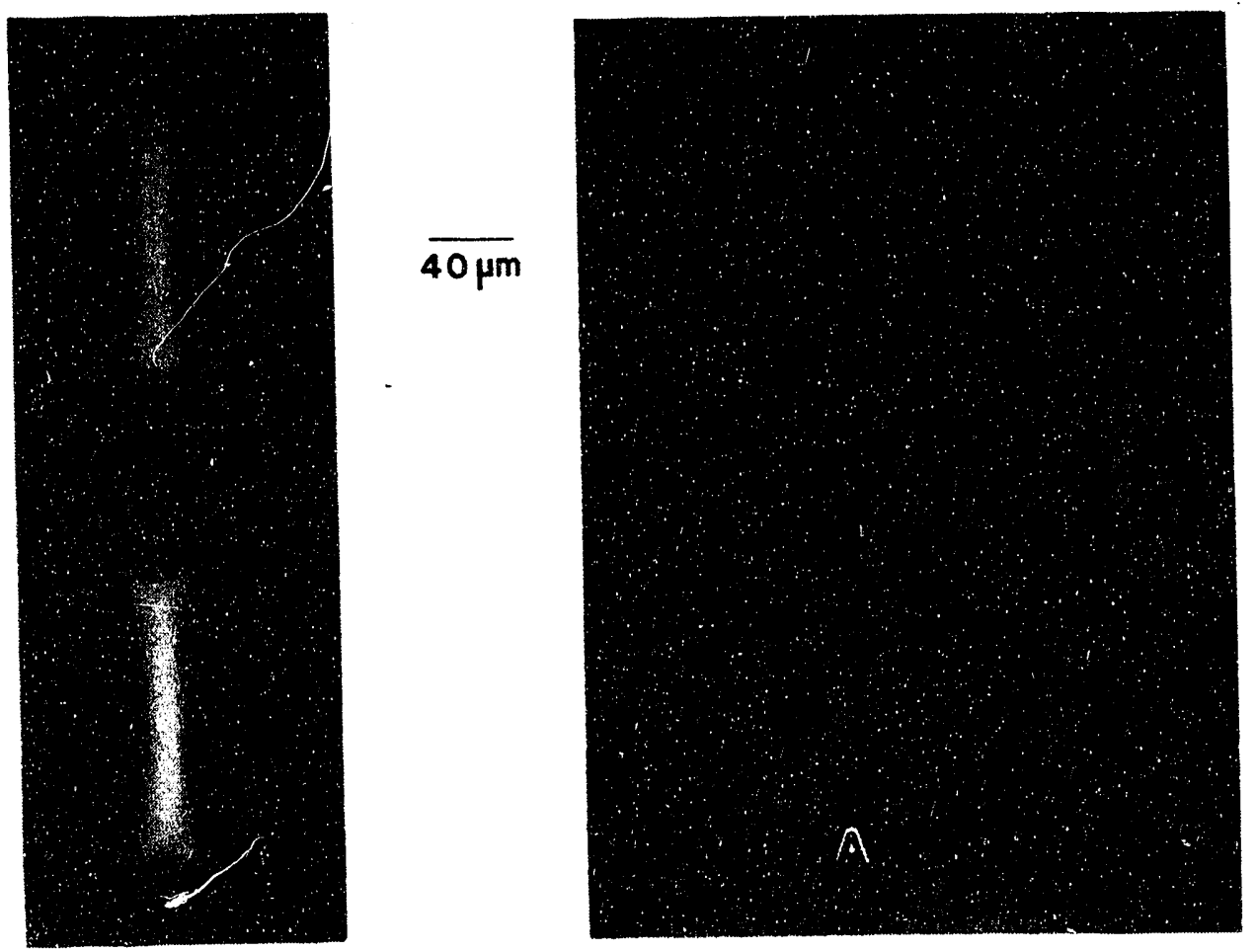

XBB $920-10230$ 


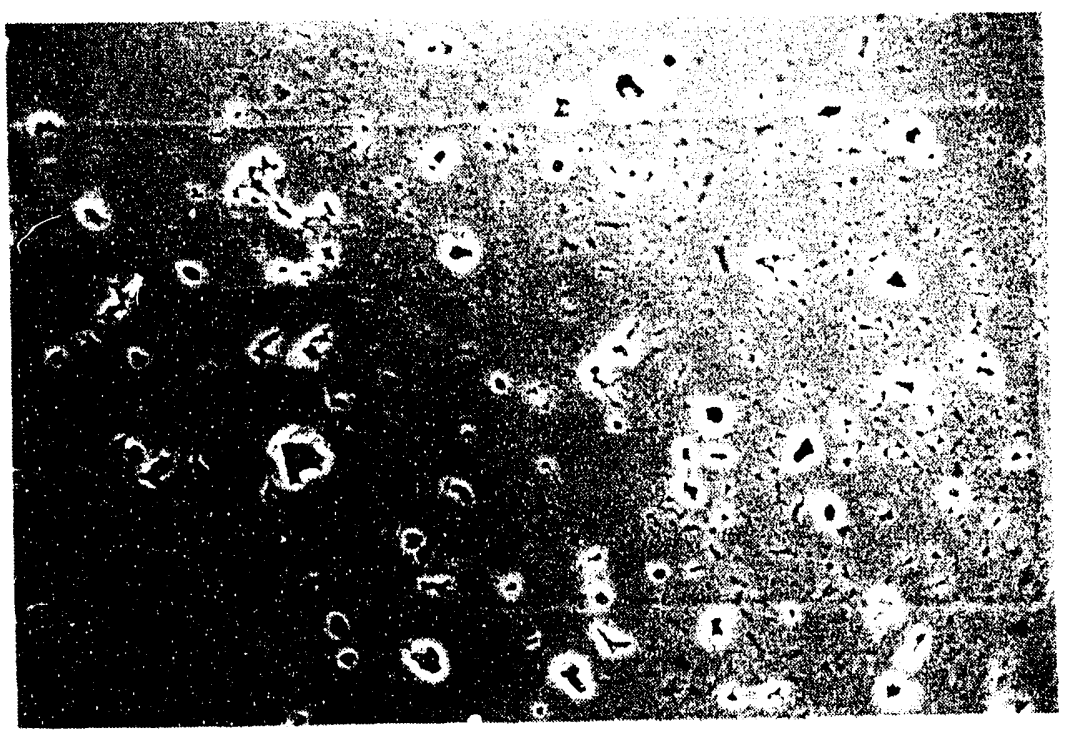

$40 \mu \mathrm{m}$

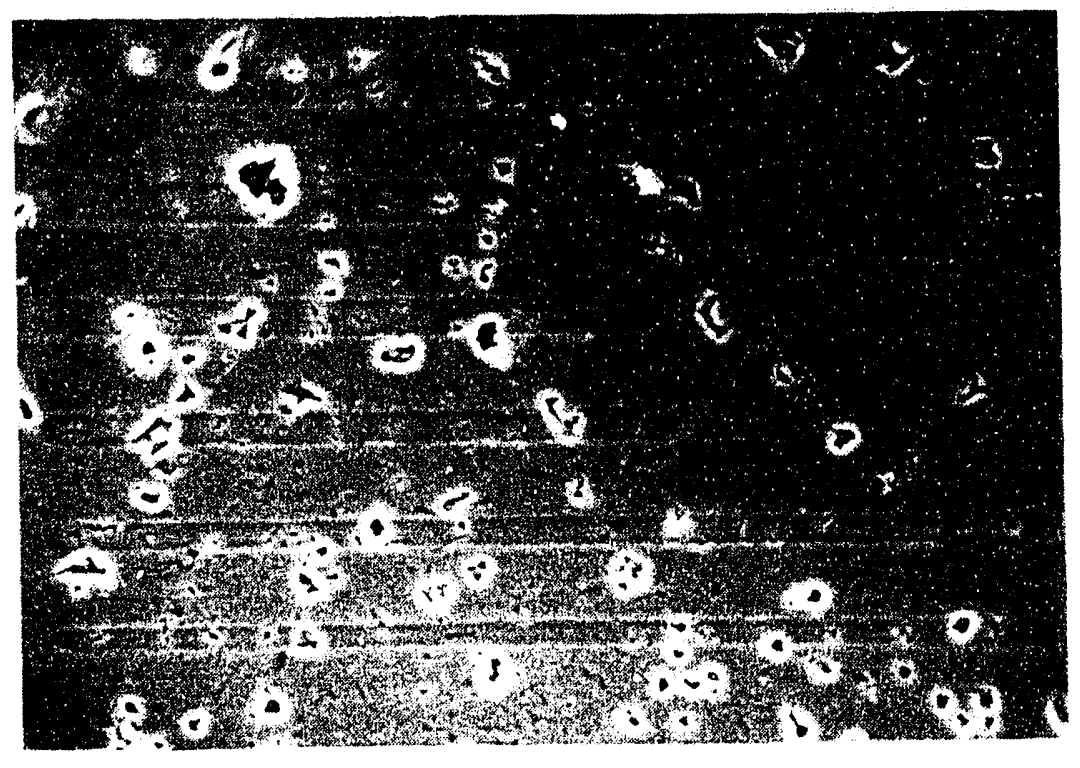

Figure 24

XBB 920-10231 


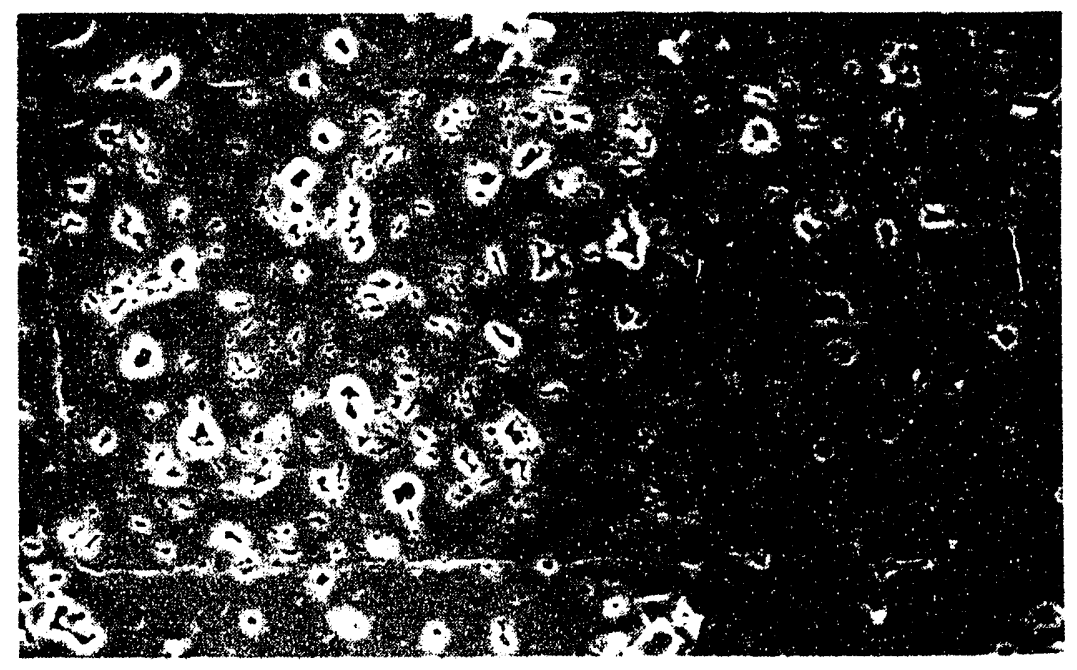

$\overline{40 \mu m}$

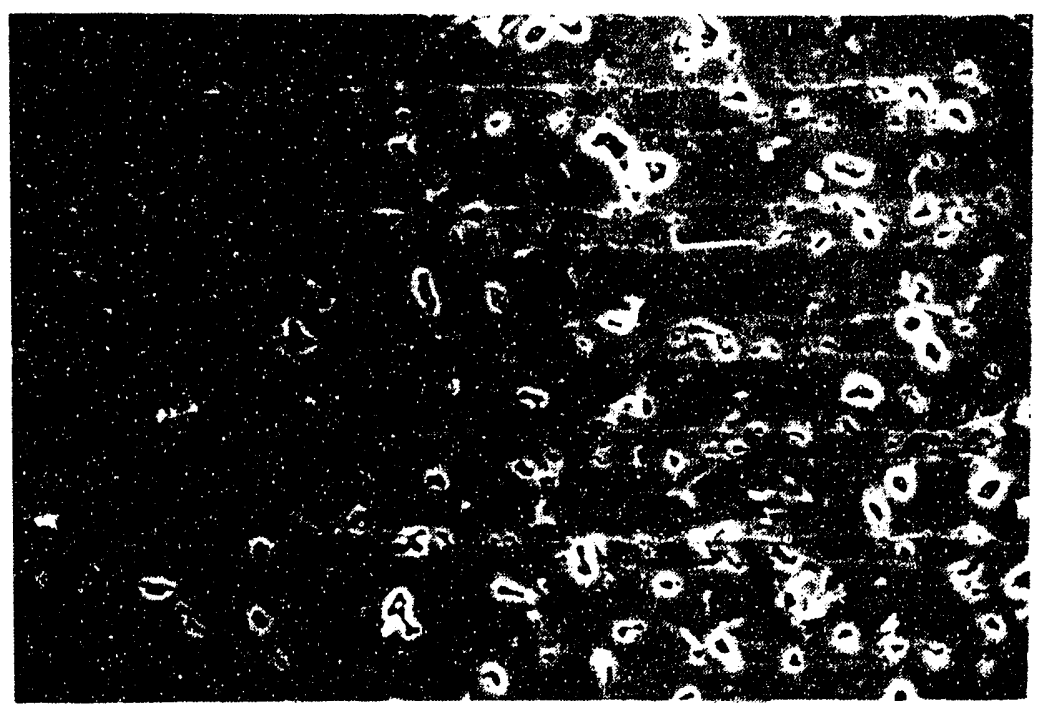

Figure 25

XBB 920-10232 


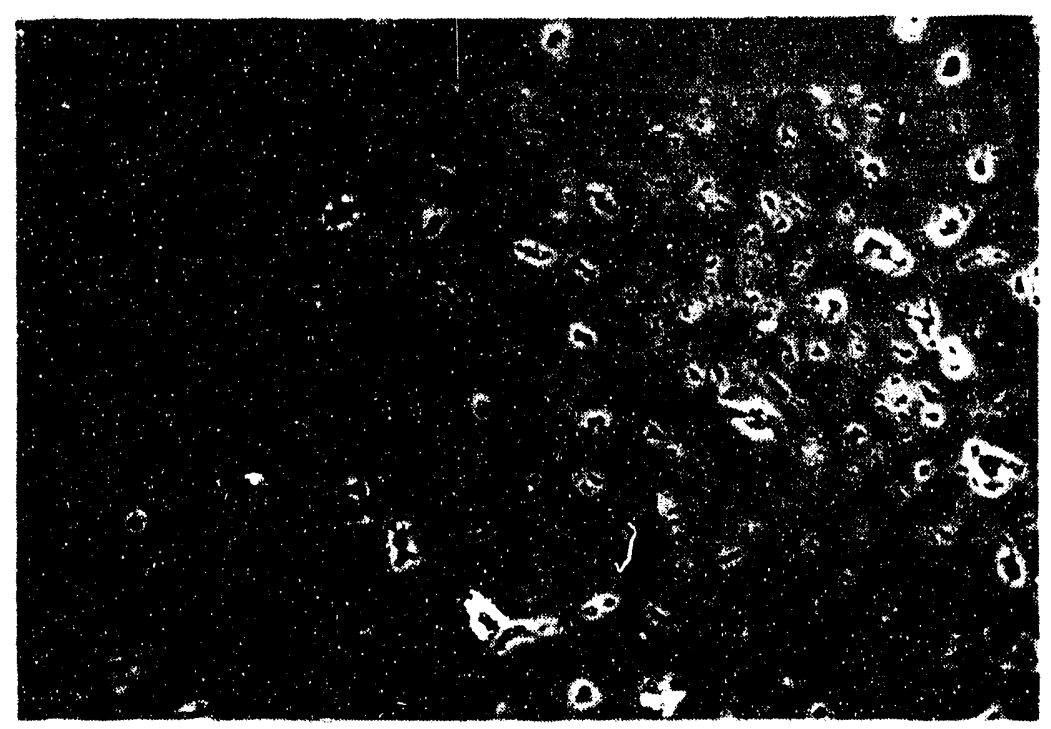

$40 \mathrm{~m}$

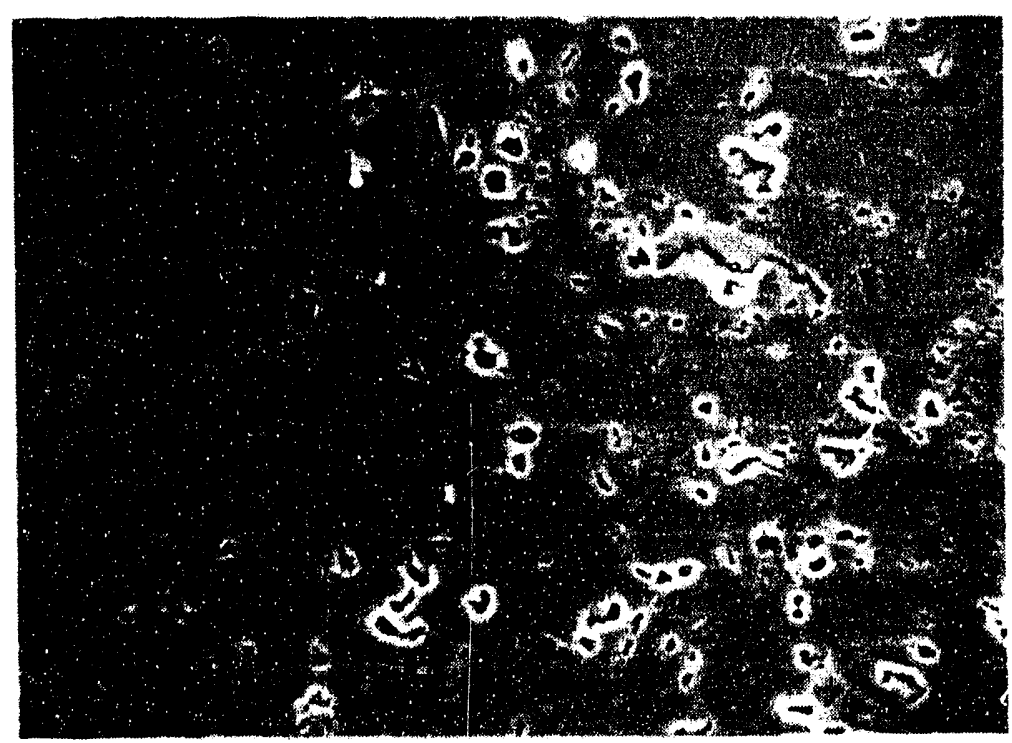

Figure 26

XBB $920-10233$ 

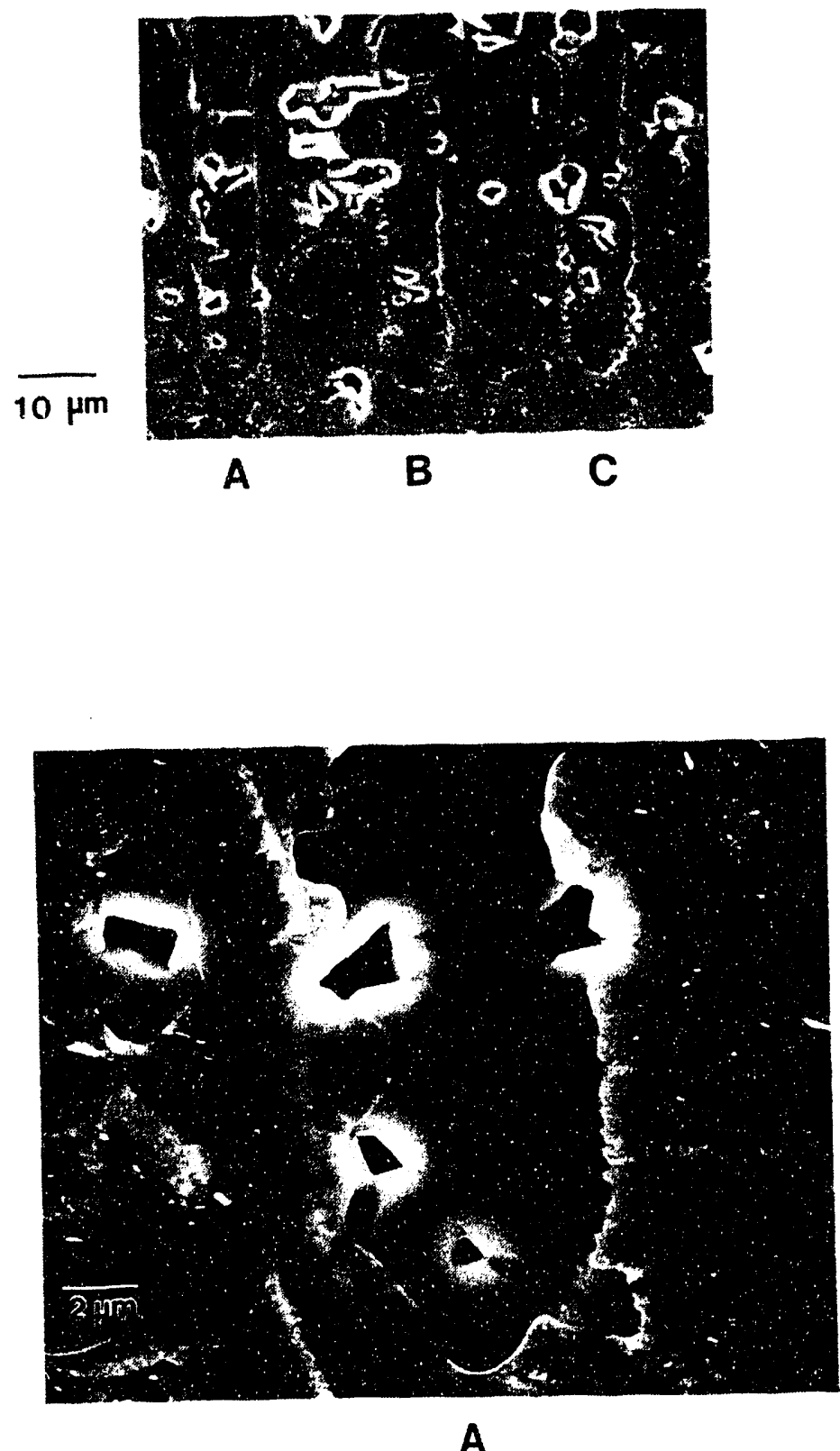

Figure 27

XBB 920-10234 


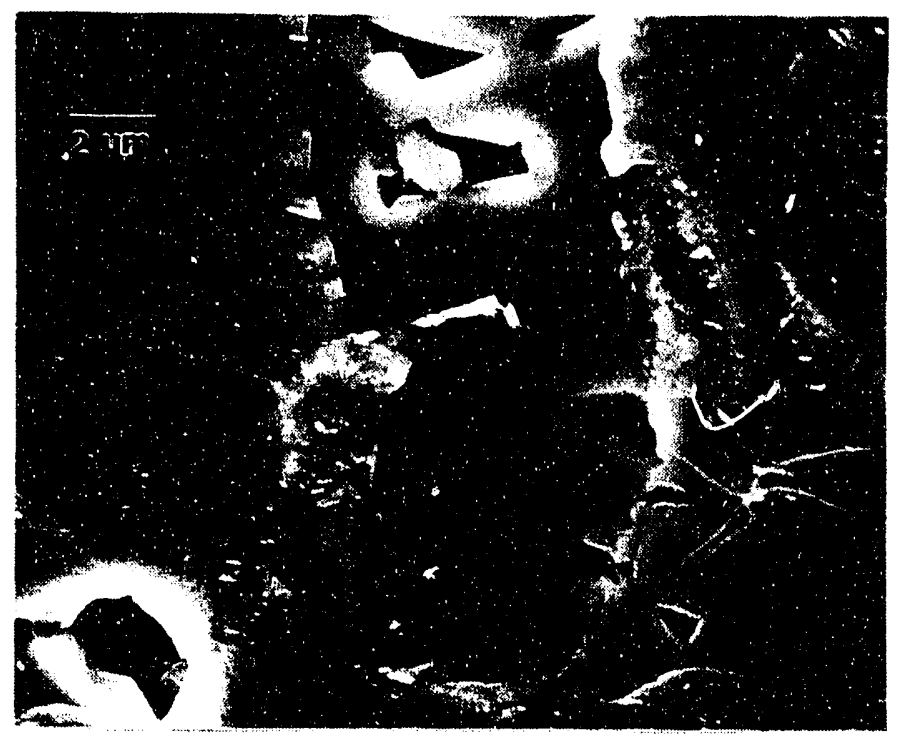

B

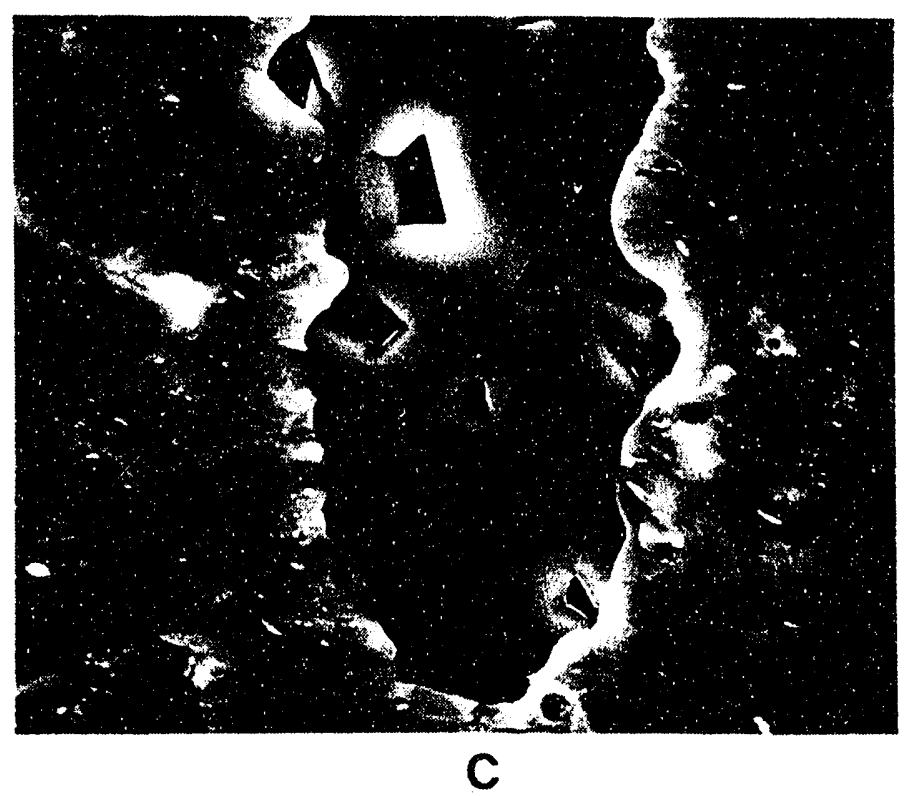

Figure 27 , continued

XBB 920-10235 
116

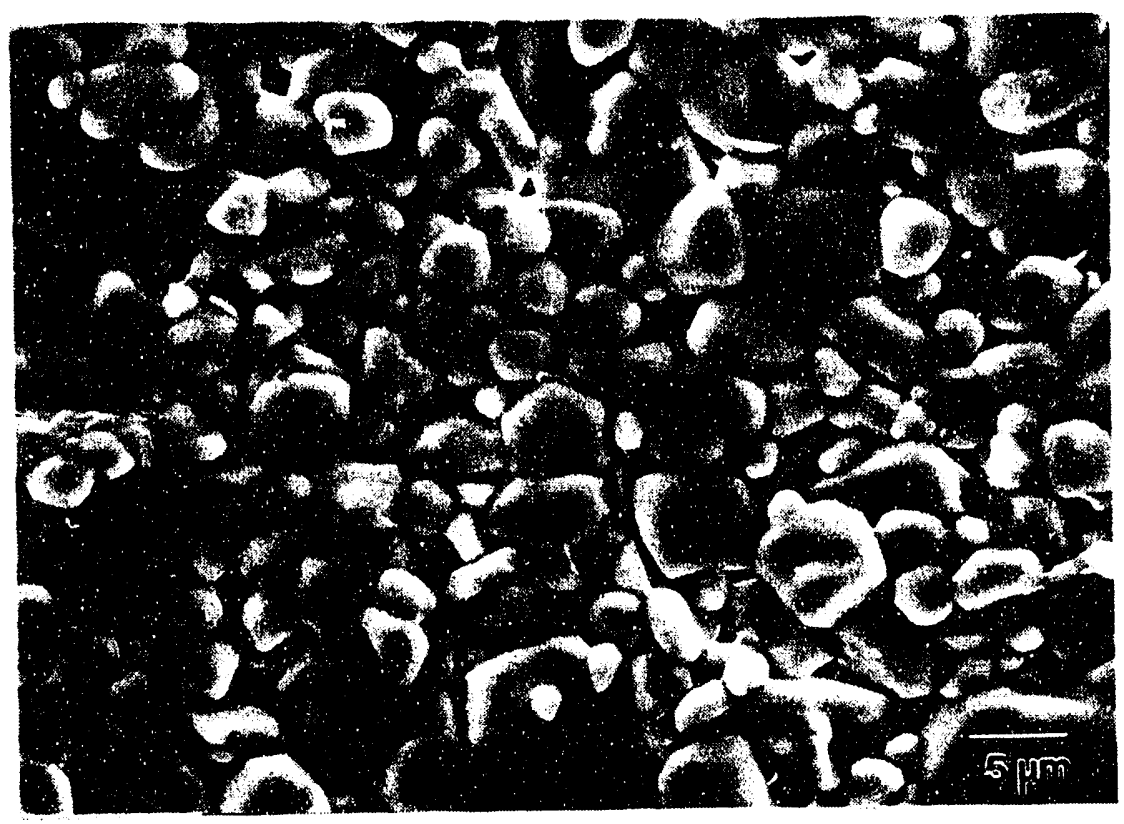

Figure 28

XBB 920-10236 

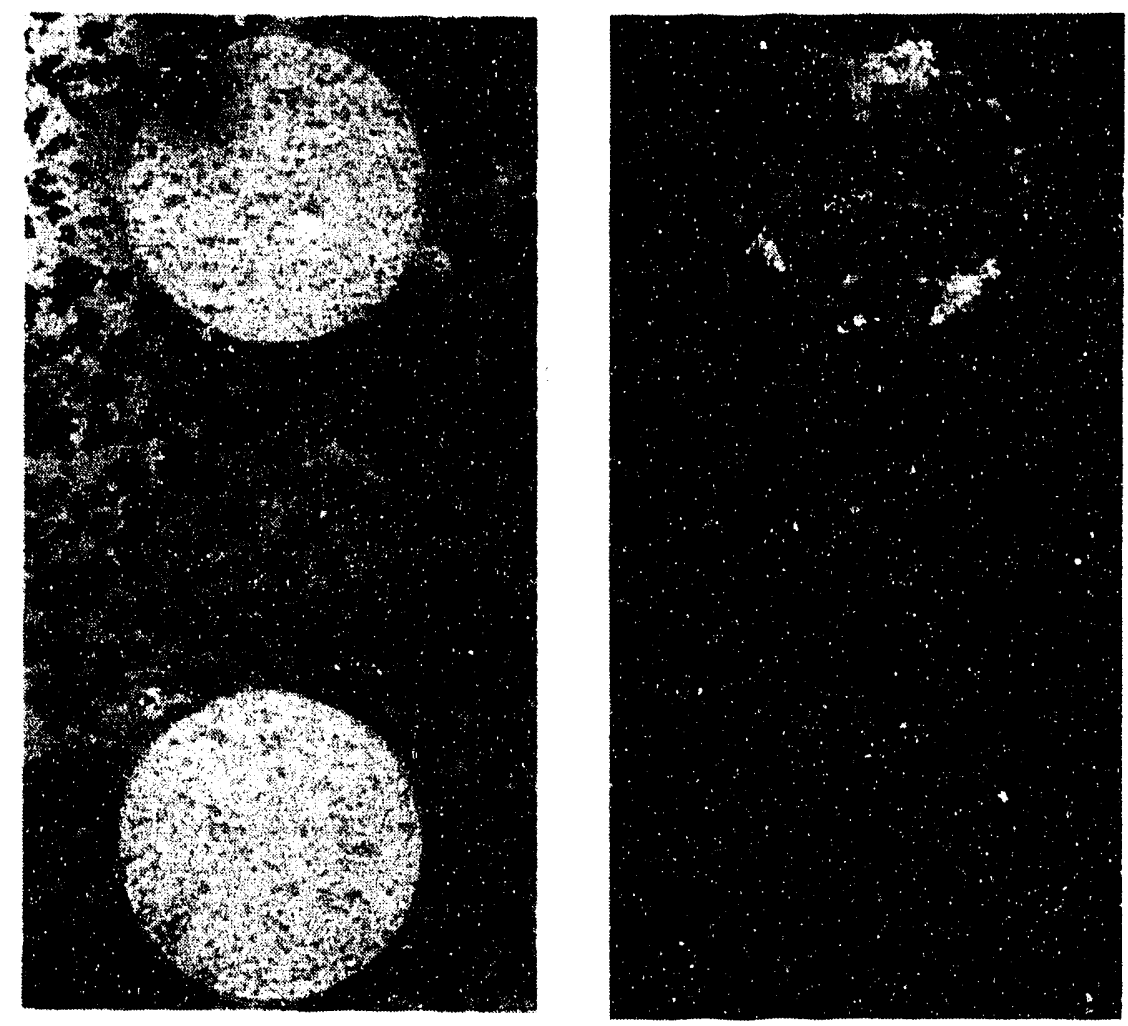

117

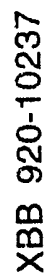

$\alpha$

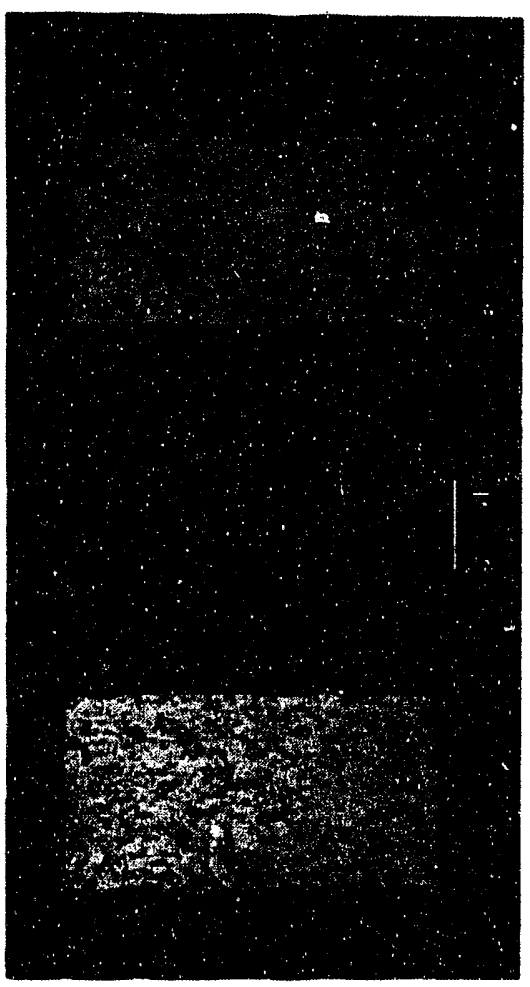

m

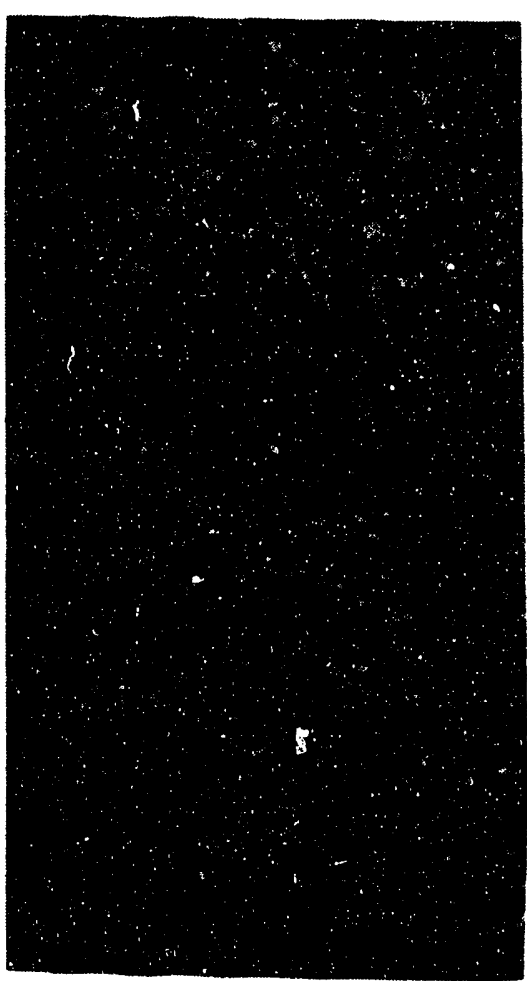

\&

옹 


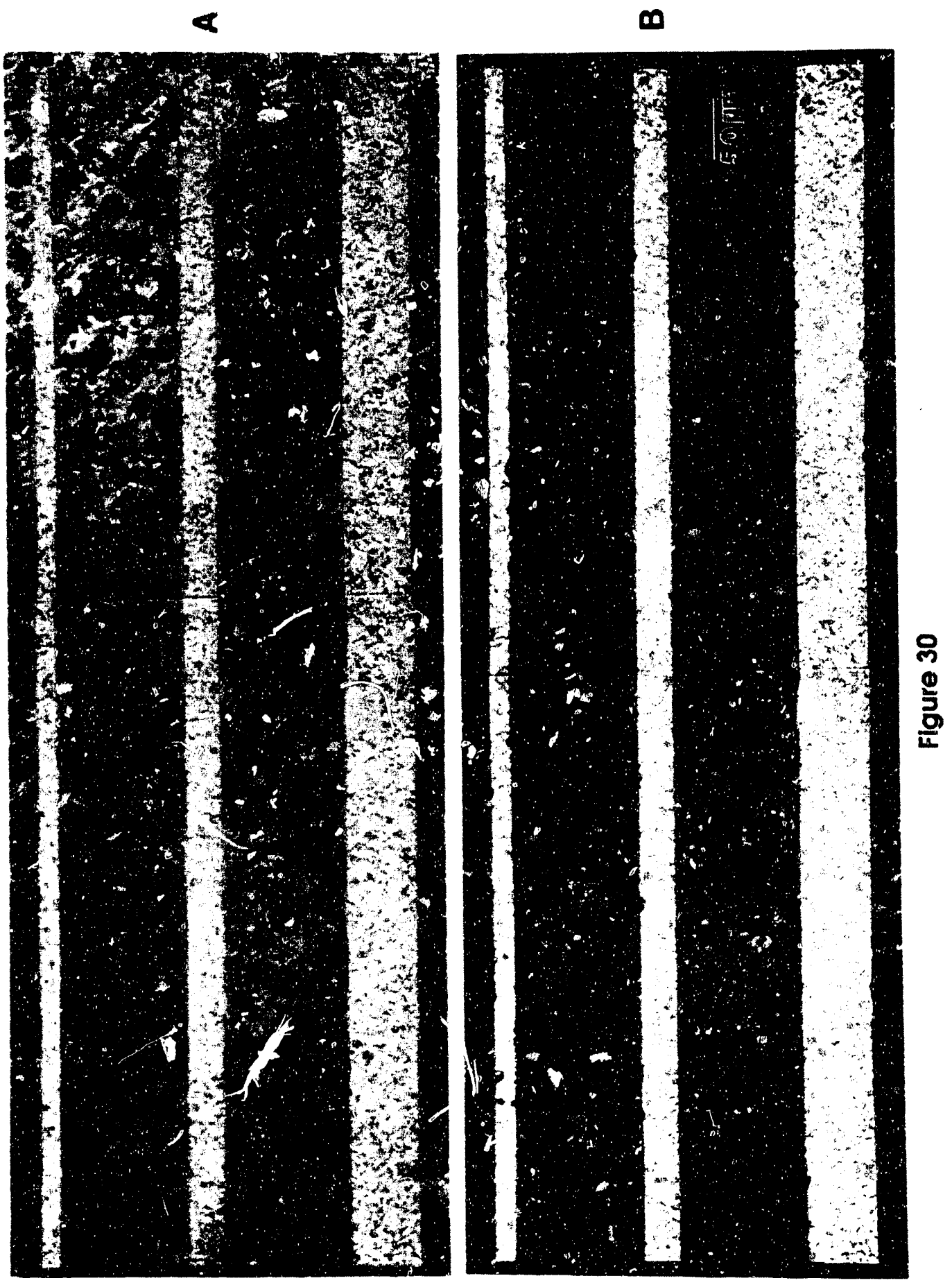

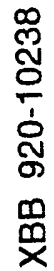



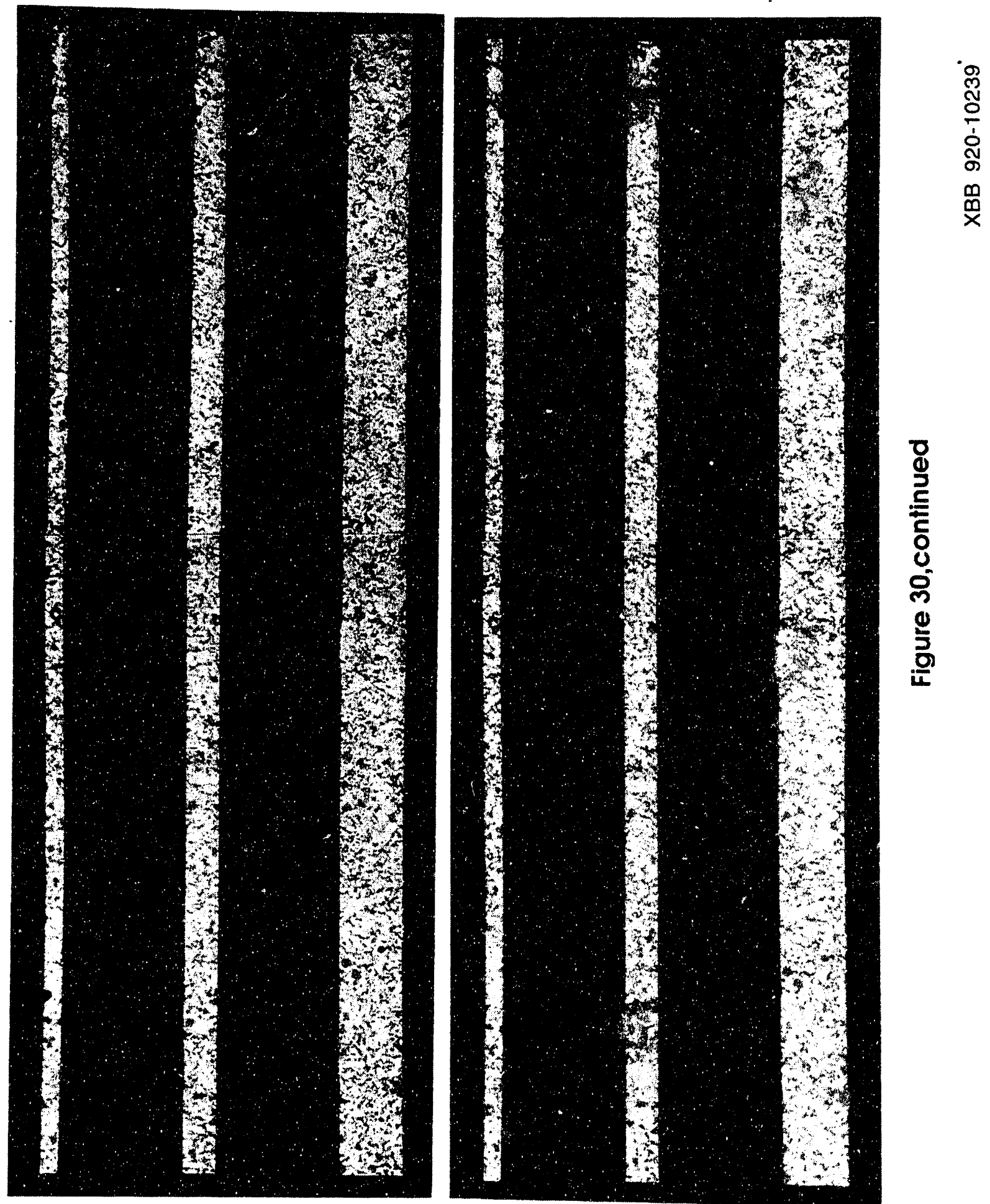

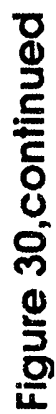

We in


120

ш

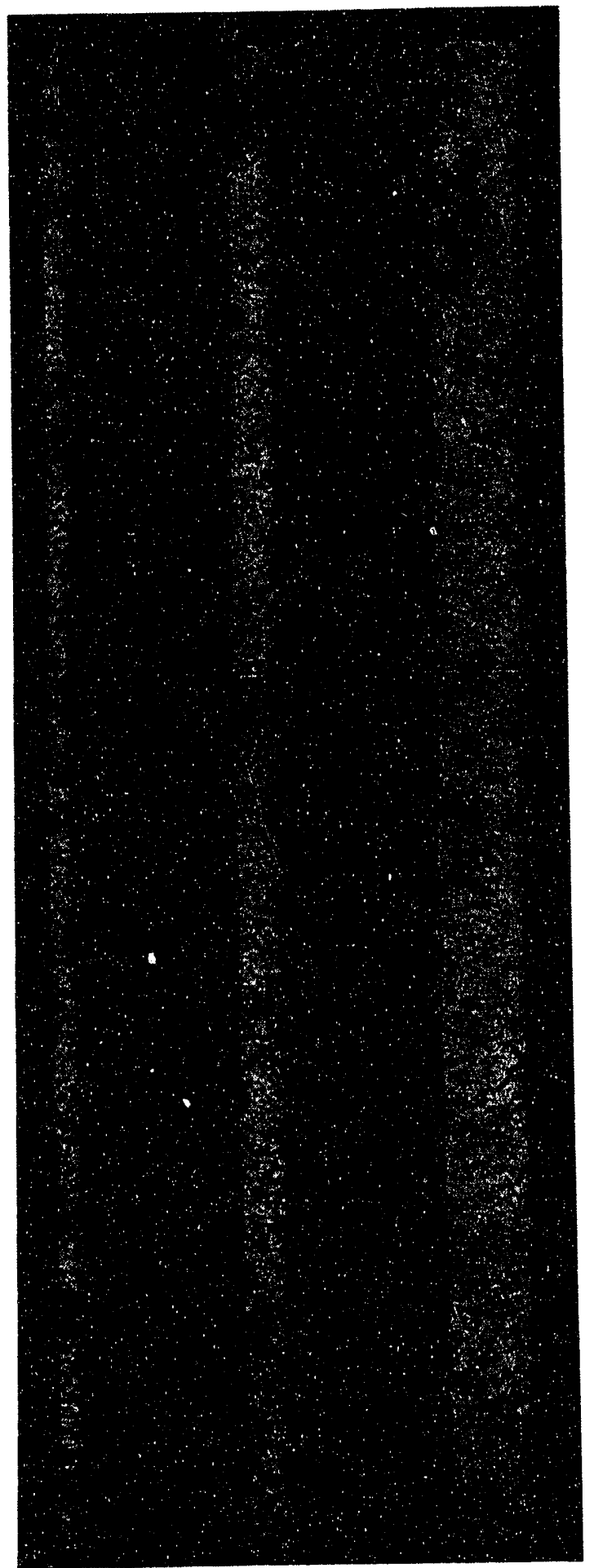

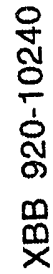

엉 

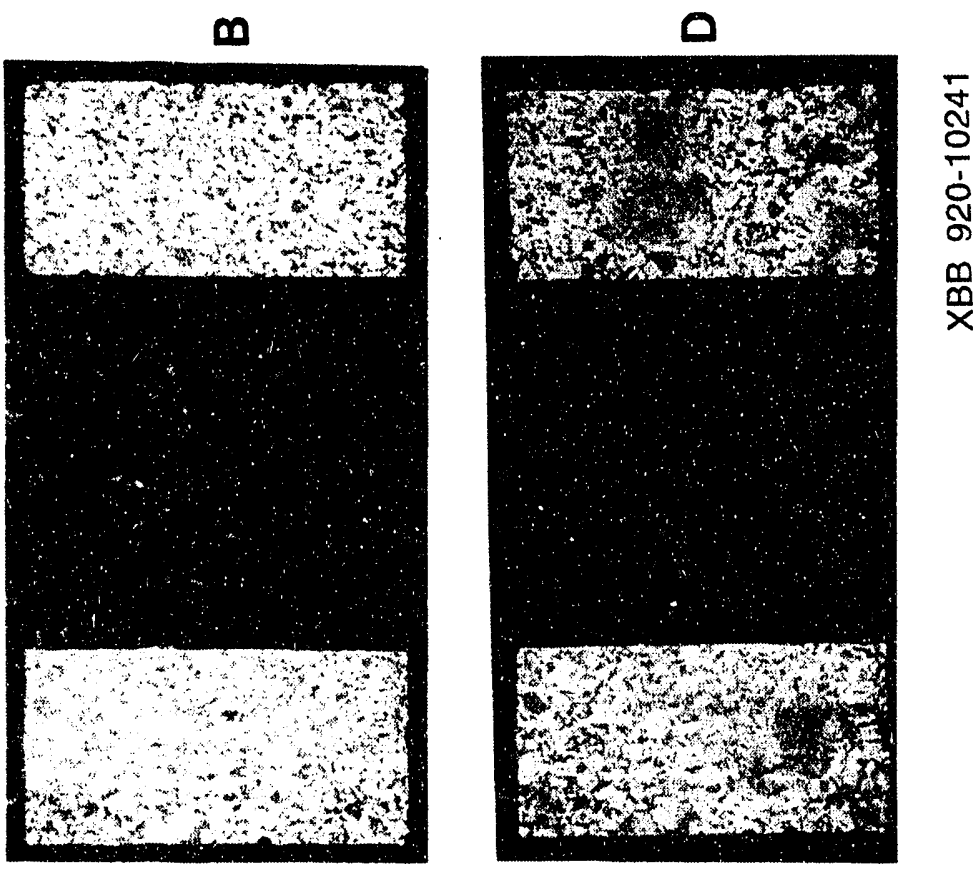

$\bar{m}$
0
$\frac{0}{5}$
$\frac{0}{4}$

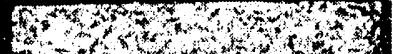

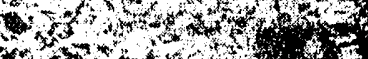
$(4,4,4,4)$

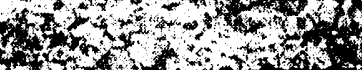

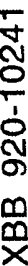

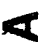

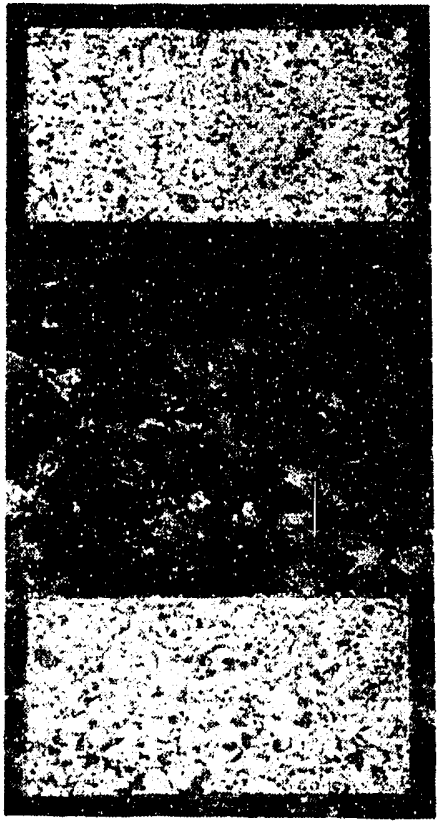

0

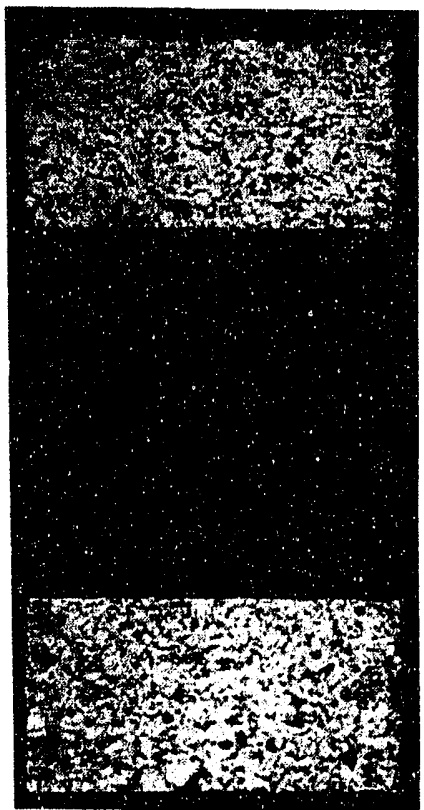

UI

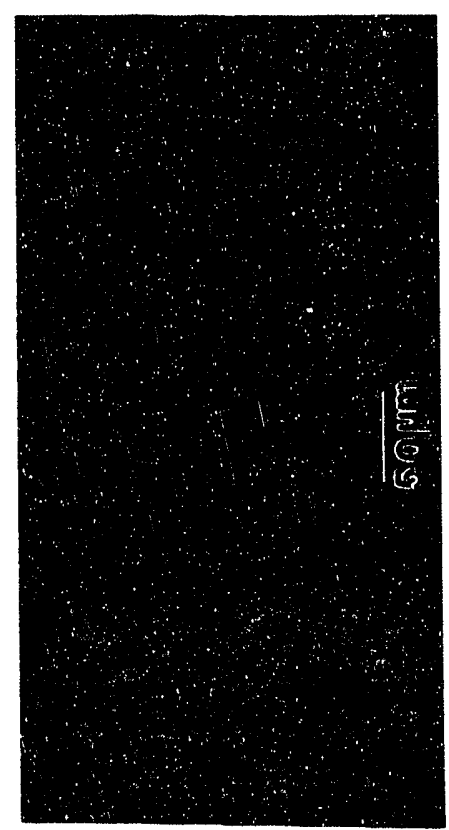



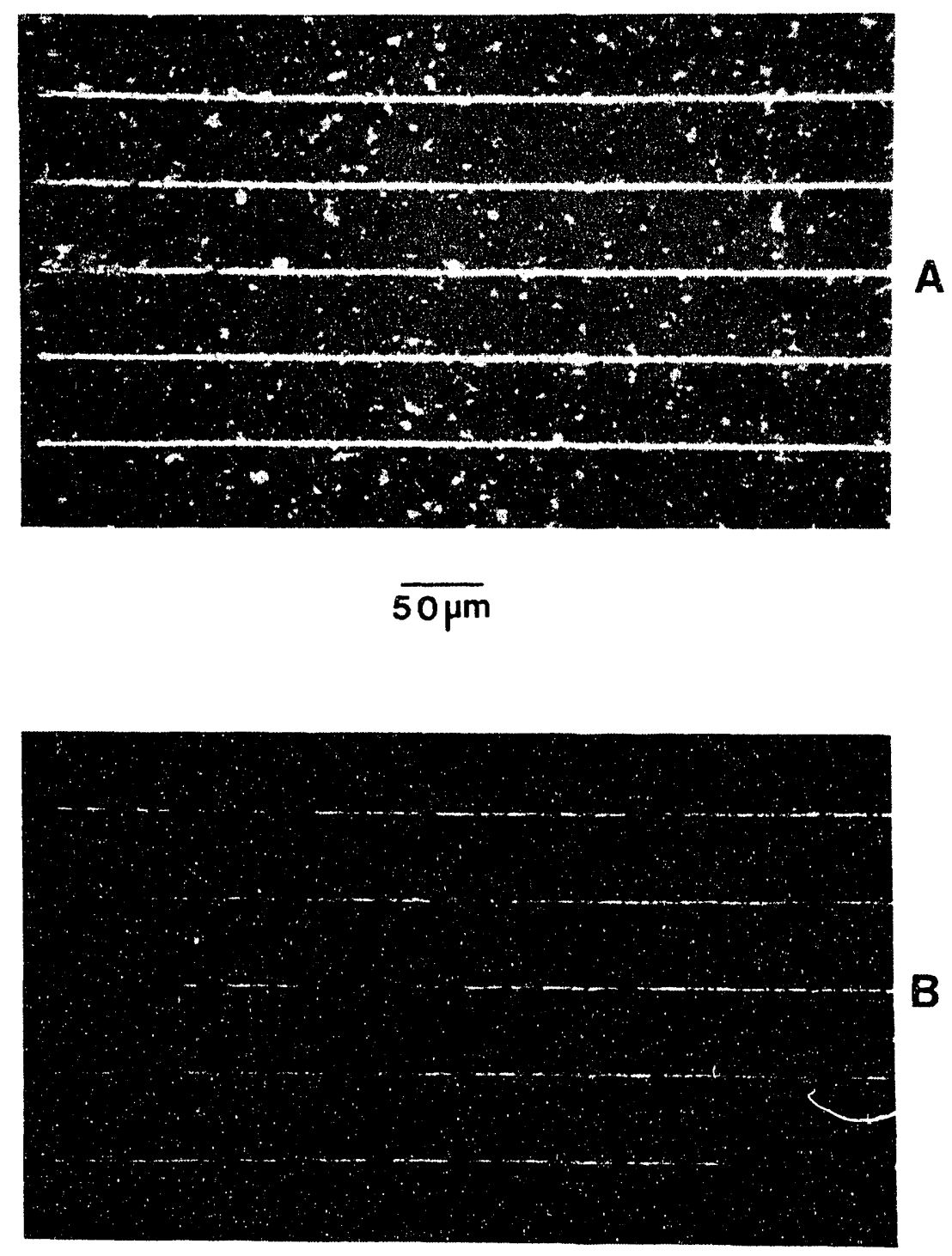

Figure 32

XBB 920-10242 


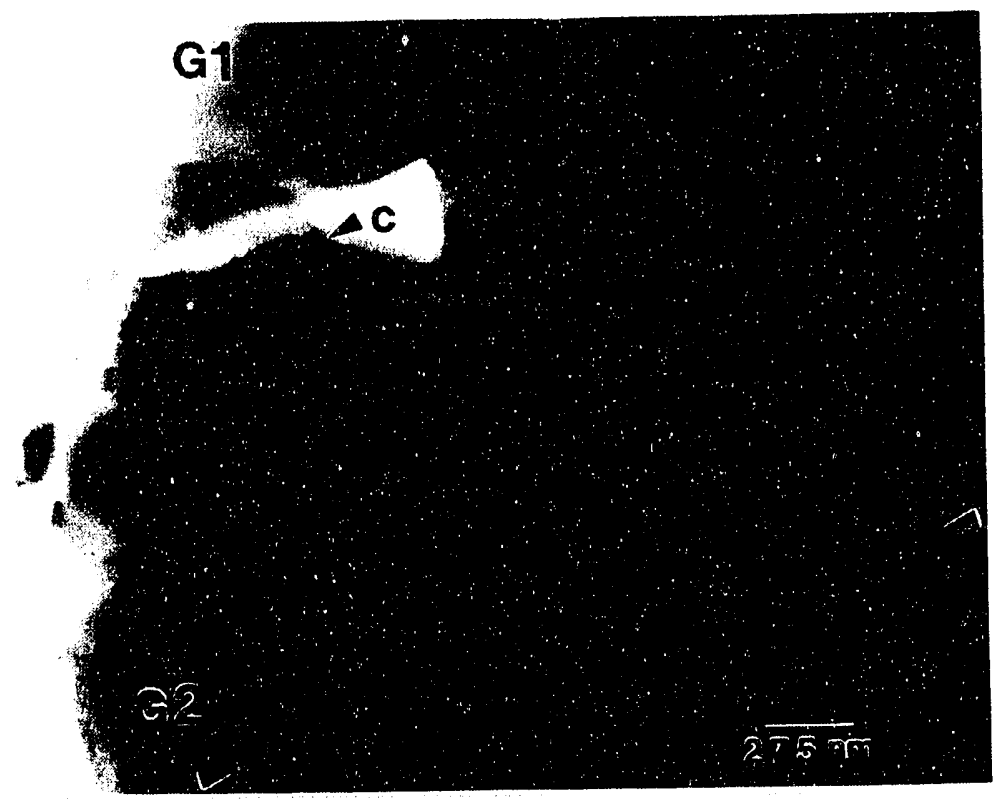

A

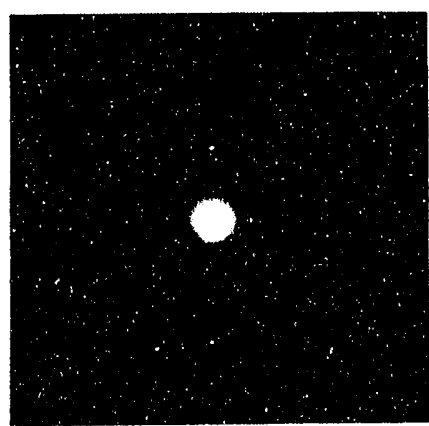

B

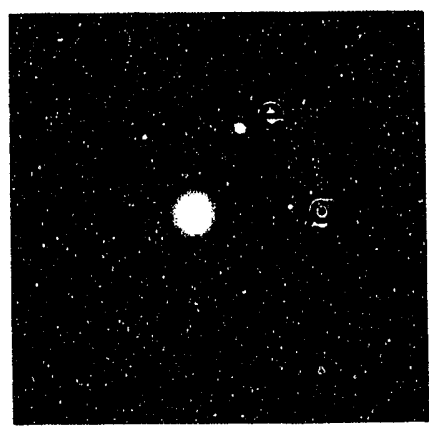

C

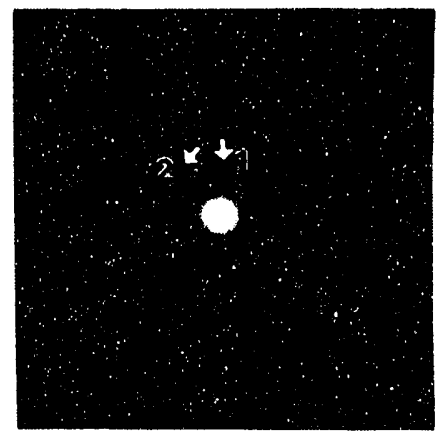

D

Figure 33

XBB 920-10243 


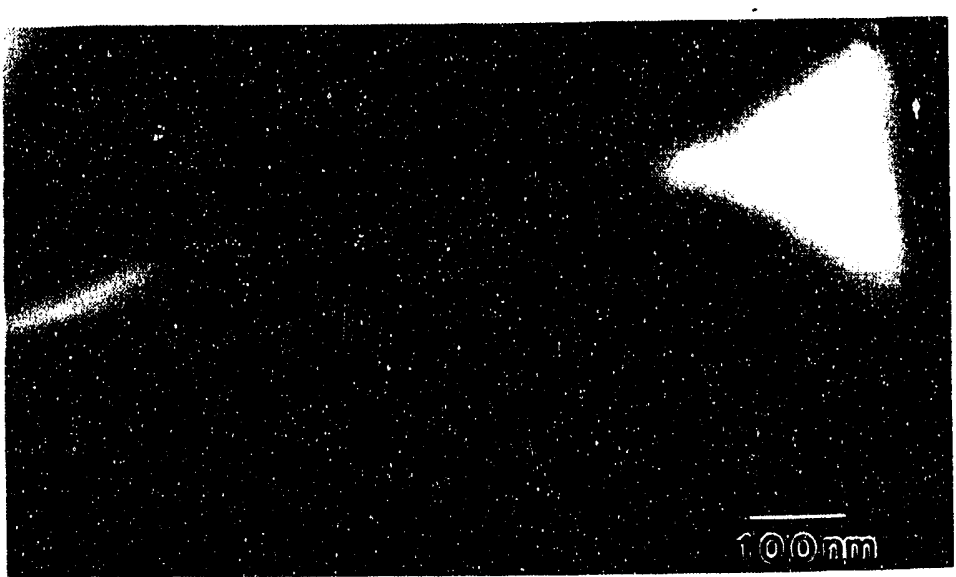

A

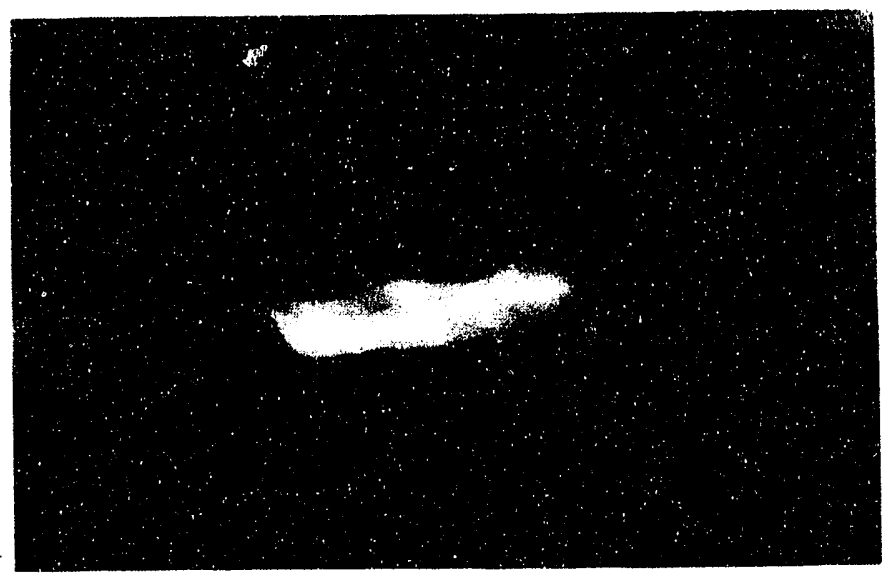

B

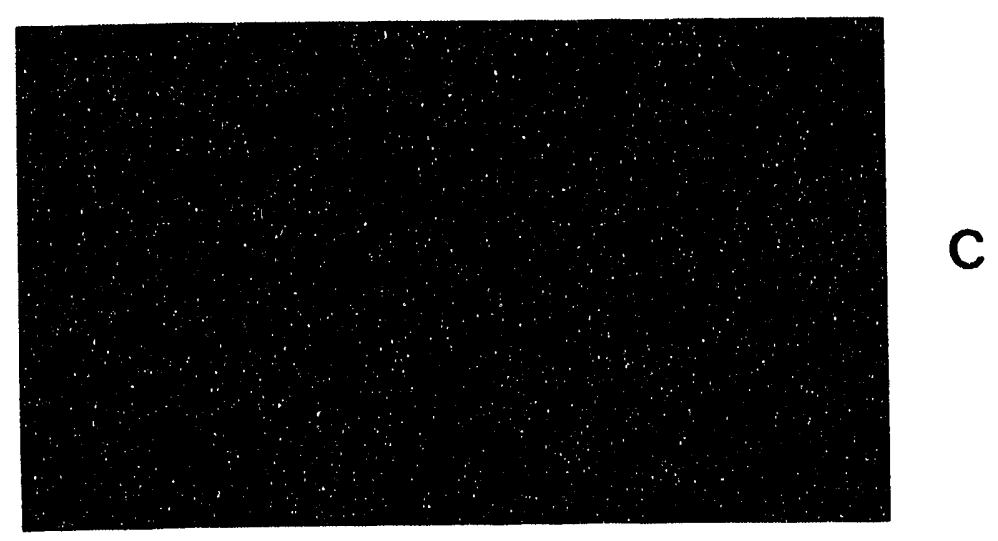

Figure 34

XBB 920-10244 
10
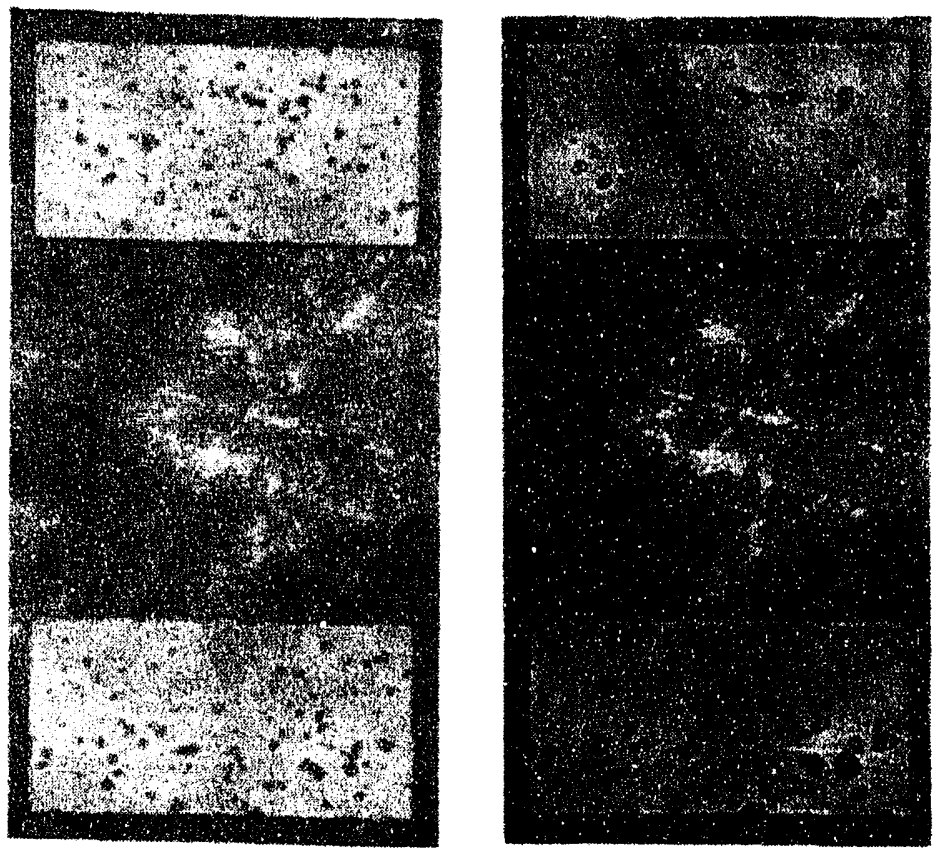

$-$

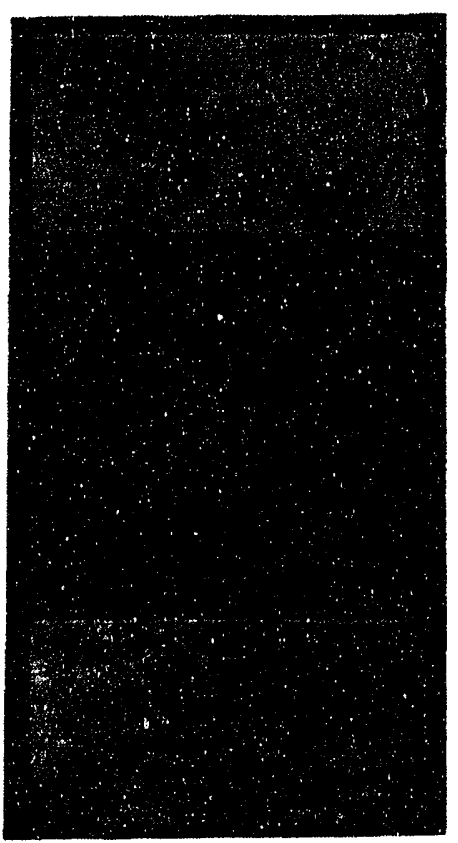

0

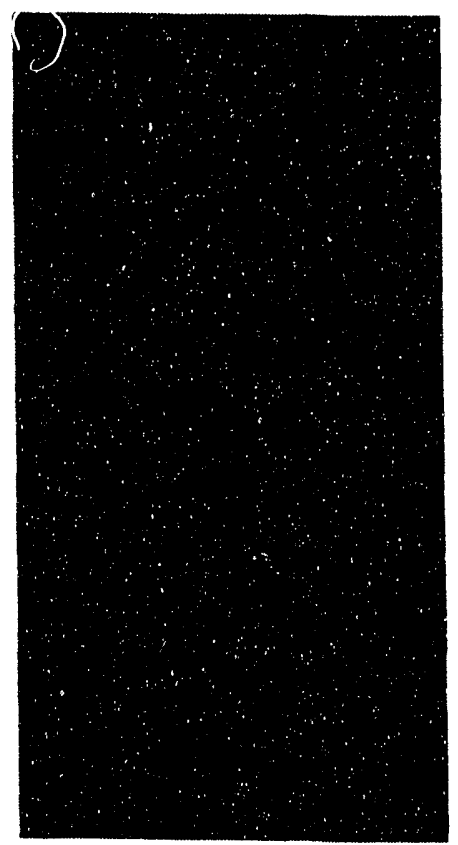

18

$\frac{0}{3}$

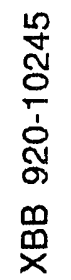

11

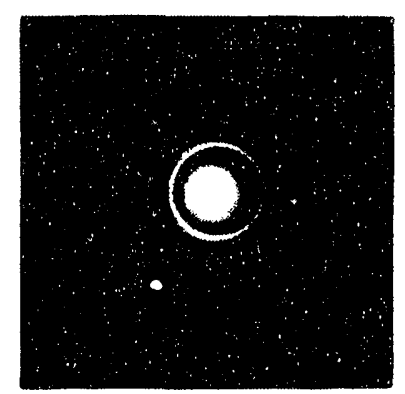

I1.

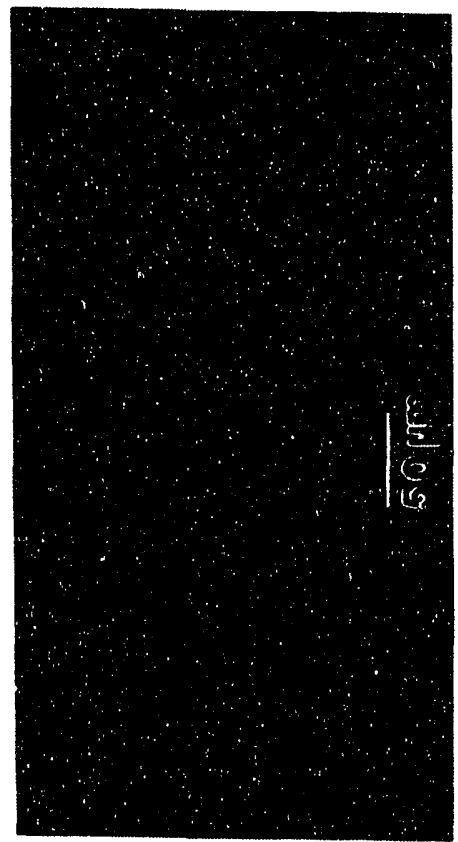


a

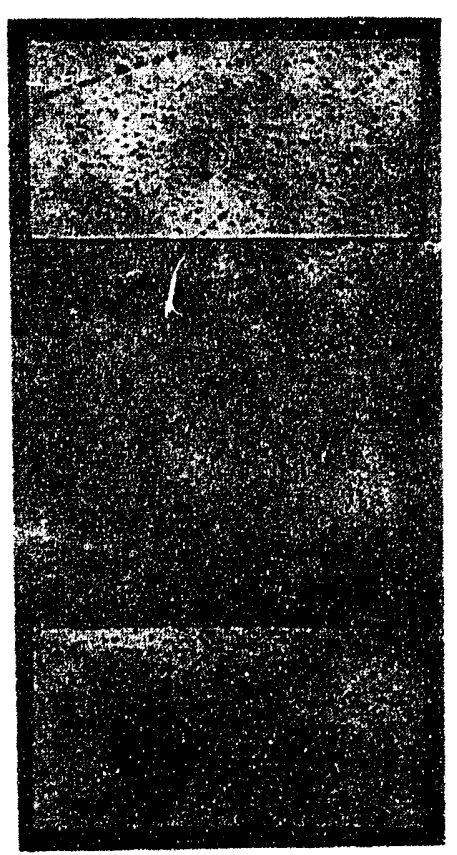

4

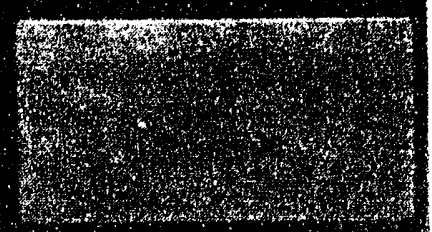

口

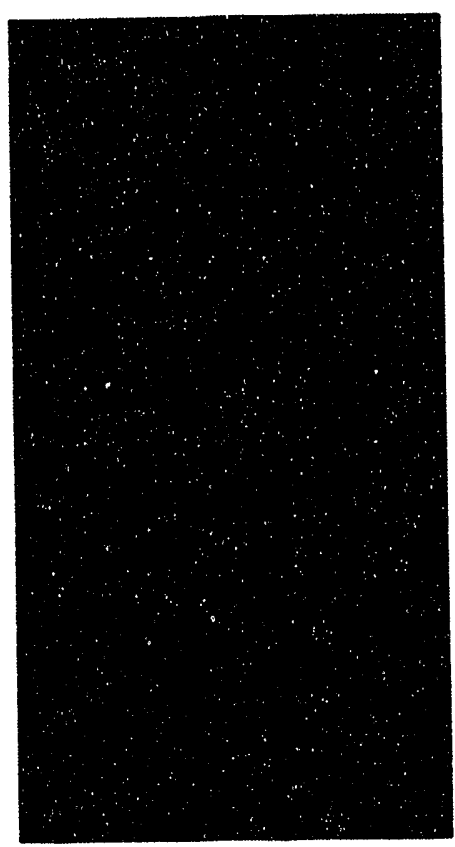

$\mathcal{U}$

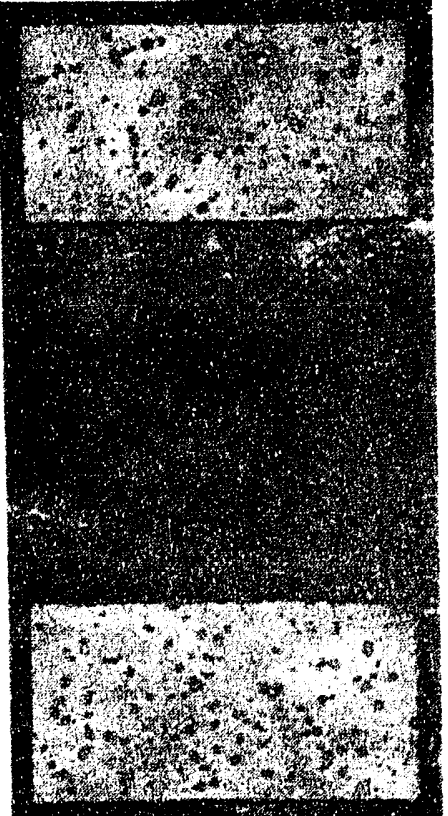

1

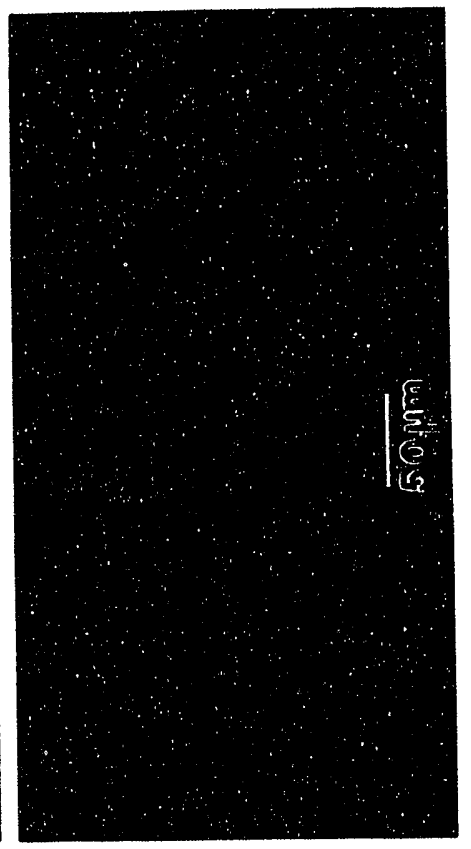

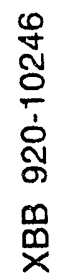

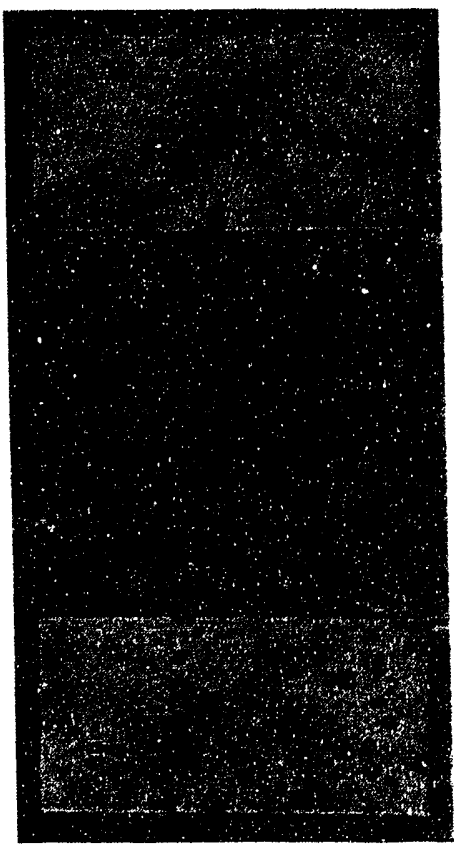


$m$

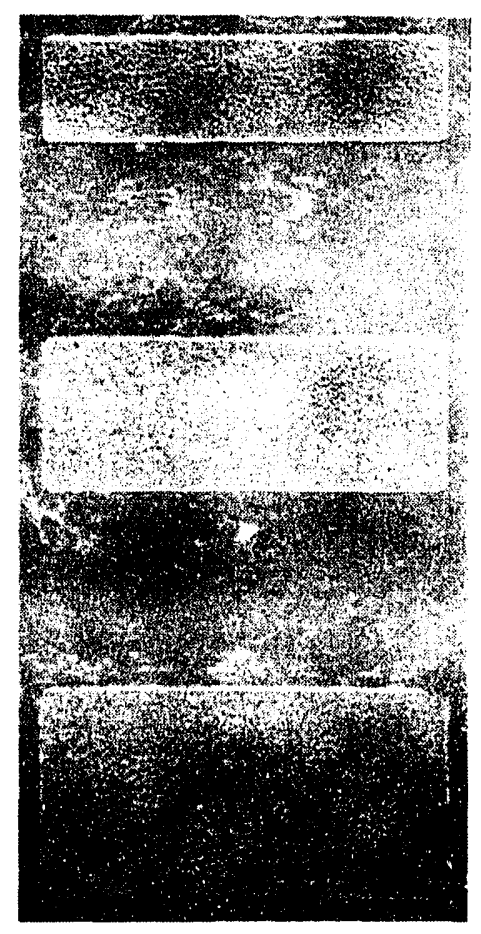

4

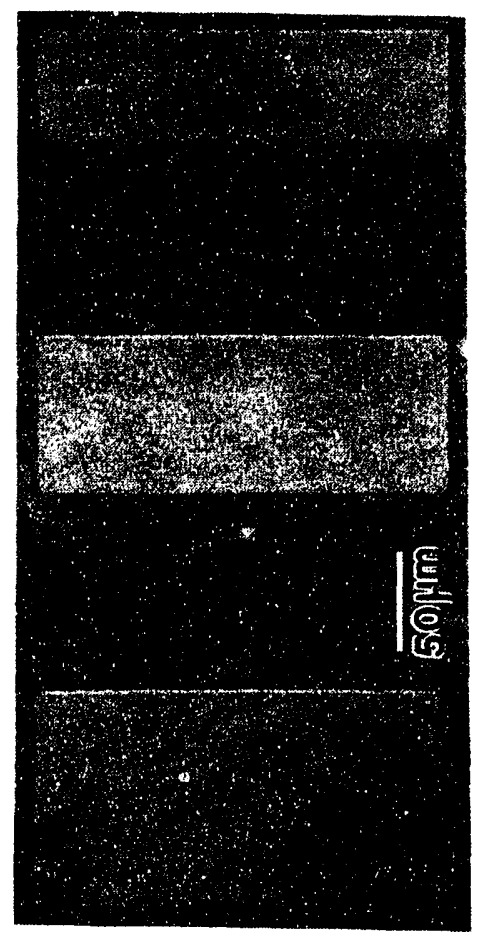

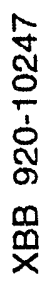

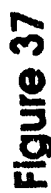

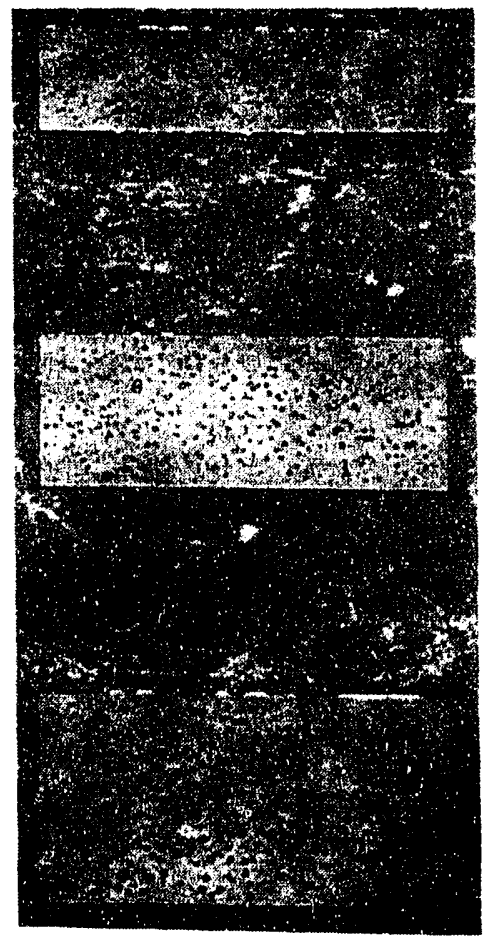


옹

U

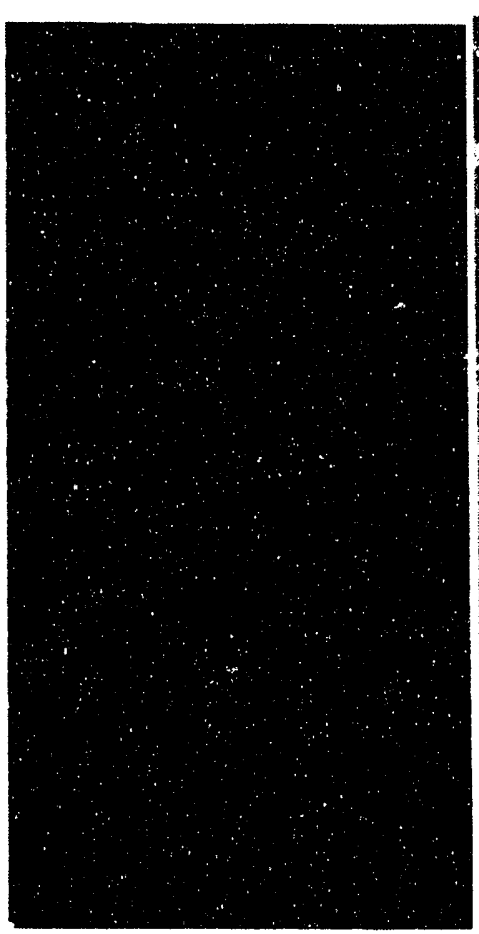

L

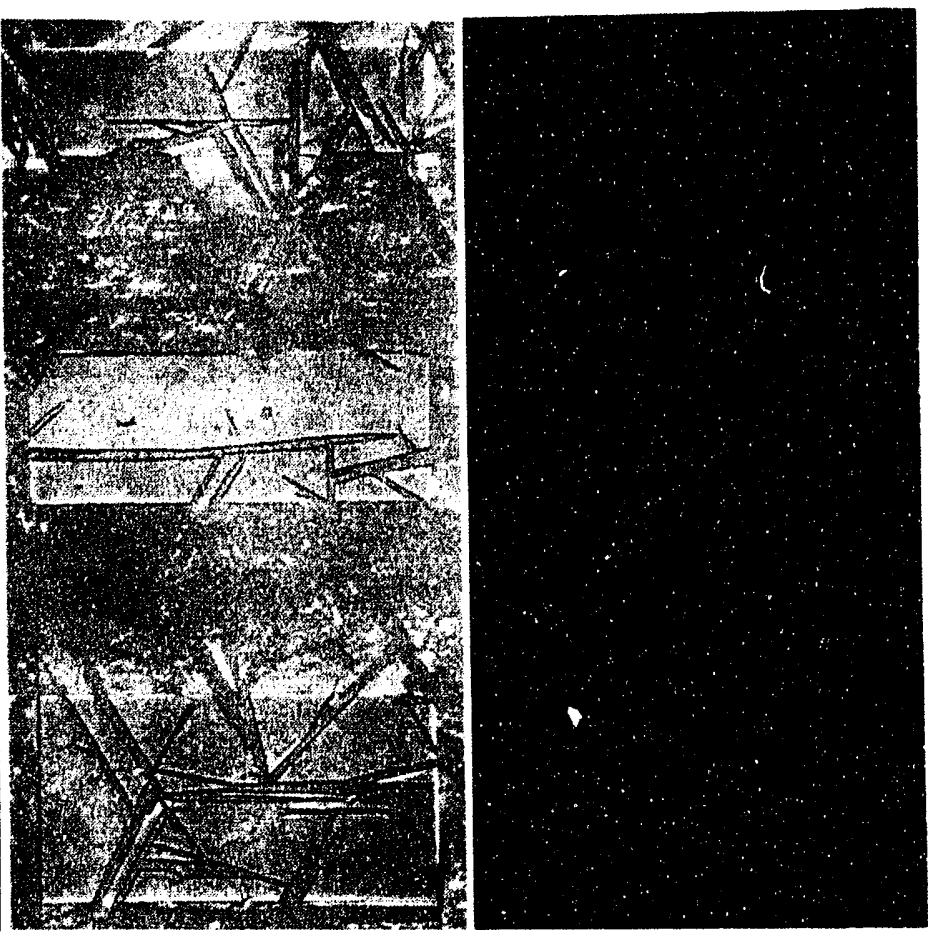

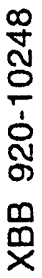



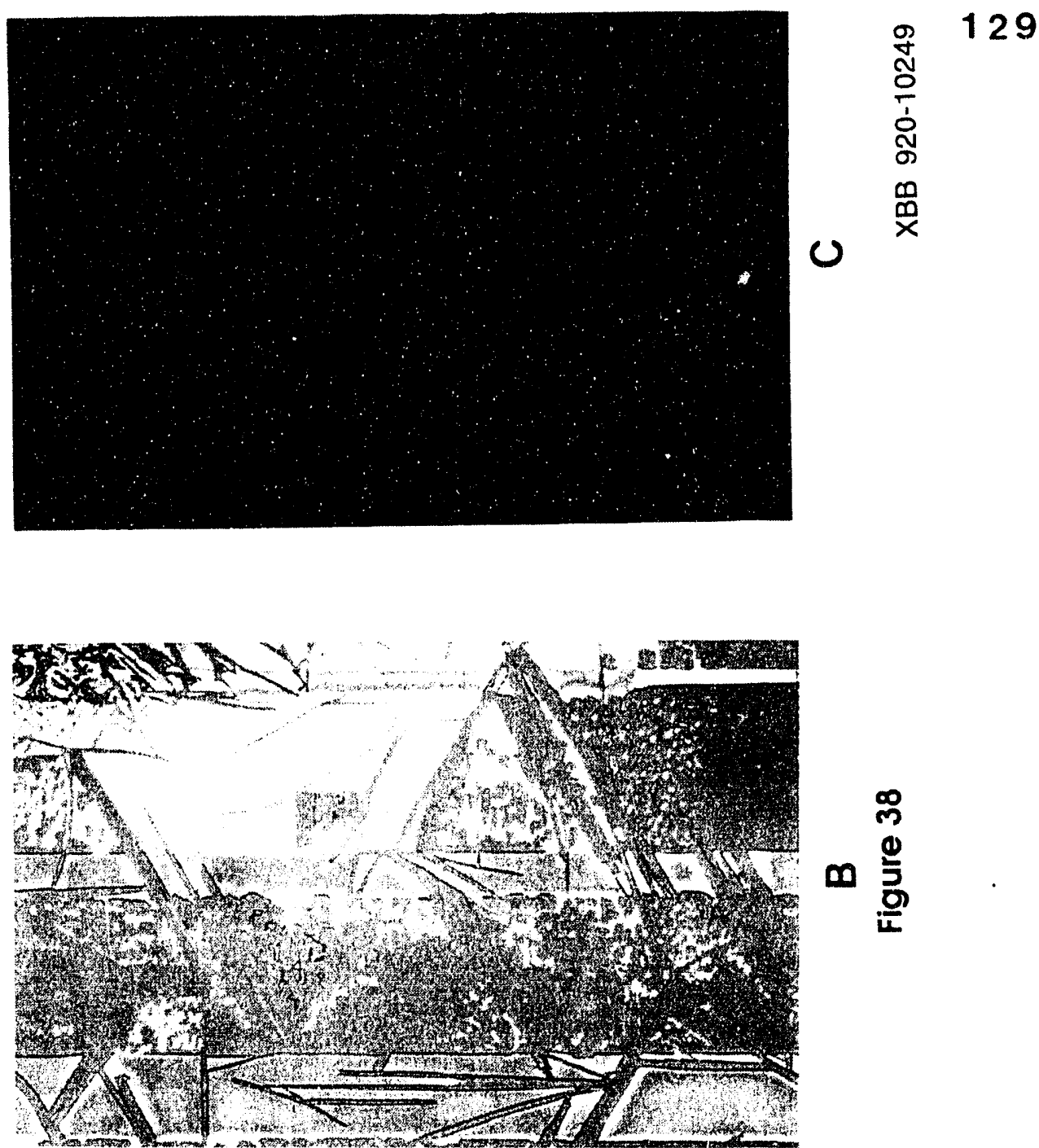

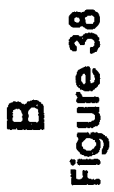
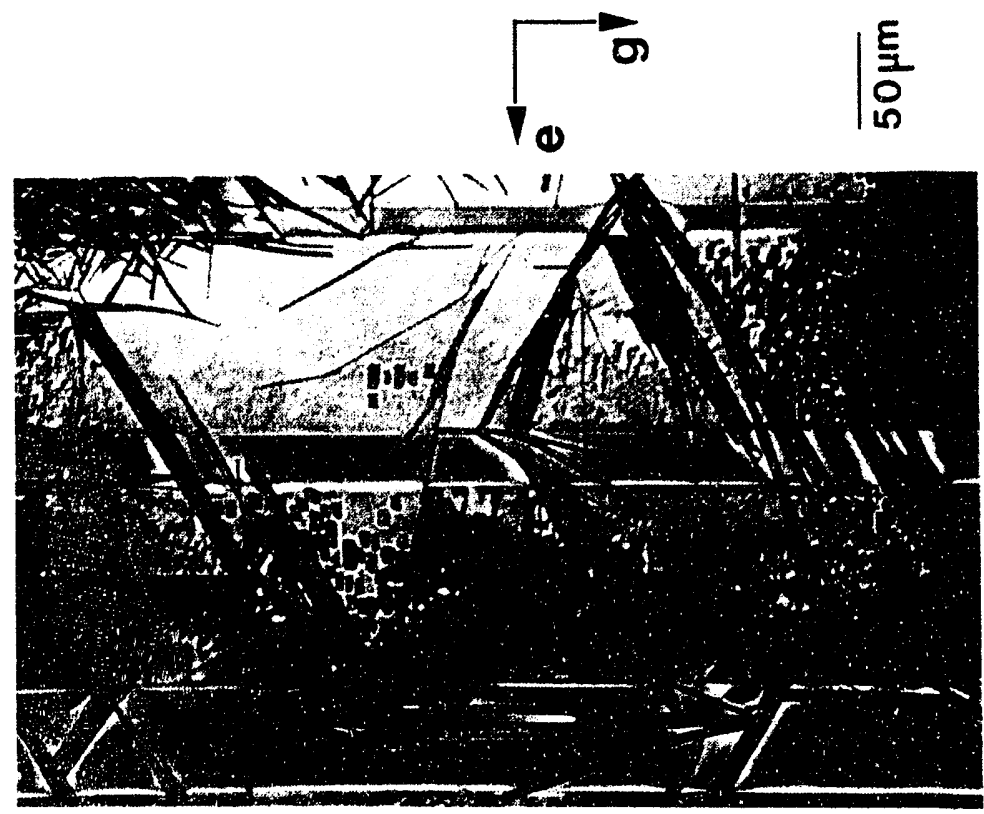

$\alpha$ 

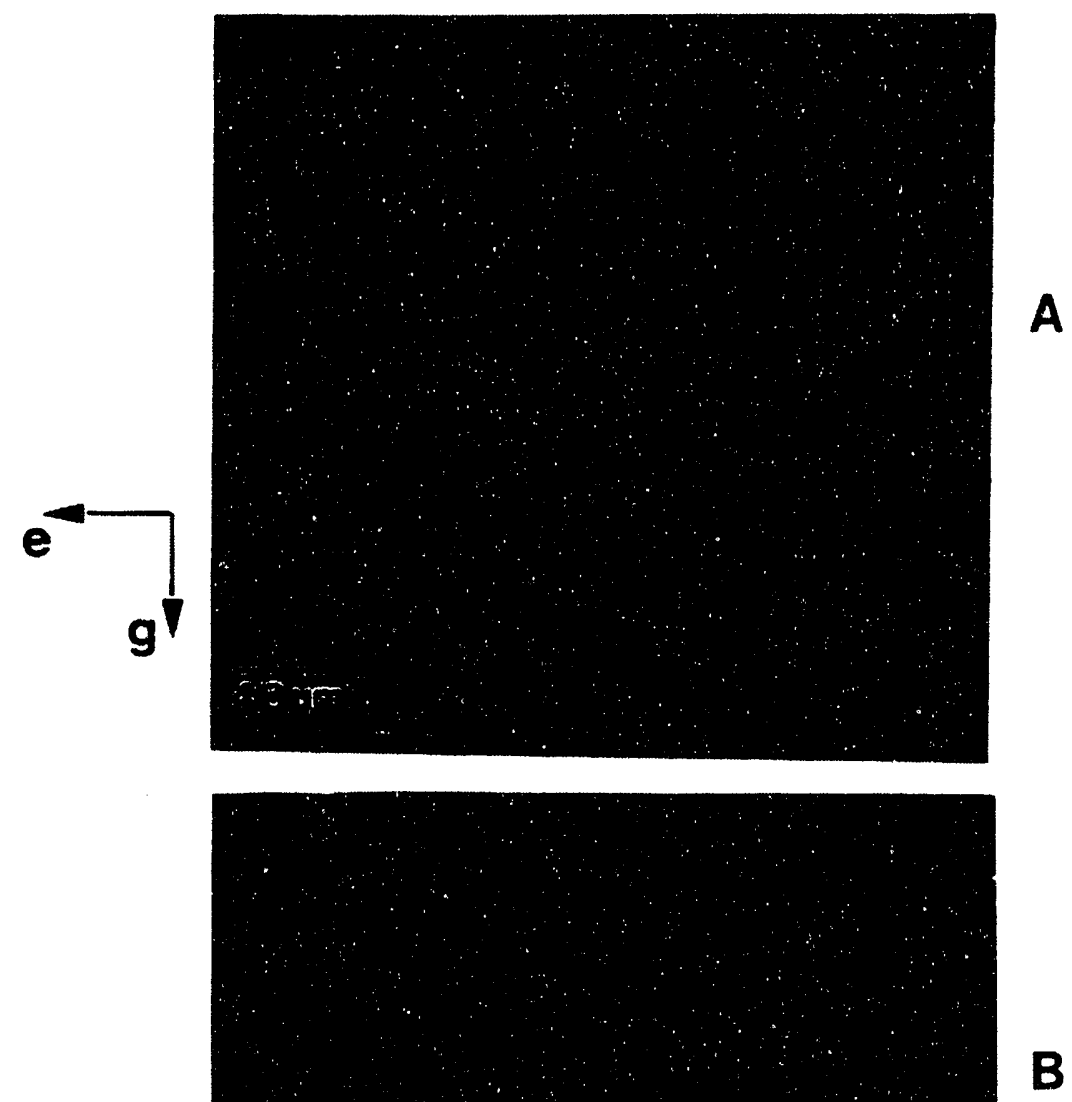

XBB 920-10250

Figure 39

A

B 

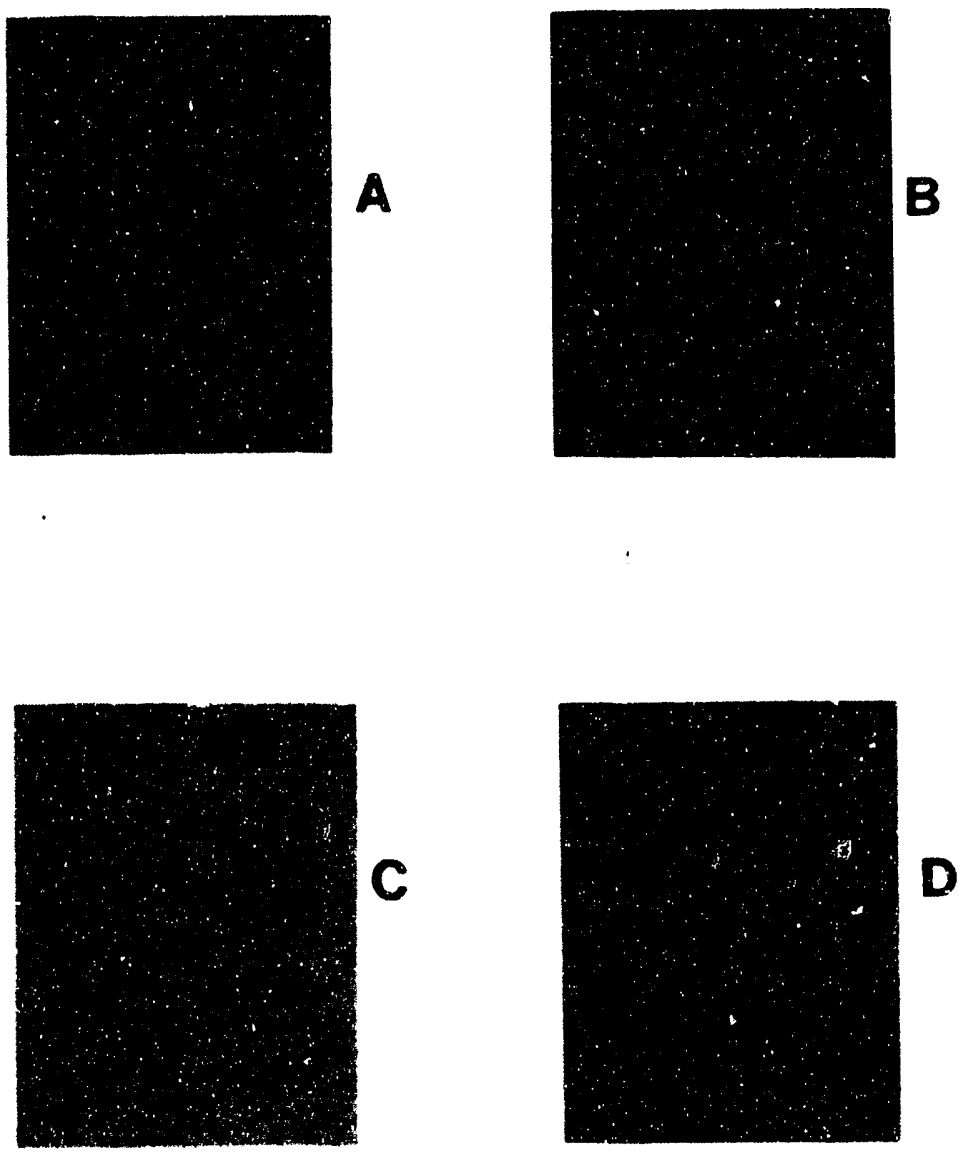

$$
\overline{40 \mu m}
$$<smiles>[CH]C[CH]</smiles>

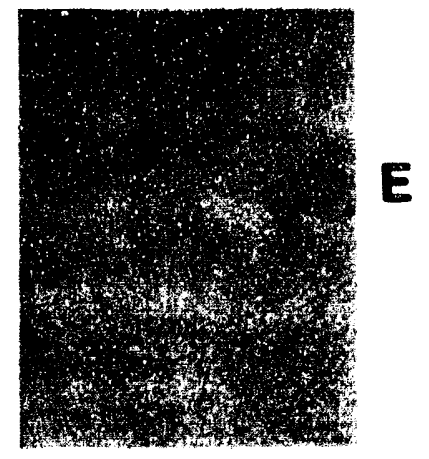

Figure $\mathbf{4 0}$

XBB 920-10251 

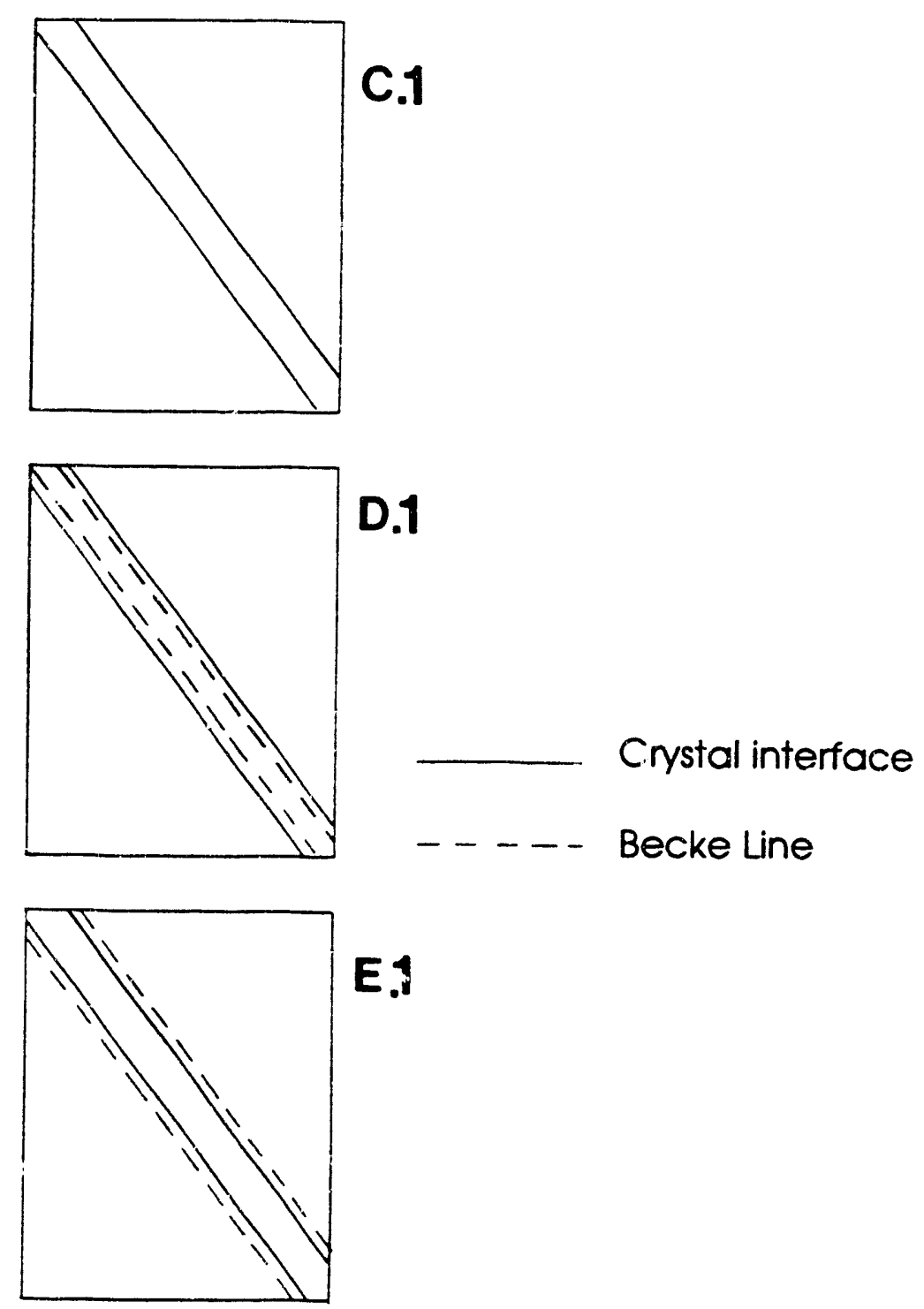
Wi $\% \mathrm{Al}_{2} \mathrm{O}_{3}$

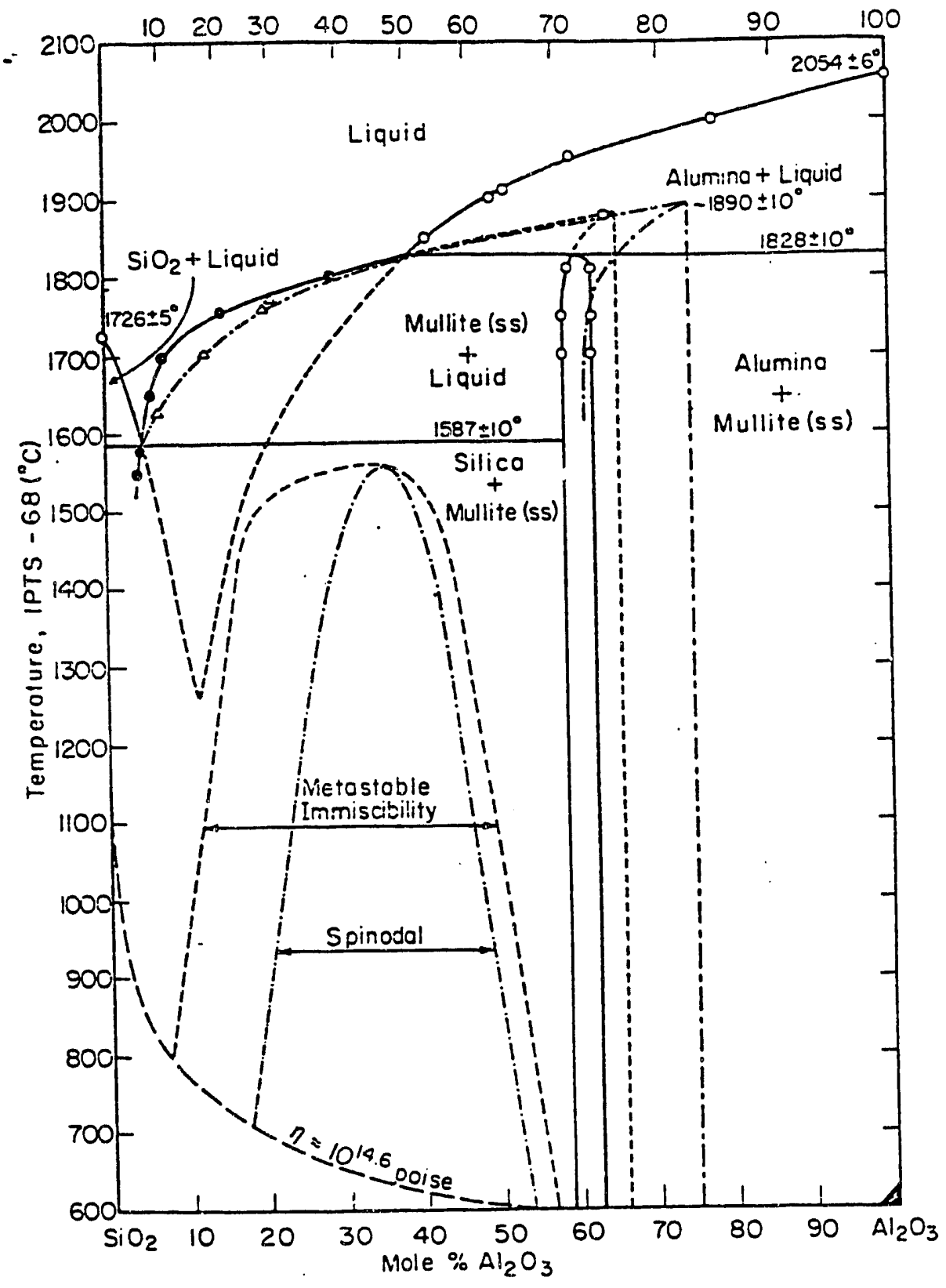

Figure 41 

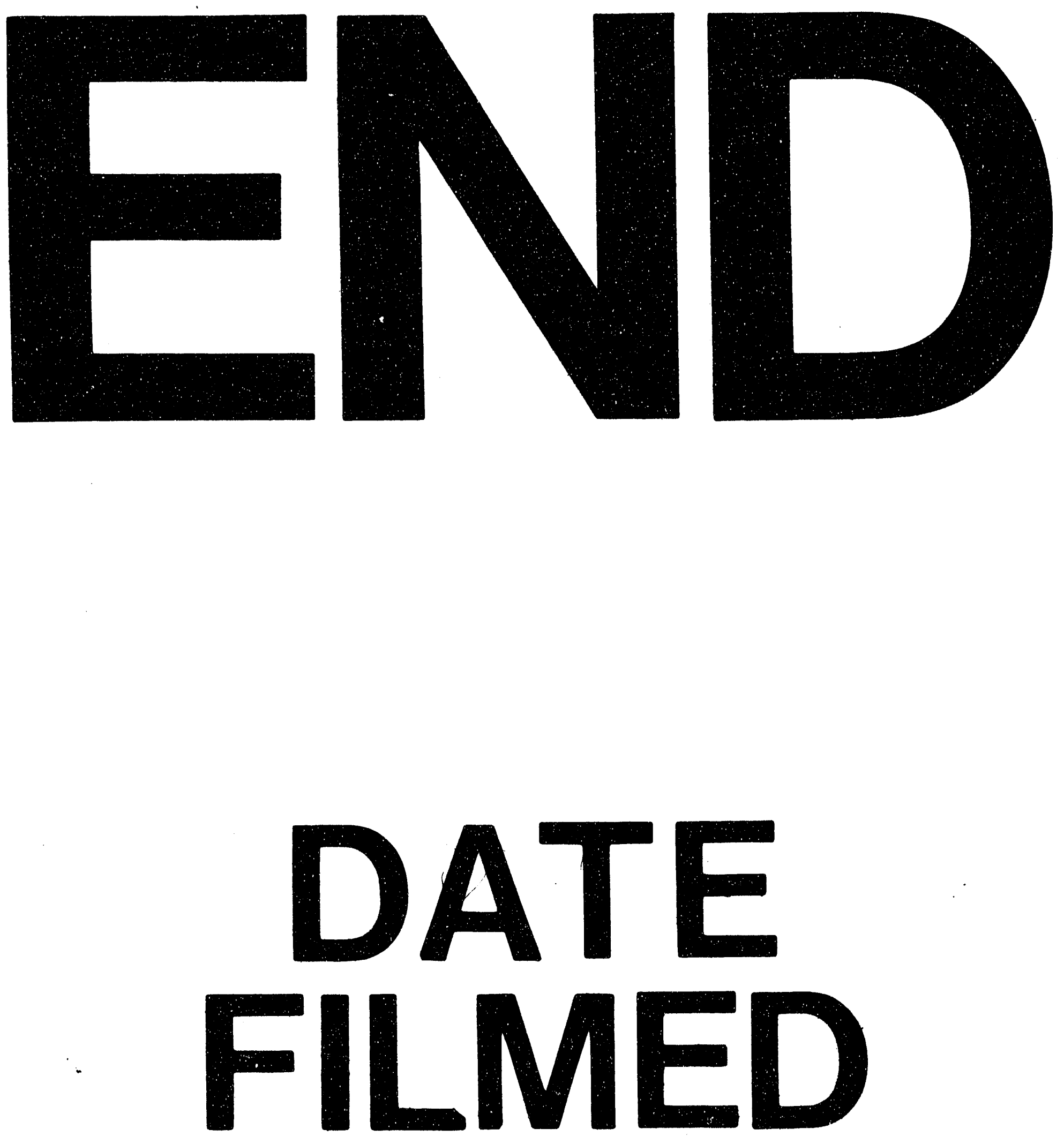

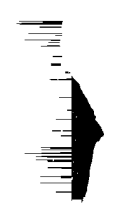

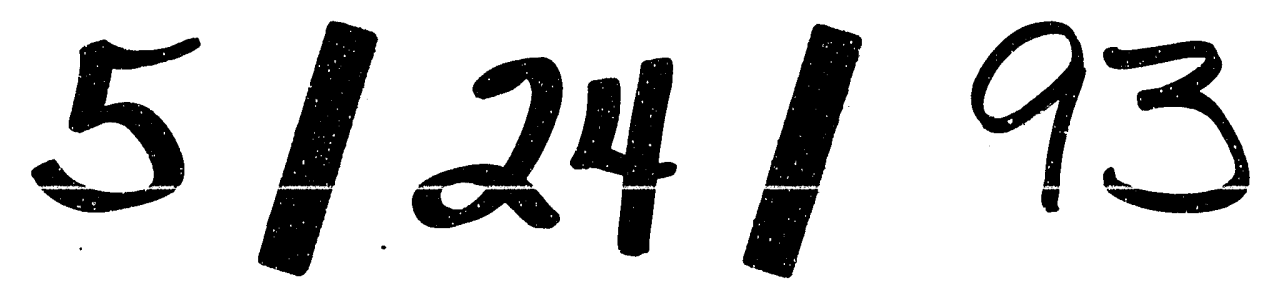


